Louisiana State University

LSU Digital Commons

LSU Historical Dissertations and Theses

Graduate School

1991

\title{
A Comparison of Models of Parole Outcome.
}

Larry Allen Gould

Louisiana State University and Agricultural \& Mechanical College

Follow this and additional works at: https://digitalcommons.Isu.edu/gradschool_disstheses

\section{Recommended Citation}

Gould, Larry Allen, "A Comparison of Models of Parole Outcome." (1991). LSU Historical Dissertations and Theses. 5120.

https://digitalcommons.Isu.edu/gradschool_disstheses/5120

This Dissertation is brought to you for free and open access by the Graduate School at LSU Digital Commons. It has been accepted for inclusion in LSU Historical Dissertations and Theses by an authorized administrator of LSU Digital Commons. For more information, please contact gradetd@lsu.edu. 


\section{INFORMATION TO USERS}

This manuscript has been reproduced from the microfilm master. UMI films the text directly from the original or copy submitted. Thus, some thesis and dissertation copies are in typewriter face, while others may be from any type of computer printer.

The quality of this reproduction is dependent upon the quality of the copy submitted. Broken or indistinct print, colored or poor quality illustrations and photographs, print bleedthrough, substandard margins, and improper alignment can adversely affect reproduction.

In the unlikely event that the author did not send UMI a complete manuscript and there are missing pages, these will be noted. Also, if unauthorized copyright material had to be removed, a note will indicate the deletion.

Oversize materials (e.g., maps, drawings, charts) are reproduced by sectioning the original, beginning at the upper left-hand corner and continuing from left to right in equal sections with small overlaps. Each original is also photographed in one exposure and is included in reduced form at the back of the book.

Photographs included in the original manuscript have been reproduced xerographically in this copy. Higher quality $6 " x$ " black and white photographic prints are available for any photographs or illustrations appearing in this copy for an additional charge. Contact UMI directly to order.

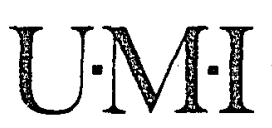

University Microfilms International

A Bell \& Howell Information Company

300 North Zeeb Road. Ann Arbor, M1 48106-1346 USA

$313 / 761-4700 \quad 800 / 521-0600$ 
Order Number 9200063

\title{
A comparison of models of parole outcome
}

\author{
Gould, Larry Allen, Ph.D.
}

The Louisiana State University and Agricultural and Mechanical Col., 1991

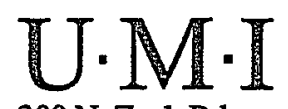

300 N. Zeeb Rd.

Ann Arbor, MI 48106 


\section{A COMPARISON OF MODELS OF \\ PAROLE OUTCORE}

A Dissertation

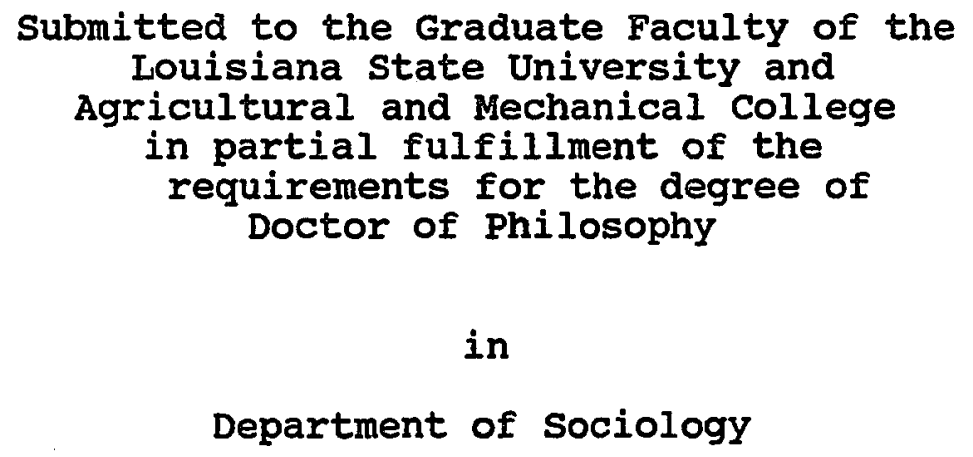

by

Larry Allen Gould

B.C.J., Louisiana State University, 1980

M.C.J., Louisiana State University, 1986

May 1991 


\section{ACKNOWLEDGEMENTS}

The author extends his genuine appreciation and gratitude to all the members of his committee: Dr. William Bankston, Chairman, Dr. William G. Archambeault, Minor Committee Member, Dr. Quentin Jenkins, Dr. Forrest A. Deseran and Dr. Thomas Durant, for their support, encouragement, and most helpful suggestions. A special thanks goes to Dr. Doris Layton Mackenzie for allowing the author to work on the project which led to the collection of the data used in this dissertation.

A sincere thanks is given to all the members of the original research project, and to the National Institute of Justice for the funding of the project. Dr. Doris Layton Mackenzie, principle investigator of the original project, also provided guidance and support vital to the undertaking of this dissertation. A debt of gratitude is extended to Lisa Riechers, whose colleagueship, invaluable expertise and friendship was of continual assistance. A debt of gratitude is owed and acknowledged to James Shaw, Deanna Bellew and Dr. Carol Thompson, whose work on the data collection made the original project, and thus this work, possible. In addition, the members of advisory committee for the original project, Voncille Gowdy, Dr. Paul Gendreau, Mariana Leger, Jean Wall, Carle Jackson, Kelly Ward, and Gary Gremillion, are acknowledged for their support of this and other works which have come out of the original project. A special thanks is 
extended to Gary Gremillion for his assistance in the collection of the additional data necessary for the completion of this dissertation. The author would also like to thank the all of the unnamed and countless people at the Department of Public Safety and Corrections for their efforts.

The author wishes to extend a personal thank you to his friends Judith Delmas, Pat Woolington, William Archambeault, Ben Wright and Mary Gauthier for their continual support, friendship and understanding throughout this project. Additional thanks is due to Kathy Rossman for her help. A very special thanks is extended by the author to Kris for her continual support, help, understanding, patience, and love throughout his entire graduate career and this project. 
Page

ACKNOWLEDGEMENTS ...................... ii

LIST OF TABLES ................ . . vii

ABSTRACT ....................... ix

CHAPTER I. INTRODUCTION . . . . . . . . . . 1

Overview ............ 1

Statement of the Problem ....... 1

Background ............ 3

Parole ........... 4

Problems with Parole Criteria . . 6

Current Guidelines for

Risk Assessment . . . . . . . . 8

organization Changes

CHAPTER II. PAROLE: THE SELECTION PROCESS AND RISK

ASSESSMENT . . . . . . . . 12

Introduction $\cdot \cdot \cdot \cdot \cdot \cdot \cdot \cdot \cdot \cdot \cdot \cdot \cdot \cdot 12$

Ideological Trends in Criminal Justice • 12

The Parole Process . . . . . . . . . 16

Function and Goals of Parole . . . 16

Parole Guidelines and the Evolution of Parole Policy ....... 18

Current Parole Selection ..... 20

Factors Influencing Parole Desisions 23

Past and Present Risk Assessment . . . 25

Expected Relationshipx in Current Model • 31

Analysis of Existing Parole Prediction

Model ........... 34

CHAPTER III. REVIEW OF THE LITERATURE . . . . . 36

Overview .......... 36

Introduction .......... 37

Theoretical Background for Suggested

Model ............ . 39

Control Theory ............ 48

Attachment .......... 51

commitment .......... 52

Involvment ........... 52

Belief........... 53

Differential Association Theory . . . 55

Some Integrating Remarks . . . . . . 58

Expected Relationships ........ 63

summary ............. 66

iv 
Overview ............ 67

Introduction ...... . . . . . . 67

Data Set Description . . . . . 67

Sample Description . . . . . . . 68

Data Collection . . . . . . . . 71

operationalization of Social Bond . . . 73

Attachment-Commitment-Belief . . . 73

Involvement ........... . 74

Operationalization of Association . . . . 76

Dependent Variable . . . . . . . 77

Independent Variables . . . . . 78

Salient Factor Score . . . . . . 78

Age ............... 78

Association . . . . . . . . . 79

Old and New Models . . . . . . . . . 79

Types of Analysis ........ . . . . 81

Logistic Regression .. . . . . 81

Method of Variable Selection . . . 83

Understanding Logistic Regression . . . 84

Tests of Significance . . . . . 86

CHAPTER V. RESULTS . . . . . . . . . . . . 87

Overview . . . . . . . . . . . 87

Descriptive Results .. . . . . . . 87

Demographic Information . . . . 87

Incarceration Information . . . 88

Age Information ......... 88

Elements of the Social Bond . . . 89

Association Information . . . . 89

Salient Factor Score Information . . 90

Logistic Regression Results . . . . . 90

SFS Regression Analysis . . . . . . . 92

Suggested Model Regressed on Parole

outcome ... . . . . . . . . . . . 94

Suggested Model Plus Incarcerated

Experience Regressed on Parole

outcome.... . . . . . . . . 101

Results of the Test of signficance . . 107

summary ................ 109

CHAPTER VI. DISCUSSION AND CONCLUSION • • • • • • • 111

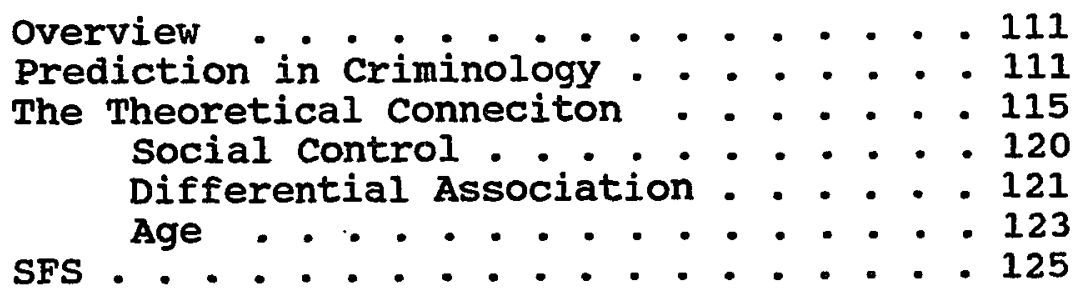

$\mathbf{v}$ 
Type of Incaceration . . . . . . . 125

Theoretical Implications . . . . . . 126

Policy Implications . . . . . . . . . 128

Future Research . . . . . . . . . 131

Summary . . . . . . . . . . . . 134

BIBLIOGRAPHY . . . . . . . . . . . . . . . 137

APPENDIX A . . . . . . . . . . . . . . . . . 146

Salient Factor Score Instrument . . . . 147

Expected Relationships • • • • • • . 148

Correlation Table of Variables in the

Model .. . . . . . . . . 150

APPENDIX B FACTOR ANALYSIS RESULTS . • • • • . • • . 151

VITA: . . . . . . . . . . . . . . . 167

Approval sheet . . . . . . . . . . . . . 168

vi

Reproduced with permission of the copyright owner. Further reproduction prohibited without permission. 


\section{LIST OF TABLES}

Table

Page

\section{1}

Coding Scheme for Involvement . . .

76

5.1

Values for the Elements of the

Social Bond . . . . . . . . . . .

5.2

Values for the Elements of

5.3

Association.

90

Univariate Analysis of the Effect of the Independent Variables on Parole outcome pendent variables on Parole.

SFS Prediction Accuracy . . . . . 93

5.5

Suggested Model Prediction Accuracy • 95

5.6

Regression Product for Suggested

Model ................ 96

5.7 Table of Values Used in Suggested

Model . . . . . . . . . . . 97

5.8

Scenario for Model II . . . . . . 99

5.9

Example of Offenders From the Sample. 100

5.10

Suggested Model Plus Incarceration Type Prediction Accuracy . . . . . 102

5.11 Regression Product for suggested Model Plus Incarceration Type .. . . . 103

5.12 Scenarios . . . . . . . . . . 104

5.13 Examples of offenders From the Sample for Model III........... 105

5.14 Comparison of Results for Group Membership .. . . . . . . . . 106

5.15 Explained Variance for Each Model . . 108

5.16 Results of Tests of Signficance Between Models .......... 108 
Table

3

Correlation Table of Variables in

the Model ............ 150

Factor Table 1. Attachment . . . . . . . . 152

Factor Table 2. Commitment . . . . . . . . 155

Factor Table 3. Belief . . . . . . . . . . 157

Factor Table 4. Factor Loading for Attachment,

Factor Table 5. Second Factor Loading for

Attachment, Commitment

and Belief . . . . . . . . 163

Factor Table 6. Final Factor Loading for

Attachment, commitment and 164

viii 


\section{ABSTRACT}

The focus of this dissertation is on the criteria which parole boards use as the basis for their decision to release an offender on to parole. The literature strongly suggests that there are some objective measures of dangerousness on parole, such as the salient Factor score; however, the literature also indicates that parole boards use a great deal of subjective evaluation in making their decisions. Many of the subjective concepts used by parole boards can objectified through a grounding in criminological theory. A model of parole outcome prediction which objectifies several of the previously subjective variables, including association and the elements of the social bond, was developed. These additional variables are added to the salient Factor score instrument to test the predictive ability of a new parole risk model. To test the addition of the new variables a sample of offenders who where incarcerated and then released on parole was used. The results indicate that the predictive power of the new model is significantly greater than that of the old model. Additionally, the effectiveness of the inclusion of the new variables suggests that theoretical criminology can be useful in practical situations. 
CHAPTER I

INTRODUCTION

\section{OVERVIEE⿱}

The introductory chapter is divided into three major parts. The first section is the statement of the problem. The second is a brief review of the background of the parole process, and the third section explains the organization of the dissertation.

\section{STATHEMTIAT OF THE PROBL,EM}

The problem addressed in this dissertation is the development and testing of a predictive model of parole outcome. The suggested model enhances an existing model, the Salient Factor Score (SFS), through the addition of selected variables that are grounded in criminological theory and research but which have not been examined before in the context of parole prediction. The literature, discussed in detail later, indicates that there are two general problems with current prediction models of parole outcome. The first problem is that current prediction instruments are inaccurate as much as 80 percent of the time (Gottfredson, 1979). The second is that many of the measurements currently used in predicting parole outcome are arrived at subjectively by the parole boards (Gottfredson \& Wilkins, 1978). The problems 
with the current model can be categorized into four specific areas: 1) the current model is not accurate in its predictive ability; 2) it explains very little of the variance in the parole outcome; 3) it makes use of subjective information which can be objectively quantified; and 4) it fails in its mission to protect the public, while at the same time failing to provide equality to offenders.

It is hypothesized that the addition of selected variables will add a significant amount of strength to the objective prediction of parole outcome. At the same time this addition replaces some of the more subjective criteria used by parole boards with objective criteria. Gottfredson \& Wilkins (1978), in their work on the parole process, and Champion (1990), in his review of the literature, suggested that these subjective criteria should be used in an objective manner. In essence these authors advocate the operationalization of many of the variables that parole boards currently use but in a subjective manner.

To summarize, the general question to be addressed in this research of this dissertation is directed is: "Will the inclusion of variables that are grounded in criminological theory significantly increase the predictive power of a parole prediction model." The current model, the SFS, was developed from practice, application, and theory; however, its full development became somewhat stunted in the late 1970's as a result of a shift in the direction of correctional research 
toward pre-incarceration treatment. This topic will be more fully explored in Chapters I and II of this dissertation.

A review of the literature suggests that control theory differential theory, and the criminal career perspective can be used in a supportive role to strengthen the predictive value of the current model. Support for the use of these theoretical and research traditions can be found in Marcos, Bahr, \& Johnson (1986) and in MacDonald (1989). In particular the variables such as the age of the offender at first arrest, the offender's age at release from confinement, elements of. the social bond, and the association of an offender with the criminal subculture, will be added to the parole prediction model. Support for each of these additions is found in Chapter III.

\section{BACKGROUND}

Parole and parole prediction has been faced with problems throughout its history. The purpose of this section is to enlighten the reader as to some of these issues, such as the need to protect the community from offenders versus the need to reduce prison overcrowaing. Another concern with parole prediction is to insure the appropriate length of incarceration, while allowing for individual differences in inmates. A related problem regards the criteria that should be used in making the decision to release. 
This section briefly reviews the history of parole. There is, however, little direct connection between the start of the parole and its current use in the United states; therefore, the major part of the background discussion focuses on more recent events in the parole system such as the public's distrust of the parole system, the flaws in the current systems, and the pressure of prison overcrowding. In the last part of the background section the current model of parole risk assessment will be discussed.

\section{a. Parole}

Since its inception in 1840, at the English penal colony on Norfork Island, parole has been used as a reward for good behavior in prison. Capt. Alexander Maconochie, Warden of the colony, abolished the flat sentence and developed a "mark system" whereby a convict could earn freedom by hard work and good behavior. This early system was abolished as soon as Maconochie died; it was no less controversial than are types of parole in the current system (Killinger \& Cromwell, 1973). The controversy of whether or not parole should be used as a form of release from incarceration stems from several major flaws in the parole systems now in use. The two most frequently used systems are what is known as "good-time" release, in which good behavior in prison automatically earns a proportional diminution of time to be served, and several variations of parole, in which early release is secured through some combination of good behavior and a review board 
decision on suitability for release (Lane, 1986). Although "good-time" release is not the subject of this dissertation, it is mentioned so that the reader does not confuse good-time release with the parole process, in which credit for good behavior in prison is included in the decision making process. Another difference between good-time release and parole is that parole requires a period of post-incarceration supervision, which is not a requirement of good-time release. studies have shown that any early release system, whether or not it is with parole board review, tends to offend both the public's feeling of safety and its sentiment for retribution (Cullen, Clark, \& Wozniak, 1985; Cullen \& Gilbert, 1982). Additionally, those programs lacking objective review allow no differentiation between inmates who are just "playing the game" and those who have actually made some changes (Grooms, 1982).

Nevertheless, ever since Maconochie's mark system, some form of early release program has almost always been a part of the Anglo-American prison systems. Despite its controversial nature and a growing pressure for the use of determinate sentences, parole remains second only to probation as the largest segment of community corrections. Approximately 74 percent of released prisoners are being released to parole supervision (Bureau of Justice Statistics, 1989). Parole is now used not only to provide an incentive for good behavior in prison but also to help reduce the number 
of inmates in the prison systems. The need to reduce prison overcrowding appears, in part, to be one of the major pressures on parole boards; however, the uncontrolled release of prisoners presents public risk problems.

Many factors, including the combination of the public's rising fear of crime and its desire for retribution through more and longer prison sentences, have contributed to an increasingly acute overcrowding problem in the prison system. The need to reduce overcrowding, however, is contradictory in some ways to the public demand for greater security from the criminal offender. It is desirable, then, to establish some equilibrium between the public's demand for safety and retribution and the necessity for alternatives that are less expensive than long-term incarceration (Mackenzie, Gould, Riechers, and Shaw, In Press). If prison officials are to release offenders early, every possible effort must be made to see that those offenders being released pose as little risk to the public.

b. Problems with Parole Criteria

There is little concrete evidence that any reasonably objective criteria have been consistently used in deciding which inmates to release on parole and which to hold in prison (Greenfield, 1987). In fact, for the most part inmates, correctional critics, scholars, parole board members, study panels, and correctional researchers agree that release decisions seem to be arbitrary, capricious, prejudiced, and 
offer little or no direction for inmates who have not been released (Champion, 1990; Greenfield, 1987; Carter, Glaser, \& Wilkins, 1984; Carlson, 1979; Gottfredson \& Wilkins, 1978; American Bar Association, 1968).

Risk assessment, also referred to as dangerousness or public risk, is the prediction of further criminal activity based on past or present behavior. A parole board, at least in part, makes its decision to release an offender based on several factors, including the projection of dangerousness of the offender and the risk posed to citizens if parole is granted. Risk or dangerousness predictions are often based on instruments devised through either application, practice or research (Gottfredson and Tonry, 1987); however, this has not always been the case. Prior to the inception and first use of the SFS there was little coordinated or consistent effort toward the development and use of an objective system of measurement of the risk of dangerousness of the parolee (Champion, 1990).

Current estimates of the accuracy of prediction tend to vary, due mostly to differences in operational definition of failure or success. However, most current prediction models are inaccurate 80 percent of the time in predicting parole outcome (Champion, 1990; Gottfredson \& Tonry, 1987). The inaccuracy rate is based on the recidivism rate of paroled individuals who committed new crimes after they were released 
from incarceration and prior to their release from supervised parole.

c. Current Guidelines For Risk Assessment

The current federal guidelines use a matrix constructed out of the characteristics of the present offense, the previous criminal behavior of the offender, and good-time credit earned while in prison to determine a release date. Although this system is an improvement over the "on-the-spot" decision-making process frequently found in nonfederal jurisdictions, it does not provide parole boards with an adequate picture of inmate characteristics, nor does it provide a significant increase in ability to predict the inmate's success or failure while on parole.

Prior prediction models have been less than successful, but this may have been at least partly due to their lack of grounding in criminological theory rather than to any innate problem with the models used. The data set used in this dissertation allows for inclusion of predictive variables that are more theory driven than is most corrections research.

As previously stated, the SFS in one form or another, is the type of evaluation most generally used by parole boards today (Champion, 1990). The variables considered in most of the currently used is this scoring system include the number of prior convictions, age at current offense, offender status at time of current offense, and drug use. In addition to these variables, the literature strongly suggests that parole 
boards also use subjective criteria in the decision making process (Champion, 1990; Greenfield, 1987; Carter, Glaser, \& Wilkins, 1984; Carlson, 1979; Gottfredson \& Wilkins 1978; American Bar Association, 1968). A more detailed discussion of the SFS can be found in Chapter II.

There are two major problems in the use of the SFS as the sole instrument of prediction. The first, which this dissertation hopes to correct, is that the major emphasis in the SFS is on the offender's most current offense, thus allowing a myopic view of the offender. The second is that the decision-making process, even when the SFS is used, remains overly subjective in nature. Support for both of these criticisms can be found in the literature cited in Chapter II.

\section{d. Suggested Changes}

The current parole system gives primary emphasis to the current offense and somewhat less emphasis to the prior adult record. Empirical research is needed to determine how best to use criminologically relevant information to aid in identifying offenders likely to have high rates of offending after release from prison. Regardless of one's policy preferences about selective incapacitation, developing knowledge about criminal careers should be an important objective of research in criminology. There only remains then the technical question of how much the model suggested in this 
dissertation can increase the predictive efficiency through addition of information, such as that suggested by Hirschi's social bonds or Sutherland's association theory. If the improvement is not significant, then objections to using such information should prevail; if the improvement is considerable, then the argument for the use of this type information is strengthened.

\section{ORGANIZATIOA}

The remainder of this dissertation is divided into five. parts. Chapter II is intended to provide the reader with a review of the major criminal justice trends that have driven corrections policy, particularly as it pertains to parole practice. This is followed by an overview of the parole process and of the past and present systems of parole release. The final section of chapter II reviews specific instruments currently in use for assessing parolee risk and the reasons for the selection of those used in the present study.

Chapter III contains a review of criminological literature leading to the selection of the predictive variables that wili be used to add to the predictive power of criteria currently used in parole decisions. Chapter IV is the methods section. It is in this section that the sample selection process and a description of the sample are discussed, as well as the justification for the statistical methods used. The results are presented in chapter $v$. Chapter VI includes the 
discussion section, in which the theory and the results are discussed, and the conclusion section, in which the overall effect of the model is summarized and implications for ifurther research are suggested. 
CHAPTER II

Parole: The Selection

Process and Risk Assessment

\section{INIRODUCTION}

The purpose of this chapter is to provide the reader with an overview of the major ideological criminal justice trends that have driven corrections policy, the parole process and a review the past and present systems of parole release. The first section will be a discussion of the major ideological trends; the second section, of the need for and function of parole; and the third section, the parole process and the factors considered by parole boards. In the final section, past and present models and formulas for predicting success on parole (or risk assessment) are reviewed.

\section{IDEOLOGICAL TRENDS IN CRIMINAL JUSTICE}

Although the concept of parole goes back to the nineteenth century, the ideologies that have influenced current criminal justice policy had their beginning in the 1920's and became prominent only in the late 1950's and early 1960's. Although there have been forms of parole in the united states since the advent of correctional systems, these early types of parole 
bear little resemblance to those of today. From the 1930 's to the present, there have been two major ideological positions within the criminal justice system: the medical model, which predominated from about 1930 to 1974 , and the justice model, which has gained widespread acceptance since about 1974 (Champion, 1990; Archambeault \& Archambeault, 1982). Although this dissertation is not a critique of either of these models of criminal justice, it is necessary to review each in order to develop an understanding of the parole process and particularly, of the salient Factor scoring (SFS) system.

The medical model views crime as an illness of the individual brought on either by inequalities in society or by environmental conditions that may lead the individual into a life of crime. The offender is seen as being either sick or the victim of negative socioeconomic factors beyond his rational control that have lead to a psycho/social deficiency precluding the offender's "normal" conduct within the society. This model implies that the offender's should not be held fully accountable for their behavior; therefore, society owes the offender some sort of compensation in the form of rehabilitation and/or reintegration (Archambeault \& Archambeault, 1982; Gusfield, 1967). One of the premises of the medical model is that the offender is not necessarily rational, so it might be necessary to force the offender into a rehabilitation program. The type of sentence used in the 
medical model is indeterminant; that is, the length of the sentence is flexible or dependent upon positive offender changes affected by treatment. The determination of parole eligibility under the medical model was made by a parole board generally consisting of a "body of experts" such as social workers, wardens, and parole officers (Rothman, 1983; Archambeault \& Archambeault, 1982).

Some of the criticisms of the medical model have been that it coerces rehabilitation (Conrad, 1981), that the offenders are treated as objects (Harris, 1984), and that the treatment is selectively applied based upon gender, race, socioeconomic status and other factors (Farnworth \& Horan, 1980; Gibson, 1978; Kelly, 1976; and Shichor, 1985). Due at least in part to the rising crime rates, there was a gradual decline in acceptance of the medical or rehabilitation model in the 1970's (Jacks \& Cox, 1984) and a gain in the popularity of the justice model (Fogel, 1979). Additional factors that lead to this change were substantial recidivism among parolees, as well as dissension about the most effective ways of dealing with offenders (Jacks \& Cox, 1984; Fogel, 1979).

Inequalities that existed in parole determination under the medical model, such problems as sentencing disparity and the arbitrariness of parole board decisions, were expected to be alleviated under the justice model (Goodstein \& Hepburn, 1985). The central logic of the justice model is that a person's tendency to commit a crime results from that person's 
intentional adaptation to the conditions of society. This approach suggests a reemergence of some elements of the classical school of criminology. The offender is seen as a rational person, exercising "his" own volition when choosing whether or not to commit a crime. The objective of the justice model approach to corrections is to humanely control the offender and to offer treatment programs, but not to force the offender into treatment (Rothman, 1983; Archambeault \& Archambeault, 1982). In the justice model, release is gained by serving flat time minus time off for good behavior. Although this condition of release is the ideal, the justice model generally allows for some type of parole release.

Two of the major criticisms of the justice model are that, in its strictest forms, it does not allow enough flexibility on the part of the parole board (Humphries, 1984) and that there is every reason to believe officials will continue to impose discriminatory parole patterns, due in part to the subjective nature of the way in which the parole decision is reached (Champion, 1990; Goodstein \& Hepburn, 1985; Humphries, 1984).

These two major ideologies within the correctional system have had a tremendous effect on the use of parole and the parole process. The medical model has either placed society at fault for the behavior of the offender and/or has treated the offender as if he is ill. In essence, the medical model has put the cause of criminal behavior beyond the control of 
the offender. Under this model the release of the offender is based on the parole board's perception that the "cure" provided by the correctional system has been effective. Since the publication of the Martinson (1976) report, with its view that rehabilitation is at best overrated, the medical model has fallen into disrepute. It should be noted, however, that Martinson softened his view on rehabilitation after further research was completed. This lead to a reintroduction of treatment as part of the justice model. The second model, the justice model, treats the offender as a rational being who must now pay his debt to society with a determinant sentence. Both of these ideologies have affected the decision-making process of the parole board, and thus the way in which the parole board functions.

\section{THE PAROLE PROCESS}

\section{A. Functions and Goals of Parole}

The functions of parole can be categorized as manifest -- intended or recognized -- and latent functions -- less apparent (Champion, 1990). The manifest functions include reintegration of parolees back into society and control and/or deterrence of crime. The latent functions include alleviation of prison overcrowding, correction of sentencing disparities, and protection of the public. The importance of each of these 
functions is dependent upon the current ideology of the correctional system.

Most correctional systems in the United States operate, in theory, under the idea that modification of criminal behavior patterns will result in the eventual rehabilitation and reintegration of the offender back into society (Champion, 1990). As mentioned in the previous section, this process has come, at least in part, to be identified as the rehabilitation or treatment model of corrections, which is identified with the medical model of deviance. The process of rehabilitation. and reintegration starts with conviction, continues through confinement, and ends with the completion of the parole period. At each step, theoretically, the correctional system provides a setting in which this rehabilitation process may take place. There has been a change in, or perhaps a synthesis of, the two principle ideologies within the justice system, leading to a strong sentiment that the theory of rehabilitation has merely been imposed upon the theories of punishment and control (Kassenbaum, Ward, \& Wilmer, 1971). This change in philosophy is apparent when one reviews parole from a historical perspective. As noted previously, the movement toward the medical model had its beginnings in the 1850 but did not reach its zenith until the 1960's. The historical end of the medical model is 1974 , although, as with many historical changes, this end did not occur suddenly. The rehabilitative aspects of parole found support among 
social reformers, religious leaders, and humanitarians (Champion, 1990; Bottemley, 1984).

In the mid 1970's the correctional pendulum started to swing toward the justice model. The primary role of parole began to change from a means of rehabilitation and reintegration toward that of a bureaucratic tool used in many cases to relieve prison overcrowding (Champion, 1990; Messenger, 1985). During the transitional period there existed within the correctional system conflicting and competing paradigms of thought between those advocating treatment and those advocating control. This dichotomy of thought led to a revolution and a paradigm change when, in the mid 1970's, the prevailing philosophy became the justice model. There has been, however, something of a synthesis of thought that has led to a dual function of the parole board, requiring it to "help" the parolee and to supervise the offender's adjustment to society, while at the same time controlling the offender and protecting society.

\section{b. Parole Guidelines and the Evolution of Parole Policy}

The concept of "guidelines" is central to the idea upon which parole policy models have been developed. The development of the SFS occurred at least in part as a direct result of need by parole boards for guidelines. Parole boards or the correctional department, in developing a set of guidelines, have already decided which variables or factors 
are deemed to be important; thus the parole process is already in action (Champion, 1990; Gottfredson \& Wilkins, 1978; Gottfredson, Wilkins, Hoffman, \& Singer, 1974). This process implies that some decision making is already in progress even prior to a parole hearing. The development of the instrument by which a potential parolee is to be assessed is thus increased in importance.

Although even those in favor of parole have admitted that the process is not always value-free and objective, it must be formal, i.e., "rule-based." In their review of parole guidelines, Gottfredson and wilkins (1978) point out that the development of parole guidelines does not in and of itself eliminate criticism of the parole process. It is maintained, however, that the decisions are to be made "rationally" which is said by Gottfredson and Wilkins (1978, p 42) to be

a probable requirement if they are to "effectively" control or reduce crime -- then some knowledge of the likely consequences of alternative choices is an obvious requisite. Rational decision making concerning offenders implies (a) a set of agreed-upon objectives for the decisions, (b) information concerning the person who is the focus of attention, (c) alternatives, and (d) knowledge of the probable outcomes for that person, given selection among the alternative disposition choices. There usually are much data about the person but little information (if that termis is defined as that which reduces uncertainty in the decision).

Thus it is suggested that the discretion used in the decisionmaking process should be structured and visible in order to eliminate the "on-the-spot" process prevalent in many parole 
boards. Some resistance to the implementation of guidelines and screening has been experienced based on the argument that too much rigidity could be introduced into the decision making process. The counter argument is that the absence of guidelines produces release disparity, which could be a demoralizing factor for the inmates (Allen, Eskridge, Latessa, \& Vito, 1985; Gottfredson, 1979; Hoffman, 1983).

In the development of guidelines for parole, the literature indicates that there are two levels of decision making. One is an individual case-by-case review; the other is at the policy decision-making level (Gottfredson, Wilkins, Hoffman, \& Singer, 1974). Gottfredson et al. found that even in those cases in which there appeared to be only a case-bycase decision-making process, there was indeed an implicit parole release policy decision-making process. The apparent policy process was driven by the success of the inmate in prison, prior criminal history, the nature of the current (present) offense and the expected behavior of the inmate while on parole. The last criteria calls for a somewhat subjective decision, based upon the first three criteria, which are more objective in nature. It is the effect of these criteria that are explained in chapter III and tested in chapter $v$. 


\section{c. Current Parole Selection Process}

A roview of the parole seleation process in most jurisdictions would reveal that few objective criteria are being used to select those inmates to be placed on parole. Most early studies reveal that the main factor used in considering selection for parole was the seriousness of the crime for which the inmate was currently serving time (scott, 1972). Carlson (1979) determined that the five most important factors considered in determining parole readiness are participation in prison programs, good prison behavior, change in attitudes, increased maturity, and development of insight. Although these variables are of importance, the subjective nature of their use by parole boards in many ways negates their value in predicting parole success. These criticisms lead to the first coordinated efforts directed at the development of SFS instruments (Gottfredson et al., 1978).

The failure of these early parole indicators in predicting parole success as well as the reported disparities in their use (dissimilar treatment of equally situated offenders) - (Gottfredson, 1979) lend support to the impression of subjectiveness in the decision-making process. This impression becomes even clearer when one looks at the process itself. In many jurisdictions the initiation of the parole selection process starts with the assignment of individual cases to individual members of the parole board. The initial 
recommendation of the individual parole board member is usually accepted by the board as a whole. The inmate may or may not be present for a formal meeting; however, even if the inmate is present, the meeting is likely to last less than fifteen minutes on average (Scott, 1974). It is important for the parole authority to have as much usable information as possible in order to make the parole decision; the situation described above can hardly be expected to provide that information using the current evaluation methods.

In sum many, ethical, moral, and legal questions are raised when predictors of dangerousness result in one offender remaining incarcerated and another offender being released when similar crimes have been committed (von Hirsch, 1984). The decision to maintain the incarcerated status of an offender largely because of his suspected future criminal conduct is, in effect, a penalty for future behavior that has not yet occurred. Because the information concerning the risk of dangerousness is used not only by parole boards but also by judges in the sentencing stage and by prison officials in the classification stage, it is necessary that these officials have faith in the prediction instruments (Farrington \& Tarling, 1985). Despite the existing problems associated with risk and dangerousness measures, they are used with increasing frequency by the above-mentioned officials; however, it has been suggested that if the quality of the predictive ability continues to remain low, a backlash may occur that will lead 
the officials back to the subject measures previously used (Gottfredson \& Gottfredson, 1988; Gottfredson \& Tonry, 1987; Morris, 1974; Tobory, 1984).

\section{d. Factors Influencing Parole Decisions}

Scott (1974) and Carroll (1976) found that the factors most likely to influence the parole decision-making process are the seriousness of the crime; the extent of the inmate's disciplinary problems in prison; and the age, education level, marital status, and race of the offender. Dawson (1966), in his review of the history of the development of the parole decision-making process, placed the criteria that influence the parole board into three broad categories:

1. Factors for granting parole based upon the probability of recidivism.

2. Factors for granting parole other than probability of recidivism.

3. Factors for denying parole other than probability of recidivism.

For most parole boards the basic concern in the decisionmaking process is the estimation of the probability of new violations of the law by the released inmate, or the recidivism factor. of the many important issues with which the parole board must be concerned, public safety is one of the most sensitive. Much public criticism may arise as the result of parolees violating the law. 
In the past, and even in the present, the parole boards' determination of the probability of offender recidivism was to a great extent subjective at best and almost completely arbitrary at worst. Part of the problem arises from the resistance by parole boards to the use of prediction tables. This is due in part to a belief in the uniqueness of each case, as further evidenced by the resistance to the use of predictive devices that measure mental attitude and success drive (Allen et al., 1985). Rather than using available quantifiable devices that may provide some clue as to the inmate's probable success on parole, subjective methods ("gut feelings") seem to be the most accepted method used by parole boards.

The need for methodologically sound prediction tables upon which to base the parole decision was first advocated by Burgess (1928). From this early attempt at providing parole boards with some form of yardstick by which to measure predicted success of the offender, there have been many other attempts, most notably Babst, Inciardi, and Jarman (1970); Glaser (1962); Bromley and Gathercole (1969); Gottfredson, Babst, and Ballard (1958); and wilkins and MacNaughton-Smith (1964).

There are several reasons for granting parole other than a determination of the general probability of recidivism. These include:

1. Little likelihood of the offender committing a crime of a serious nature. 
2. The determination that the inmate will gain little additional benefit from further institutionalization.

3. Relatively short time left to be served on the sentence.

4. Release to supervision even for a short period, rather than direct release to the street.

5. Age of the offender.

6. Amount of time served.

Reasons for denying parole other than probability of recidivism include:

1. Outbursts of violent and assaultive behavior.

2. Community attitude, as in a high profile case.

3. Continued drug dependency problems.

4. Instances when further incarceration may aid the offender, such as continued education or corrective surgery.

5. Release prior to the serving of the minimum sentence imposed by the court.

PAST AND PRESENT RISK ASSESSHFNT

Risk assessment, which is also referred to as dangerousness or public risk, concerns the perceived risk of further criminal activity based on past or present behavior. As previously noted, parole boards base their decisions on several factors, including the projection of dangerousness of the offender and the risk posed to citizens if parole is granted. Risk or dangerousness predictions are most often 
based on instruments devised through either application, practice or research (Gottfredson \& Tonry, 1987); however, this was not always the case. Prior to the first use of the SFS, there was little coordinated or consistent effort toward the development and use of an objective system of measurement of the risk of dangerousness of the parolee (Champion, 1990). The SFS in its earliest form was first used in the early 1970's; however, other predictive instruments predate this use. The SFS went through several stages of development until about 1983. The SFS is still in use the federal system as well as in many state and local jurisdictions; however, there does not appear to have been any further development of the model since about 1983 (Hoffman, 1983; Hoffman \& Beck, 1985).

Parole boards may or may not use the information provided through by the SFS; however, numbers can be persuasive, regardless of whether or not they are valid (Champion, 1990). The use of scaling instruments increases the need for a valid and reliable instrument. Hoffman (1983) reported favorable results from the use of the SFS in the federal system; however, Wright et al., (1984) are doubtful about any instrument's predictive utility for anything beyond managerial use. When the broad categories of poor, fair, and good parole risk were used as a result the use of a predictive, as in the case of the Texas Department of Corrections, accurate distinctions could be made (Eisenberg, 1986). Another criticism of the SFS is the "false positive" and "false 
negative" dilemma, which as Champion (1990, p 321) points out, can never be solved. Champion writes:

False positives are those predicted to be dangerous and turn out not to be, and false negatives are predicted to be harmless and actually turn out to be dangerous. An injustice is committed against one aggregate of offenders (prolonged detention of the false positive), while an injustice is perpetrated against society (the release into society of the false negatives).

This involves the issue of selective incapacitation, which is based on measures of predicted dangerousness. The addition of the variables discussed in Chapter III addresses this issue. The assumption is that the more information available, the better the decision.

Although each jurisdiction may use a slightly different model for predicting success on parole, the models can be categorized into two different types. These are referred to as the matrix and the sequential models. The development of both types were based on applied usage. The parole board makes a decision as to whether or not the offender is a good parole risk, based either upon the scores of the offender in the matrix model or on the progress of the offender in the sequential model.

In the matrix approach, information is gathered concerning the parole applicant, and then a score (SFS) is calculated. Based upon that score, the offender is classified according 
to two or more dimensions. ${ }^{2}$ The expected disposition of the case is based upon the interpretation of the classification by the parole board. This type of model is similar to that used by the United States Parole commission. The two dimensions used by the Commission are the seriousness of the offense and the probability of another offense being committed. Users of this type of model also relate the score for the offencier to the seriousness of the offense in order to form a matrix, which is then used to determine the time that the offender should spend in prison before being released. Experience has shown that when the weights of these two variables are considered the seriousness of the offense is the more important factor, at a ratio of 60:40 (Wilkins \& Gottfredson, 1978).

The matrix model specifies the general area into which the decision to grant parole should fall, based upon the information pertaining to the individual offender. Stated differently, based upon the information contained in the offender's file, it must be decided whether he has reached a SFS, in combination with the serious of the offense, to be eligible for parole. The parole board may deviate from the expected decision but must provide the reasoning for doing so. In this form the parole board is allowed a certain amount of

1 An example of a SFS form can be found in the appendix. 
discretion in judging the exceptional cases. One of the problems with the matrix model is that it:

- uses imprecise information (such as is ordinarily available in case files) in such a way that the information is amplified to help "zero in" on the general area of the "target." The guideline ranges in a matrix model are thus somewhat akin to "confidence intervals" in estimation problems. (Wilkins \& Gottfredson, 1978)

The second general category of parole release, sequential

or branching networks, was first used in parole decision policy by the Board of Parole in North Carolina (Wilkins, Kress, Gottfredson, Calpin \& Gelman, 1976). This type of decision-to-release procedure requires the offender to pass along a path that branches into a network. At each juncture the progress of the offender is assessed. The review of the offender's progress then determines which path will be taken next. It is believed that the greater the progress shown, the shorter his trip will be through this maze. The branching network attempts to provide an aid to the specific choices of whether or not to parole an offender. Thus there is little or no discretion allowed for exceptional cases.

Regardless of the type of predictive model used, the accuracy of parole prediction must be rated as poor at its best. If the assumption is made that a parole board releases an offender because of the expectation that the offender will not return to incarcerated custody within the supervision period, then the current models are grossly inaccurate. Depending on how and when failure is operationalized, the 
accuracy of current models in predicting success on parole is 20 to 50 percent (Glaser, 1983; Markley \& Eisenbery, 1987; o'Leary \& Clear, 1984; Petersilia, Turner, Kahan, \& Peterson 1985; Petersilia, 1985; Gottfredson, 1979; Gottfredson, Babst, \& Ballard, 1958). In other words, up to 80 percent of the individuals placed on parole violate the terms of the parole. It is generally expected that approximately 40 to 50 percent of the offenders will commit new crimes, while approximately 60 percent will commit a technical violation of such a serious or continuing nature that parole will be revoked. When these two categories are combined, up to 80 percent of the offenders have committed a new crime and/or a technical violation or both; thus failing in the expectations that the parole board had of them (Petersilia, Turner, Kahan, \& Peterson 1985; Petersilia, 1985).

Another measure of the explanatory power involves the amount of variation that can be explained in the current models. The amount of variability explained depends, of course, on the operational definition of success or failure as well as the variables included in the model. In either case the amount of variability explained, as expressed in the term $\mathrm{R}^{2}$ is relatively low. Petersilia (1985), in reviewing the literature, reports $\mathrm{R}^{2 \prime} \mathrm{s}$ as high as .32 and as low as .12 , while Gottfredson (1979), and Gottfredson, Wilkins, Hoffman, and singer, (1974) report $R^{2} ' s$ as high as .31. Although the higher end of the reported range is not totally unacceptable 
for the social sciences, the lower end is disappointing. one of the expectations of the addition of the variables referred to in Chapter III is the statistically significant increase in the amount of variability explained in the new model as compared to the old.

EXPECTED DIRECTION OF RELATIONSHIPS IN CURRENT MODEL

Currently, the most widely used form of parole risk prediction is the Salient Factor score (SFS/81). This is the model against which the model suggested in this dissertation will be tested. The score is made up of two parts: the first being the scoring instrument itself and the second being a table with suggested sentence lengths based upon the type and seriousness of the crime for which the current sentence is being served.

The SFS is made up of six parts or questions (see Table 1 in Appendix A). In scoring the individual offender, the higher the score, the less risk the offender should present on parole. As noted previously, there are two inadequacies in this method: first, much influence is still allotted to subjective criteria; and second, there are no criminological concepts involved. Again, the second of these inadequacies is the major concern of this dissertation.

The first question on the SFS concerns the number of adult or juvenille convictions/adjudications. The greater the number of these events the lower the score is on the SFS, and thus 
the greater the risk the offender poses while on parole. This means that, based upon the offender's prior criminal experience or lack of it, a partial score can be obtained.

Although it is important to know how many convictions the offender has had, it is just as important to evaluate the number of commitments. A commitment for a prior crime may give the evaluator some indication of the seriousness of the crime. The more serious the crime, the greater is the likelihood of commitment; thus the second question concerns those crimes for which the offender was committed for more than thirty days. As in the previous measure, the greater the number of commitments for more than thirty days the lower is the score, thus the greater is the risk presented by the offender while on parole.

The next indicator of risk used on the SFS concerns the offender's age at the time of the current offense. The older the offender, the higher is the score. "Those individuals twenty-six years of age or older are given a score of two, while those in the age range of twenty to twenty-five are given $a$ one and those under the age of twenty are given a zero. Although this part of the SFS appears to be drawn from the criminological concern for the relationship between age and future criminal activity, it provides only part of the necessary information. Blumstein $(1986,1987,1988,1989)$ and others (Greenburg, 1983) point out that the age at first arrest is also important. 
The fourth factor evaluates the amount of commitment-free time, or time not spent under correctional supervision. If the offender was not under correctional supervision in the last three years prior to the commission of the current offense it is assumed that he is less of a parole risk. Again, the higher the score the less risk the offender presents while on parole.

The fifth variable on which the offender is evaluated the status at the time of the current offense. If the offender was confined, on probation, on parole, or had escaped, then the offender is a greater future parole risk than an offender who was legally free at the time of the current offense.

The final category on which the offender is evaluated is drug use. If the offender is a drug abuser, then a lower score is received. It is assumed that former drug users are a greater risk while on parole, and thus they are given a lower score.

The score from the SFS is factored in with a score based on the type and seriousness of the current offense. The number of years to be served on the sentence before parole can be considered is then determined by that score. After the score is evaluated, it is then left to the subjective view of the parole board as to whether or not to parole the offender. This is the model against which the model suggested in the next chapter will be tested. In the next chapter the argument is presented that the currently used predictive model 
is inadequate, owing to its failure to take into consideration changes (social and psychological) in attitude and behavior of the offender, as well as other variables such as peer and family association, which may affect the probability of the offender's future involvement in criminal activities.

\section{ANALYSIS OF EXISTING PAROLE PREDICTION MODEL}

All the models reviewed provide objective evaluation of parolees and are admirable, but all remain weak in terms of their predictive power. The weakness of the models is demonstrated by the high rate of recidivism (Gottfredson \& Wilkins, 1978; Cullen \& Gilbert, 1982), by the general lack of faith in the subjective nature of the parole decisionmaking process (Champion, 1990: Goodstein \& Hepburn, 1985), and by their lack of grounding in the more recent criminological theories.

The insufficient predictive ability of the current models, in combination with the apparent subjective nature with which many parole boards make their decisions, has led to the release of many individuals who may not have been ready for parole, and to the continued incarceration of some who were ready for release. The lack of objective parole processing may be due in part to the lack of faith that the parole boards have in the current predictive models. Although that lack of faith is not the direct focus of this dissertation, it may certainly be important as one of the unintended consequences 
of the lack of grounding in criminological theory. If a good predictive model is

developed, then the parole boards may develop more faith in the objective approach.

In Chapter III the theoretical basis for adding variables to the current models will be discussed. The extent of the expected increase in predictive power, if any, that can be acquired through the use of criminologically grounded variables will be investigated. Also examined in Chapter III is the issue of whether or not the model suggested in this dissertation can address the subjective variables that parole boards consider before making parole decisions. 
CHAPTER III

REVIEW OF THE IITERATURE

\section{OVERVIEW}

During the 1970's and early 1980's, evidence accumulated indicating that a relatively small group of offenders committed most of the serious offenses. These findings, coupled with increasing pressures on the budgets of criminal justice agencies, led to calls for more effective use of the public expenditures for crime control by identifying and incarcerating the most serious and persistent offenders (Greenwood, 1982). These calls for selective incapacitation have focused attention on the causes of crime and on the problem of predicting which individuals will commit crimes in the future. The subject matter of this dissertation takes the suggestion of selective incarceration one step further in the process with the suggestion of delayed release (extended incapacitation). As noted in the previous chapter, most predictions of the likely future actions of offenders are made informally on the basis of experience or "clinical" judgment. There has recently been, however, increased interest in statistical or actuarial predictions. The underlying concepts on which the statistical or actuarial predictions are and should be based is the subject matter of this chapter.

The first section of this chapter, the introduction, briefly reviews some of the findings of studies evaluating 
the parolee success or failure. The second section discusses the theoretical grounding for the addition of new variables to the old model, and the final section reviews the expected relationship of the new variables.

\section{INTRODUCTION}

Practitioners and researchers alike measure the effectiveness of correction by the rates of recidivism, which is the "percentage of former offenders who return to criminal behavior after release" (Martinson \& Wilkes, 1976). Reported rates of recidivism vary from 5 to 80 percent, depending on the method used to do the measuring. The variation in recidivism rates has leads to one of the problems in measuring and then comparing the rates of recidivism. The concept itself means different things to different people; thus the rate of recidivism is dependent on three things: the event used to define recidivism (arrest, conviction, parole revocation), the duration of the period in which the measurement is made, and the seriousness of the behavior counted. The most common approach to the analysis of recidivism is based on reimprisonment within one or two years for either another felony conviction or a parole violation (Clear \& Cole, 1990). A parole violation may be the result of a technical violation, a violation of the court-ordered 
terms of the parole, an arrest, or conviction of a crime, even a misdemeanor.

Historically criminology researchers have made the assertion that between 50 and 75 percent of former convicts recidivate; more recent research tends to place these figures in dispute. Martinson and Wilkes (1976) studied the case histories of approximately 100,000 criminals and found that during the first three years after release from prison the recidivism rate was slightly lower than 25 percent. Martinson's work indicates that prisoners released under. parole supervision had a return rate of 25.3 percent while those prisoners released without parole returned at a 31.5 percent rate. Sacks and Logan (1984) compared a similar group of individuals and found that those discharged without supervision recidivated at a faster rate, especially during the first year of freedom. The parole group stayed out of prison for a longer period of time, but by the third year 77 percent had recidivated, compared with 85 percent of those discharged directly to the "street."

Although these two studies and others (Glaser, 1983; Markley \& Eisenbery, 1987; 0’Leary \& Clear, 1984) indicate varying degrees of reported success on parole, they also indicate that release on parole supervision is superior to release straight to the streets. The concern here is with those individuals who have served time in prison and are out on supervised parole, and with the development of a model that 
will predict the outcome of that parole based on the offender's past and present behavior. In order to develop this model, two major sociological theories of criminality and delinquency -- social control theory and differential association -- are considered. The assumption is also made that, in the case of short-term incarceration, the prison experience will be somewhat positive in nature; that is, the prosocial attitudes of the offender should be improved.

\section{THEOREIICAL BACKGROUND FOR SUGGESTED MODEL}

A heuristic concept that will aid in the parsimonious selection of the variables of concern here is that of criminal career. This concept refers to the longitudinal sequence of offenses committed by an offender who has a detectable rate of offending during some period. The criminal career is characterized during a life cycle by three phases: the onset or initiation; the duration; and the termination (Blumstein, Cohen, \& Farrington, 1988). To those who study the criminal career, the period of greatest interest occurs between the onset and termination of the career. The focus of interest is in learning about such features as the rate of offending, the pattern of offense types, and any definable trends in offending patterns. At least intuitively, these same concerns 
have influenced the construction of the currently used models of parole risk prediction.

The criminal careers approach is not a theory of crime; that is it is not focused on specifying the various causes of crime. The criminal career approach allows for the possibility that different causal factors and processes may be at work at different times in the offenders' life cycles. As suggested by Blumstein, et al. (1987), within the criminal career model, different theoretical approaches may be tested to understand which factors may work to encourage, to intensify, or to inhibit criminal activity.

There are three closely related perspectives that are part of the concept of the career criminal and may provide some guidance toward the development of indicators of future criminal activity. These perspectives are the generality of deviance (Osgood, Johnston, O'Malley \& Bachman, 1988), the career criminal (Barnett, Blumstein \& Farrington, 1989; Blumstein \& Cohen, 1987; Blumstein et al., 1986, 1988a, 1988b), and the latent trait (Rowe, Osgood and Nicewander, 1990).

If future criminal involvement can be predicted based on past behavior (a criminal careers approach), then it is reasonable to assume that the risk of recidivism based on those same variables could also be predicted, along with the addition of latent trait variables, as suggested by Rowe, et al. (1990). The latent trait evaluation is one that is often 
overlooked by parole boards. If the latent variables are evaluated at all, it is done using subjective rather than objective criteria. It is the effects of the latent traits of both the social bond and association that are explored in this chapter in addition to the effect of age at first offense and age at release.

of particular interest from a parole prediction model point of view is one of the underlying themes of each of the criminal career approaches: selective incapacitation. Blumstein et al. (1988) promote the use of selective incapacitation to the extent that persistent offenders with a high "lambda" can be identified at an early stage in their criminal careers.

Although Blumstein is more concerned with predicting criminal careers in general than with the narrower field of parole risk assessment, his approach is applicable. Blumstein proposes that a wider range of information should be used in determining who should be incarcerated or, in this case, who should remain incarcerated. This dissertation also suggests that a wider range of information should be used in determining who should and should not be released. Blumstein (1988) cautions, however, that the predictive variables of any model should have legal relevance, (e.g., the seriousness of the current offense and the seriousness and extent of prior

Blumstein defines lambda as the frequency of offending by active offenders or the individual crime rate. 
conviction record), while Rowe (1990) suggests that, in addition to those variables currently in use, latent trait information can add to any model predicting criminal career patterns.

A period of incarceration is seen by those supporting the criminal careers approach as nothing more than a point of reference within a criminal career. Whether or not the behavior of the offender can be predicted after the period of incarceration is the question. What this model is attempting to do is similar to the works stimulated by wolfgang, et al. (1972), which has been to identify that small group of "chronic offenders" who contribute disproportionately to the crime rate. If the chronic offender -- the offender most likely to recidivate, can be identified -- this information would be useful in the parole decision process.

Deviant behavior may be a unique phenomenon that requires a separate explanation for each action, or it may be a unified phenomenon with a single explanation. The advocates of the concept of generality of deviance support the idea that different types of deviance may have the same underlying causes. Osgood, et al. (1988) advance two general explanations for the correlations among different types of deviant behavior. One suggests that engaging in one form of deviant behavior leads to engaging in other forms. In other words, and more strongly stated, an initial form of deviant behavior may cause later forms of deviant behavior. The other 
explanation suggests that different forms of deviant behavior are related in that they have the same influences in common. The second explanation promotes the idea that the cause for different types of deviant behavior is the same thing.

Although it has been firmly established that a wide range of deviant behaviors are positively correlated with one another during adolescence and early adulthood (Akers, 1984; Donovan \& Jessor, 1985), it is Osgood's contention that the second explanation is just as important. Either of these approaches has implications for parole prediction, the first having been the most predominant in the risk models used to date. It is the second explanation, that deviant behaviors are related because they have shared influences, that is of more importance for this dissertation. If, as Osgood has posited, peer influence, self-esteem, and social bonds all share in their ability to influence deviant behavior, then, if properly measured, they may also add to the predictive power of a parole risk model.

It is these shared influences, explored by Donovan and Jessor (1985), Jessor and Jessor (1977), Osgood, et al. (1988) and Rowe, et al. (1990) and referred to as latent variables, that may be combined into a general latent variable of unconventionality. Further support for this approach is found in Hirschi's (1984) work on the relationship between drug use and delinquency, in which he stated that these forms of deviance are not merely influenced by some of the same 
factors, but that "they are manifestations of the same thing." (p. 51). The importance of these implications for this dissertation is that, as mentioned previously, if different deviant behaviors are manifestations of a single underlying construct, and causes specific to any particular form of deviance are relatively unimportant, then the ability to identify those specific variables that may lead to a particular form of failure is not important in the prediction of parole risk. It is only necessary to identify those variables that may lead to any future criminal activity.

One of the variables of importance to the criminal career approach is the effect of age upon the duration and termination of the period of criminal activity. If age is important in predicting the length of the criminal career, then it is also important to parole risk assessment. Agge

Although the arguments concerning the relationship of age and the rate of offending are by no means settled, it is relatively clear that age of onset of criminal activity does have an effect on the duration of the active period. Thus, if persistent offenders with high "lambdas" can be identified at an early age, then age as weil as rate of criminal activity are interrelated and of equal importance within a predictive model (Blumstein, 1988). 
Depending on the type of criminal activity, age is generally a good predictor of the end of a criminal career (Kercher, 1987; Steffensmeier, et al., 1989; Greenberg, 1985; Farrington, 1986). The proposition that involvement in crime diminishes with age is one of the oldest and most widely accepted in criminology (Quetelet, 1831; Parmelee, 1918), although the cause and effect relationship is somewhat in dispute (Hirschi \& Gottfredson, 1983; Gottfredson \& Hirschi, 1986; Greenberg, 1985; Farrington, 1986; Shover, 1985). Hirschi and Gottfredson (1983\& 1986) contend that the age distribution of crime is essentially invariant across time and space, regardless of offense, while others (Greenberg, 1985; Farrington, 1986; Steffensmeier, et al., 1989) argue that crime types vary in peak ages of criminality and in rates of decline from the peak years, and that owing to industrialization, peak ages have become younger in recent years and the descent of the age curve from the peak has become steeper.

The use of age as a determinant for release from prison appears inviting, especially in light of the findings that one to six percent of criminals commit at least half of all crimes committed and those criminals come from clearly identifiable age categories (Wolfgang, Figlio, \& Sellin, 1972;

2 With the "graying" of the general population, as well as the inmate population some of the relationships between age and crime may change in the future. 
Mednick \& Christiansen, 1977; Wilson \& Herrnstein, 1985). The "career criminal" seems to "disappear" from the criminal scene as he approaches the upper ages of the age/crime distribution. Thus, those who support the incapacitation model have come to realize that the commission of crime declines with age and that, in order for incapacitation to work at its best, it must occur during the time that the incapacitated offender would be committing criminal acts at a high rate. There is, however, some disagreement with this approach as noted by Hirschi and Gottfredson.

For such a dream to be realized two conditions must be obtained: First, selective incapacitation cannot simply duplicate existing criminal justice practices (which, after all, clearly involve highly selective processes). Second, those selected for incapacitation under proposed policies must be legally and socially eligible for such treatment. (Gottfredson \& Hirschi, 1986, p. 217)

There would be several problems with using age as the sole variable in predicting criminal activity and thus recidivist rates. The first involves the problem of fitting the punishment to the crime, a question that was raised earlier in the modern development of the criminal justice system by some of the nembers of the "Classical School" (Beccaria, 1819; Bentham, 1779; as reprinted in Jacoby). It would be both unconstitutional and morally unacceptable in this society to simply incarcerate individuals until they reach an age at which they are outside of the normal crime curve. This type of incarceration would add to the overcrowding problem in the 
prison system by unnecessarily incarcerating individuals beyond the point of effectiveness. The second problem, one that Gottfredson and Hirschi (1986) point out, is that the decline in criminal activity as age increases suggests that the optimal point of intervention, for purposes of incapacitation, is just prior to the age at which crime peaks -- that is, at thirteen or fourteen. This policy would suggest the lengthy incarceration of children in the interest of crime prevention, a policy that is hardly likely to appeal to the general public.

Although a policy of this nature is unappealing, it does not preclude the use of age at onset as a predictive variable. In other words, the age at onset as well as the age of the offender at the time of parole review could be part of a model used to aid a parole board in their decision_making process. The importance of age is not limited merely to the age at which we would expect an individual to drop out of criminal activity; the age at which the individual first starts committing crimes, the point in the individual's life cycle at which incarceration takes place, and the point in the life cycle at which the individual is released from incarceration are also important.

The age of the offender at the time of the current offense is used as one of the predictive variables in the SFS. Although it is important to retain this variable, it is equally important to consider the effect of age at first 
arrest and age at release. The inclusion of these points in the offender's life cycle should help to improve the predictive power of the suggested model.

other factors not included in the SFS, are the effects that the social bond and association with others might have on recidivism rates. These theoretical concepts are discussed in the next sections.

\section{COATROL THEORY}

Basic to control theory are the assumptions that, until properly socialized, individuals are inclined to commit deviant acts or more properly they are not as inclined to conform, and that children are more likely to commit deviant acts than adults. Also important is the idea that the socialization process of the individual does not stop upon attainment of the age of adulthood but continues throughout life. If one is left free to seek his or her interests, behavior driven by personal rather than societal needs. The individual acting in this manner is more likely to come into conflict with the rules of society. Thus the distance, as measured by the social bond, at which the individual removes himself from society may provide an indication of that individual's propensity to deviate. If that distance can be measured then it may provide an indication of future rule violation. The weaker the links with the groups to which the 
individual belongs, the less he depends on them, and the more he consequently depends only on himself and recognizes no other rules of conduct than those founded on his private interests (Durkheim, 1951).

For Hirschi (1969) the social bond consists of four elements -- attachment, commitment, involvement, and belief. Attachment refers to affective ties toward parents, school, and friends, while commitment refers to a youth's aspirations for, and behavior consistent with, attainment of conventional goals such as higher education or training and the obtaining of a prestigious occupation. Involvement is participation in conventional activities which precludes time spent involved in deviant behavior, and belief is acceptance of the moral legitimacy of the rules of society.

The premise of control theory is that deviant behavior will occur and continue if there is insufficient attachment to family and school; lack of commitments to, or involvement in, conventional behavior; and inadequate internalization of conventional "beliefs." Hirschi predicted that adolescents with higher levels of attachment, commitment, involvement, and belief would be less likely to deviate from the norms of society. The independent effect of each element on deviance is also reinforced by each of the other three elements of the social bond. Hirschi stated that "the more closely a person is tied to conventional society in any of these ways, the more closely he is likely to be tied in other ways" (Hirschi, 1969, 
p. 27). It is important to point out that a weakly bonded person is simply free, but not forced or driven, to commit deviant acts. Nothing in control theory accounts for motivations to deviate; therefore, it is necessary to include differential association into the otherwise pure control model. Each of the concepts of control theory have been operationalized in different ways by different researchers; there are no universally accepted precise meanings for these concepts, and Hirschi's original theory lacked conceptual clarity (Marcos, et al. 1986). Even though Hirschi's own descriptions are at times rather vague, there is a general underlying theme involved in the operationalization of the concepts in each of the studies that have attempted to replicate or extend Hirschi's earlier findings.

Despite differences in the way social control theorists explain criminal behavior, they all share one basic thought. Rather than asking the normal criminological question -"What makes people criminal?" -- these theorists share a conviction that deviant behavior is to be expected. What must be explained, they say, is "Why do people obey rules?" (Hirschi, 1969, p.10). As a result, some social control theories are reminiscent of a view of human nature that reflects the beliefs of Thomas Hobbs, who was convinced that humans are basically evil. This view is not particularly crucial for the creation of social control theories, but these theories must at least assume a neutral human nature. This 
puts social control theories at odds with some aspects of differential association, particularly in the areas of motivation. It is thus necessary to look at social control theory from the point of view of a socialization theory. since undersocialized humans will simply act out their desires, it is the presence of other people that necessitates that those behaviors be controlled. The most important way we exercise that control is through the process of socialization. We teach the "right" way to do things both informally, as in the family, and formally, as in school. In fact, much of our early upbringing is designed to socialize us so that we can function in society. Social control theories emphasize the quality of this process.

\section{ATTACHRERT}

The most important of the elements of the social bond is attachment, which is generalized as the affection for and sensitivity to others. Attachment is the basic element necessary for the internalization of values and norms; thus it is comparable to Reiss's (1951) concept of personal controls and Nye's concept of internal and indirect controls.

- . it can be argued that all of the characteristics attributed to the psychopath follow from, are the effect of, his lack of attachment to others. To say that to lack attachment to others is to be free from moral restraints is to use lack of attachment to explain the guiltlessness of the psychopath, the fact that he apparently has no conscience or superego. (Hirschi, 1969, p. 17-18)

As stated earlier, attachment generally refers to 
affective ties toward parents, school, and friends (Brotman, Silverman, \& Suffet, 1970; Hindelang, 1973; Hirschi, 1969; Marcos, et al. 1986; Jensen, 1972). Attachment to school has been measured through the respondent's fondness for school (Brotman, et al., 1970; Hirschi, 1969) and by the use of school performance (Wiatrowski, et al., 1981).

\section{COMPITTENT}

Commitment represents the investment one has already built up in conventional society. This investment may take such. forms as the amount of education, a good reputation, or the establishing of a business. Those with these forms of commitment to conventional society also have more to lose if they are caught engaging in deviant behavior. Commitment as a concept has been operationalized using items about educational or occupational aspirations (Brotman, et al., 1970; Hirschi, 1969; Wiatrowski, et al., 1981; MacDonald, 1989).

\section{INVOLVENGWT}

Involvement indicates the degree of participation, the time and energy, spent in conventional activities to the exclusion of unconventional or deviant behavior. In other words, those persons most occupied by conventional activities will simply have less time to be involved in deviance. Increases in the involvement in conventional activities tend 
to increase the stake in conformity of the individual. Those offenders having had employment prior to incarceration may have developed a greater stake in conformity than those with a poor employment record.

The concept of involvement has been conceptualized in several ways. Employment status has been used as an indicator in some studies (Hỉndelang, 1973; Hirschi, 1969; MacDonald, 1989), whereas the degree to which one is involved in sports activities (Brotman, et al., 1970) or dating behavior (wiatrowki, et al., 1981) has been used in other research.

\section{BELIEF}

Belief constitutes the acknowledgment of society's rules as being fair; that is, one has a respect for those rules and norms and feels a moral obligation to obey them. As stated by Hirschi (1969, p.23) ". . .the control theory assumes the existence of a common value system within the society or groups whose norms are being violated." Hirschi assumed, unlike Sykes and Matza (1957), that the beliefs that allow men to commit acts of deviance are unmotivated, in that it is not necessary for them to construct or adopt them in order to facilitate the attainment of illicit ends (1969, p. 25). For Hirschi, it was not necessary that neutralization of beliefs occur for delinquent acts to be possible. As the internalization of the norms of the society increases, the belief in the values of the system increase. The control 
theorist believes that delinquency is not caused by beliefs that require delinquency, but rather it is made possible by the absence of (effective) beliefs that forbid delinquency. Hirschi operationalized belief through questions concerning feelings toward the police and the law.

One of the critical questions in the study of criminality is the effect of prior criminal occurrences and of peers and family on the offender. One of the most consistent findings is that the association with criminal peers is positively correlated with criminal behavior (Hidelang, 1973; Jensen, 1972; Johnson, 1979; Marcos, et al., 1986). In short the association with criminal activity must be incorporated into the model; however, this cannot be accomplished through the use of a measure of the social bond alone. Hirschi after reviewing his findings, admitted that he had "underestimated the importance of delinquent associations" (1969, p. 230). Marcos (1986) states:

To be consistent with his data, Hirschi proposed that "delinquent companions" be placed in his model between the elements of the social bond and the dependent variable, and that there is an independent direct effect from delinquent companions to delinquent behavior. But in doing so, he left the realm of social control theory and entered into the territory of social learning theory.

In order to fully develop the predictive model suggested in this dissertation, it is necessary to follow the lead of Marcos, et al. (1986) and MacDonald (1989). In each of these research articles, differential association was used to augment or supplement the elements of the social bond. In the 
next section, this augmentation is developed.

\section{DIFFERENTIAL ASSOCIATION THEORY}

Differential association theory, first developed in the early 1930's by Edwin H. Sutherland (Sutherland \& Cressey, 1979) posits that criminal behavior is, like noncriminal behavior, learned in a complex process involving behavior patterns either favorable or unfavorable to crime. This process is not one of casual association, but of learning behavior from intimate group association, primarily family and close friends. Membership in subcultures, as well as other "signs" of differential social organization, is used to explain why some individuals come to internalize norms and values (motives) that are in conflict with those of the larger society.

Sutherland's differential association theory has two elements. The first he identified as being the content of what is learned, and the second as being the process by which the learning takes place. The content includes the techniques necessary for the commission of the crime, such as the appropriate motives, drives, rationalization, and attitudes as well as the more general "definitions favorable to law violation." These are all cognitive, in that they are ideas rather than actions. The second element, process, identifies the means by which the learning takes place. In Sutherland's 
form of association, learning is not acquired indiscriminately, but through association with significant others or in intimate personal groups (Vold \& Bernard, 1986). Sutherland derived his concept of content from Mead's general argument that "human beings act toward things on the basis of the meanings that the things have for them" (Blumer, 1969, p. 2-3). Thus, for Mead, a cognitive factor such as meaning determines behavior. An external concrete happening in an individual's life cycle can mean very different things depending upon social or economic position, employment, race, peer group pressures, or family ties. Mead argued that individuals derive particular meaning from particular experiences, but then generalize them in such a fashion that they become a set way of looking at things. For Sutherland this meant that the key factor in determining whether people violate the law was not the social or psychological conditions they experienced but the way the conditions were defined by the individual (Vold \& Bernard, 1986). Thus it was argued by Sutherland that people will tend to violate laws when "definitions favorable to law violation" outweigh "definitions unfavorable to law violation."

Sutherland's second element, also derived from Mead's theory, concerned the process by which the definitions were learned. In this instance Mead argued that "the meaning of such things is derived from, or arises out of, the social interaction one has with one's fellows" (Blumer, 1969). For 
Sutherland this meant that the meaning of criminal acts arises primarily from the meanings given those acts by other people, particularly those in intimate personal groups of which the individual is a member. The key characteristics of the association that affected the learning are the frequency of association, the duration, the priority and the intensity. In summary, the key to differential association theory can be found in its focus on the individual's ratio of definitions favorable and unfavorable to crime (MacDonald, 1989).

A measure commonly used in the empirical testing of the theory of differential association is the nature of peer group affiliation among delinquents or criminals. This concept has been operationalized using variables such as the number of delinquent peers with whom an individual associates (Short, 1957; Matsueda, 1982; MacDonald, 1989), the number of adult criminals one knows (Voss, 1964), or the number of friends using illicit drugs (Burkett \& Jensen, 1975; Kandel, Treiman, Faust, \& Single, 1977; Tec, 1972). A second strategy used to test differential association theory is the degree of favorableness an individual has toward law violation. In order to operationalize this variable, researchers have measured the level of crime in an individual's community (Short, 1957; Voss, 1964), the degree to which an individual agrees or rejects statements about being law abiding (Short, 1960; Akers, et al., 1979), the number of times that an individual has been arrested (Matsueda, 1982) as well as the 
number of times the individual has been officially labeled delinquent (Voss, 1969). This body of variables represents the measurement tools generally utilized to empirically test differential association theory.

\section{Some Integrating Remarks}

If criminology should ever achieve any unity, it will be through a concern for a concrete problem rather than through the development of a single theoretical perspective (Quinney and Wildeman 1991:18)

Before moving to a formal statement of propositions, it will be of value to summarize the various criminological perspectives used to direct the research. The purpose of the present research is to apply relevant criminological theory in the construction of a model which will improve the prediction of parole success/failure. However, no general paradigm exists in the discipline of criminology which explains in an integrated fashion all aspects of crime-related phenomena. Indeed, the history of criminology has been characterized as the thorough search of numerous blind alleys. One reason for this lack of theoretical unity has been that criminology incorporates the analysis of different levels of social reality: the origin of criminal definitions (criminalization process); the influence of societal reaction in shaping the reality of crime; and the determinants of behavioral patterns defined as criminal. The present study is grounded in the latter concern; however, even here, there 
are several theoretical perspectives which are relevant. Nevertheless, there is a common thread of theoretical logic which has guided the selection of variables to be investigated in the analysis. At least with respect to sociologically oriented theories, that common thread is the role played by the relative degree or intensity of integration of the individual with conventional others and conventional institutions. Sociological reasoning, even as early as Durkheim's study of suicide, has depicted deviance in terms of what could be described as a "valence model" of the relationship between individual and society. simply put, this means that deviance (crime) most likely will emerge in the conduct of persons where: 1) the attraction to conventional, institutionalized behavior is low, or 2) the attraction to unconventional behavior is high, or 3) especially, both occur simultaneously. Moreover, the nature of this "attraction" has generally been conceptualized as taking its form from the "web of group affiliations" in which social interaction takes place. The explanatory variables used here are selected with the intention of examining this general principle of sociological criminology.

Given the goal of this study, the most pressing theoretical issue is that of predicting disengagement from patterns of criminal behavior. For the most part, criminological research and explanatory models have emphasized the processes by which persons become involved in criminal 
behavior. It may be for this reason that relatively few theoretical principles have been used to direct the search for predictors of parole success -- an event conceptualized here as an exiting from a criminal career. Nevertheless, any sociological theory which is applicable to answering why persons get into crime has relevance with respect to the question of why they get out.

The theoretical perspectives discussed above do have some fundamental incongruencies when we apply them to the general problem of "the cause of crime." However, when we focus on a concrete problem of prediction there are some common explanatory themes embodied in them which lead to a set of propositions regarding what variables may predict parole success.

Following control theory, clearly in Hirschi's formulation and in the various empirical applications of the theory, we are led to predict that, to the extent that we can identify by some measure or measures the presence and intensity of the "social bond", we may predict future deviant conduct. The presence of relational bonds form "side-bets" (Becker, 1963) or "stakes in conformity" (Toby, 1957) which increase the potential costs (material and nonmaterial) of deviance and thus reduce its likelihood. The absence of the bonding factors, or a lowering their intensity, implies that social actors are "free" to engage in deviance and that the attracting factors, whatever they may be, will have greater 
relative influence in the "pull" toward deviance.

Though it is a more processually oriented perspective, the logic of differential association theory is consistent in its emphasis on the attraction to deviance resulting from "favorable" definitions emerging in interaction with nonconventional others who also hold value orientations favorable to law violation. This is principally a subcultural perspective and could be stated as arguing that deviance is most likely to occur or continue where the attachment and attraction to a deviant subcultural world view is maintained through interaction with others who share that world view (Lofland, 1966; Bankston, Forsyth, \& Floyd, 1981). In addition, involvement in "differential association" with those whose definitions (values) are favorable to norm (law) violation suggests the inverse effect of involvement in the conventional interaction emphasized by control theorists. Moreover, participation in more or less organized deviant lifestyles potentially has the consequence of increasing an actor's dislocation from conventional institutions both normatively (subjectively) and ecologically (physically) (Wallace, 1968). Conceptualized in this manner, control theory and differential association theory are not so inconsistent, but rather are "symmetrical" perspectives.

A similar logic can also be applied in interpreting the association between age and the criminal career. The concept of career implies a movement or trajectory through time in 
which there are changes in objective status and subjective interpretations of one's social identity (Goffman, 1961). However, it not the biological process of aging which is important here, but rather the social and interactional changes which aging encompasses that are important in interpreting involvement in crime, and disengagement from that involvement (Shover, 1985). The association of age and crime as reflected in the age-crime curve clearly suggests that the likelihood of desistance from criminal behavior increases with age, especially as persons enter into early adulthood, a pattern which continues into mid-life. This general pattern is recognized to be a consequence of either a decline in the prevalence of crime in older age cohorts, or of a decline in the incidence of crime (individual offending rate) of older offenders, or both. Though the relationship between age and crime have become almost a truism in criminological literature, the reasons for this strong association has not been extensively researched. However, research has suggested a number of "contingencies" common to aging offenders which move them toward exiting criminal careers. Generally, these contingencies result in more unfavorable evaluations of the rewards of criminal involvement relative to the potential costs. Age, as a social process, brings with it an increasingly critical appraisal of the self (i.e., one's past as representing foolishness and wasted time), reduced material aspirations and thus higher evaluation of legitimate 
employment, greater relational ties to other persons (e.g. wives and family), and disengagement from criminal subcultures seen largely as composed of foolish youths (Shover, 1985). Taken together, age brings with it increasing involvement with conventional others and conventional lines of action (integration) which are more likely to be perceived as "stakes in conformity". Simultaneously, the attraction and differential association with deviant others is likely to decrease.

Thus, a "valence model" which leads us to measure pushes and pulls, and their strengths, seems to be the logic by which we can begin combining the relevant parts of those theories most directly applicable to the problem at hand. To the extent that we can measure and add the influences suggested by the above perspectives, our ability to predict disengagement from crime (i.e. parole success) should be enhanced.

\section{EXPECTED RELATIONSHIPS}

Although the subjects studied in this dissertation differ in several ways from those in Hirschi's, in that they have been adjudicated as criminal, they are slightly older and they may have had more opportunities to develop relationships outside of the school, peer group, and family. Thus the operationalization of the elements of the social bond may in some cases be somewhat different than in Hirschi's work; however, the expected effects of the social bonds should not 
differ (See Table 2 in Appendix A, for a summary of the expected relationships).

on the average, as attachment to the positive aspects of the community increases, it is expected that the chance of success on parole will also increase. The greater either the expressed attitude (as determined through pencil and paper evaluation) and/or the observed behavior (as measured by actual events) toward a positive attachment to parents, school, spouse or conventional peers, the greater is the likelihood of success on parole.

As commitment to the conventional community increases it is expected that the chance of success on parole will increase. It is also expected that the greater the amount of self-reported and police-reported prior criminal activity, the less likely the chance of success on parole. The greater the commitment to education and job, the less likely is a return to crime; thus the likelihood of success on parole is expected to increase. Commitment to the conventional, such as years of education, employment record, self-reported attitudes, and criminal record, particularly juvenile record, will provide a measure of this social bond.

Involvement in conventional activities is expected to increase the chance of success on parole. Involvement in noncriminal activities is expected to decrease, as the amount of time which the offender has to complete criminal activities has decreased. The decrease in the amount of time spent in 
criminal activities is expected to increase the chance of success on parole.

Belief appears to be a key independent variable, in that delinquency tends to go up as internalization of the norms of the community decreases. The expected relationship is that, as belief in the conventional (as measured by pencil and paper methods) increases, the chance of success on parole should also increase.

As the amount and strength of the association with unconventional individuals prior to incarceration increases, the likelihood of success on parole is expected to decrease. This variable will generally be a measure of observed association, in which association with former crime partners and individuals of dubious character will decrease the chances of success on parole. As the number of family members involved in criminal activities increases, the chance of success on parole is expected to decrease.

As an indicator of projected success on parole, age is important at three points in the life of the offender. These points are the age at the inception of the criminal career, the age at the current offense, and the age of the offender at the time of release. At each point the expected relationship is such that as age increases, the likelihood of failure on parole decreases. 


\section{SURMARY}

The use of the SFS has been a great step forward in the parole decision-making process; however, it is, by itself, inadequate as a predictor of success or failure while on parole. The review of the literature strongly suggests that the essential factors of both social control theory and differential association theory have greatly increased our ability to predict such things as future drug and alcohol use, as well as future criminal activity. It has also been shown that these two theories, used in conjunction with each other, are better predictors of future behavior than is either one separately. The concept of the criminal career also suggests that the age of the offender is of value in predicting future criminal activity. It is therefore only reasonable that these same predictors be tested in a parole prediction model.

In the next chapter the operationalization of each of the predictive variables will be discussed. Additionally, the sampling method, the research design, the description of the sample, and the statistical methods will be reviewed. 


\section{OVERVIEW}

This section contains the description of the data; the sampling technique; the research design; the operationalization and measurement of the independent; dependent, and control variables; and the development of the model. In the section pertaining to the models, both the old and the new models are developed and explained.

\section{INTRODUCTION}

\section{a. Data set Description}

This dissertation makes use of what is essentially secondary data analysis. This, however, is a unique data set that contains information concerning four types of individuals, all of whom are or have been under some form of correction supervision. But only two of the four samples contain all of the information necessary for the development and testing of the model developed in this dissertation. The research design and the information may at times be limited due to the general limitations usually associated with 
secondary data analysis; however, the limitations are within acceptable ranges.

\section{b. Sample Description}

The sample used in this study consists of two groups of offenders serving time under the supervision of the Louisiana Department of Public Safety and Corrections(LDPSC). The first group consisted of first offenders serving time for non violent crimes. The second group, the one to which the first group was matched, consists of offenders serving time in the IMPACT program. IMPACT is an intensive incarceration program located at Hunt Correctional Institute in st. Gabriel, Louisiana. Both of the groups were then followed on parole for twelve months or until parole was revoked, whichever came first. Although each of the sample groups has had slightly different prison experiences, the samples were matched based upon critical variables. For the purposes of this study, the two groups have been combined into one group. The different prison experiences will be controlled as explained later in this chapter.

The IMPACT program is the Louisiana Department of Public Safety and Correction's (LDPSC's) version of shock incarceration. shock incarceration is currently being used in an attempt to: 1) reduce prison overcrowding; 2) rehabilitate first offenders through a program of mortification of self combined with both physical training 
and psychological therapy; and 3) provide intensive afterincarceration care.

It was essential that the two groups be matched as closely as possible for the original study. That requirement is no less important in this study because the groups are combined into one group that experienced a term of prison incarceration. The two groups consist of males, who were either accepted into the IMPACT Program at the Hunt Correctional (st. Gabriel) facility (the experimental group) or would have been eligible had they been sentenced to IMPACT by the sentencing judge. To be accepted in the control group, the inmate had to have been legally eligible for the IMPACT program.

The inmates in the control group were chosen using a screening process similar to the process used in the selection of the IMPACT inmates. The control group inmates were chosen weekly during their intake process at the Adult Receiving and Diagnostic Center (ARDC). The selection process was continued for four weeks. The first criteria considered in the selection of the matched sample of offenders was whether they had any of the characteristics that would have eliminated them from the IMPACT program, had they been sentenced to it. The characteristics that would exclude an offender from selection included commission of an aggravated violent crime, commission of a sex offense, age of more than forty, and a sentence length of over seven years. If the offender was not 
disqualified, the next stage was to determine whether or not the offender was parole eligible. If the offender was parole eligible, then his status was evaluated. For an offender to be placed in the IMPACT program or in the control group, his current offense had to be a first felony conviction. Additionally any offender judged to be a strong escape risk was excluded from the control sample because he would have been excluded from the IMPACT sample:

The argument for combining the two samples is supported by the findings of researchers who had used the same data for different reasons. Early analysis done on the sample selection process comparing the two groups -- those that completed the IMPACT program and those in the control group -- indicates that the matching of the two samples of interest in this dissertation was successful (Riechers, 1988). Riechers (1988) analyzed the matching based upon the average age and IQ of the offenders as well as the race composition and educational structure, sentence length, prior adult record and current offense. This earlier study indicates that the average age of the IMPACT sample $(n=42)$ was $24(s d=4.7)$ and that for the control group $(n=37)$ the average age was 25 ( $n d=4.8)$. The average IQ for the IMPACT sample was $80.8(\mathrm{sd}=14.2)$ and for the control group $76.9(s d=13.2)$. All of the other criteria used to match the samples were of similar difference, in other words, there were no significant differences between the two groups. 
Another indicator that the two samples, the IMPACT and the control groups, are similar is the rate at which each group recidivated. Mackenzie (1989) reports that 93.1 percent of the IMPACT group and 94.0 percent of the control group survived six months on parole. When the same measurement was taken at nine months, it was determined that 79.0 percent of the IMPACT group and 75.3 percent of the control group had survived. When the same time periods are compared for arrest, it was found that IMPACT group had, on the average, 85.7 percent who survived six months and 75.5 percent who had survived nine months. The findings for the control group are similar in that on the average, 84.6 percent survived six months and 77.5 percent survived nine months before being arrested. The IMPACT program had no observable results when compared to regular incarceration followed by regular parole.

\section{c. Data Collection}

In order to achieve the goals of the original study, the offenders were tested at three different times during the incarceration period and then followed for twelve months while on parole. Several different methods of data gathering, including archival research, self-report, pencil and paper assessment, and third party follow-up and assessment were used. Testing of individuals generally started during the second week in which the offender was incarcerated. The offender was also being evaluated in the Adult Receiving and 
Diagnostic Center, before release into the general prison population. The set of tests includes Self Report Demographic Data, the Jesness Inventory, Expectation About IMPACT or Prison, a Locus of Control scale, PCE Scale, Self Report Criminal Activities, and self Report Drug Use. At about this same time the researchers were also collecting information concerning the offenders' official records, such as psychological evaluations, presentence investigations, and prior criminal records. Most of the information used in the data analysis for this dissertation involves standard measures of criminal activity, demographic information and selfreporting. The Jesness Inventory, however, is not often used in criminological work; thus it needs more explanation.

The Jesness Inventory is a 155 item self-report instrument. It contains approximately 20 scales that measure such personality traits as social maladjustment, asocial attitudes, manifest aggression, and immaturity, to name a few. None of the pre-existing scales fit the needs of this dissertation; therefore, additional scales were developed as described later in this chapter.

After the offender had been out of the Adult Receiving and Diagnostic Center for approximately two weeks, he was again tested using various psychological scales, none of which are used in this study. After the offender had been institutionalized for approximately 90 days, the psychological scales, including the Jesness Inventory, were given again. 
A once a month follow-up was done for all of the offenders released on parole. This follow-up involved a monthly evaluation by the offender's parole officer for the first twelve months of the parole period.

\section{OPERATIONALTZATION OF SOCIAL BOND}

\section{a. Attachment-Commitment-Belief}

In order to create the separate measures of attachment, commitment, and belief, a two stage process has been used. The measures used to develop these elements came from questions contained in the Jesness Inventory. The first stage of the process was to use one of the modified forms of scaling developed by Thurstone (Thurstone \& Chave, 1929). This form of scaling makes use of judges to select items that, on the basis of face validity, appear to be testing the same unidimensional concept. In the case of the scales for attachment, commitment, and belief, ten judges were presented with the definition of each concept. Each judge was told to pick one concept at a time and then to read the questions in the Jesness Inventory. Each judge was then asked to mark those questions that appeared, on face value, to "get at" that concept. This process was repeated for each of the three concepts.. After all judges had prepared their lists the results were compared. If an item received seven out of ten 
votes within a concept, it was then selected for the next stage (See Factor Tables 1 through 3 in Appendix B.). This approach was used by Hardt and Hardt (1977) to develop a selfreport prosocial scale.

The second stage of the selection process makes use of a content validity approach, which consisted of a factor analysis. Those variables which seven of the ten judges picked for each concept were then factor analyzed. The variables that had a high loading on an extraneous factor or a low loading were removed (see Factor Table 4 in Appendix B). The factor analysis was then run again.

At this stage the analysis indicated that items indicative of the concept of Attachment made up only one factor; thus no further factoring was necessary. This was not the case with Commitment and Belief, which still had items loading high on an extraneous factor (see Factor Table 5 in Appendix B). The dubious items were reduced and the concepts were analyzed again. This time there was only one factor measured within each of the concepts (see Factor Table 6 in Appendix B). These items became the measure of each of the concepts: Attachment, Commitment, and Belief.

\section{b. Involvement}

No relevant questions for the fourth element of the social bond could be found in the Jesness Inventory; however, there does exist a measure of employment and school 
involvement in the data. An additional measure of involvement is marital status.

The question involving employment and school activities was stated: "At the time of your arrest, were you: working; in school; working and in school; looking for work; or unemployed?" It is reasonable to believe that those who were working or going to school were more likely than those not employed to be able to find employment on release. The employed parolees would have less free time to be involved in other activities, such as crime. To summarize, a determination of with the offender was involved work and/or school at the time of arrest is used in part to predict future activities of a similar nature that, in turn, is used to approximate involvement.

The second measure of involvement is marital status. offenders who are married are less likely to have free time to commit crimes than are unattached offenders. Marital status has been divided into: married, widowed, common-law, divorced, legally separated, and never married.

For the purposes of coding and combining the concepts of involvement, the following scheme is used (See Table 4.1). If the offender was working, going to school, or both at the time of arrest, the variable was given the value of one. If the offender was not employed, the value was zero. If the offender was married, his marital status was coded as one; however, if the marital status is common-law, the value was .5. All other 
marital statuses are coded zero. An offender who was working or going to school and was married at the time of the arrest would receive a score of 2.5, while an offender who was neither working nor going to school nor married would receive a score of zero.

Table 4.1. Coding Scheme for Involvement

Status Married(1) Common-Law(.5) $\quad \begin{aligned} & \mathrm{N} \\ & \text { Married(0) }\end{aligned} \mathrm{t}^{\mathrm{t}}$

\begin{tabular}{|c|c|c|c|}
\hline Working(1) & 2 & 1.5 & 1 \\
\hline School (1) & 2 & 1.5 & 1 \\
\hline $\operatorname{Both}(1.5)$ & 2.5 & 2.0 & 1.5 \\
\hline Neither (0) & 1 & .5 & 0 \\
\hline
\end{tabular}

\section{OPERATIONALIZATION OF ASSOCIATION}

It is assumed that the offenders encompassed within this study have learned at least some of the techniques for committing crimes, although they may not have learned them well in light of the fact that they were caught. It is also assumed that criminal activity was learned through or within association with peer or intimate personal groups. Given that this process has taken place at some point prior to the offender's arrest, conviction, and incarceration, our interest then lies in what was taking place before and near the time 
of the current offense. This is measured by the number of prior official criminal contacts and criminal associations within the family (Voss, 1969).

\section{a. Dependent Variable}

The operationalization of the dependent variable involves the identification of whether or not the offender succeeded or failed while on parole. Failure is defined as a revocation of the parole status by the DPSC. The follow-up period is limited to the first twelve months after the offender was released from incarceration.

An arrest while on parole may not, in some cases, lead to revocation of the offender's parole status; for example, a parolee might be "arrested" for driving a vehicle without a driver's license. This type of arrest normally would not lead to the revocation of the offender's parole status unless it is one of a series of events. Arrest as an indication of failure on parole will thus include only arrests that led to revocation.

Technical violations, another method of arrest that might lead to revocation, usually results from the violation of one or more of the conditions of parole. Technical violations may include, but are not limited to, curfew violations, failing to meet the parole officer, changing the place of residence without prior notice, repeatedly associating with undesirables, absconding, and drinking alcohol or use of 
drugs. Because these are conditions of parole that must be met, failure to repeatedly meet them is considered as failure.

\section{b. Independent Variables \\ The independent variables are measures of attachment, commitment, involvement, belief, association, and the composite of the SFS, as well as the effects of age of first arrest and age at release.}

\section{c. Salient Factor Score}

The composite of the variables in the SFS will be used to test its predictive value in both the old model and the one suggested in this dissertation. For scoring purposes the scale will be scored as specified by Gottfredson, Wilkins, Hoffman and Singer (1974) and by Champion (1990). Rather than use each item within the score, the composite of the score will become one of the independent variables.

\section{d. Age}

Age of the offender at the time of the current offense is already accounted for in SFS composite. The remaining age variables that might have an effect on recidivism are the age of the offender when his first offense was committed and the age of the offender at the time of his release. As noted previously, the older the offender was at either of the two 
points, the less likely he is predicted to recidivate. Each of these age dimensions have been treated separately. Age at first arrest does not necessarily have an influence on age at release and age at release certainly has no effect on age at first arrest.

\section{c. Association}

Two of the measures of association that have been used in the past are association with criminals (short, 1957; Matsueda, 1982; MacDonald, 1989) and the number of times an individual has been arrested or officially labeled deviant (Matsueda, 1982; Voss, 1969). Each of these concepts have been measured within the confines of this data set. The association with criminals concept is measured in the question "Has anyone else in your immediate family ever served time in jail or prison?" The second concept of association has been measured through assessment of the offender's criminal history record. Prior criminal history has been classified into the categories of DWI, Drug offenses, Violent offenses, NonViolent offenses, and Alcohol Defined (non-traffic related). The sum of each of these categories was used to classify the extent of the prior criminal activity

\section{OLD AND NES TODELS}

The model proposed in this paper is similar to the work done in other research using social bonding as a predictor of 
future behavior (Hirschi, 1969; Marcos, Bahr, \& Johnson, 1986; Wiatrowski, Griswold, \& Roberts, 1981), in that the same variables are of interest. The proposal is for the development of a prediction model based on the elements of social bonding -- attachment, commitment, involvement, and belief -(Hirschi, 1969) in conjunction with variations in association (Sutherland, 1947; Sutherland \& Cressey, 1978; Short, 1957; Voss, 1964 ).

To do the analysis, while at the same time making the end product of the analysis more understandable for the correctional practitioner, logistic regression (Hanushek \& Jackson, 1977), which provides a "chance" of failure or success in its solution, was used to develop the model statistically. This form of regression allows the researcher or the practitioner to plug information into a model or scenario; thus an individual's variable information can be entered into the model and the chance of his success or failure can be predicted. A second reason for using logistic regression is that the dependent variable in this model is dichotomous; thus multiple regression, while no less effective, is less understandable in terms of the solution to the model. The model is as follows:

\section{Current Model}

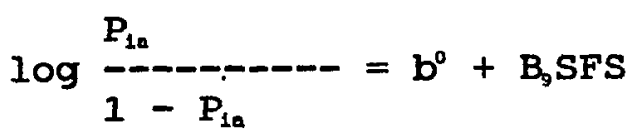


Suggested Model

$$
\begin{aligned}
& \log \frac{P_{10}}{1-P_{1 a}} \\
& b_{0}+B_{1} A+B_{2} I+B_{3} C+B_{4} B+B_{5} D 1+B_{6} D 2+B_{7} A 1+B_{8} A 2+B_{9} S F S
\end{aligned}
$$

Where:

"A" equals attachment, "I" equals involvement, "C" equals commitment, "B" equals belief, "D1" equals association measured by prior criminal activity, "D2" equals association with other criminals, "A1" equals age at first arrest, "A2" equals age at release, and "SFS" equals the Salient Factor Score. Although the indications are that the two groups of offenders are similar it is also necessary to statistically control for type of prison experience.

\section{TYPES OF ANATYSIS}

Two types of analysis will be used in this dissertation. The first is logistic regression, which will be used for the testing of the predictive model. The second analysis is a simple test of significance in which the model suggested in this dissertation will be compared to the SFS.

\section{a. Logistic Regression}

Predicting whether or not an event will occur and identifying those variables that are important in making the prediction is important from both a theoretical and an applied point of view. There are a variety of multivariate 
statistical techniques that can be used to predict a dichotomous dependent variable from a set of independent variables. Multiple regression and discriminant analysis are just two of the techniques that are available; however, difficulties are encountered when the dependent variable can have only two values, some of which are addressed below.

The assumptions necessary for hypothesis testing in regression analysis are violated when the dependent variable can have only two values. The violation of the assumptions leads to several problems, the most important of which are: 1) it is unreasonable to assume that the distribution of errors is normal; 2) the multiple regression analysis values cannot be interpreted as probabilities because they are not constrained to fall in the interval between 0 and 1 . Another form of analysis that is at times used is linear discriminant analysis; however, according to Norusis (199),

Linear discriminant analysis does allow direct prediction of group membership, but the assumption of multivariate normality of the independent variables, as well as equal variance-covariance matrices in the two groups, is required for the prediction rule to be optimal.

Because of the problems mentioned above, linear regression appears to be the most viable statistical method available to do the analysis of the data used in this dissertation. Logistic regression allows for the direct estimation of the probability of an event occurring, while requiring far fewer assumptions than discriminant analysis. Even when the assumptions required for discriminate analysis are met, 
logistic regression still performs well (Hosmer \& Lemeshow, 1989).

In linear regression the parameter estimates of the model are made using the method of least squares, which results in the selection of regression coefficients having the smallest sums of squared distances between the observed and the predicted values of the dependent variables. Logistic regression parameters are estimated using the maximumlikelihood method; thus the coefficients that make the observed results most likely to occur are selected. The logistic regression model is thus nonlinear, necessitating an iterative algorithm for parameter estimation (Norusis, 1990). b. Method of Variable Selection

Hastie and Tibshirani (1986, 1987) suggest the use of a generalized additive model for the analysis of binary data. This type of application can provide an effective plotting tool in logistic regression. Upon the completion of univariate analyses, variables are selected for the multivariate analysis. Any variable whose univariate test had a p-value of $<0.25$ should be considered for inclusion in the multivariate analysis.

The use of the 0.25 level as a screening method for the selection of the variables to be included in the multivariate analysis is based on the work by Bendel and Afifi (1977) on linear regression and on the work by Mickey and Greenland (1989) on logistic regression. These authors show that use 
of a more traditional level (such as 0.05) often fails to identify variables that are known to be important. One problem with any univariate approach is that it ignores the possibility that a collection of variables, each of which is weakly associated with the outcome, can become an important predictor of outcome when taken together. Use of the larger level has the disadvantage of including, at the model-building stage, variables that may be of questionable value. For this reason, it is important to critically and theoretical review all variables added to a model before making a final decision.

\section{UNDERSTANDING IOGISTIC REGRESSION}

For the case of multiple independent variables, the logistic regression model can be written as

$$
\begin{aligned}
& \operatorname{Prob}\left(\text { event) }=-\frac{e^{z}}{1+e^{z}}\right. \\
& \text { or equivalently, }
\end{aligned}
$$$$
\operatorname{Prob}(\text { event })=\frac{1}{1+e^{-2}}
$$

where $z$ is the linear combination

$\mathrm{Z}=\mathrm{b}_{0}+\mathrm{B}_{1} \mathrm{X}_{1}+\mathrm{B}_{2} \mathrm{X}_{2}+\ldots+\mathrm{B}_{\mathrm{p}} \mathrm{X}_{\mathrm{p}}$

where $B_{0}$ and $B_{1}$ are coefficients estimated from the data, $\mathrm{X}$ is the independent variable, and $e$ is the base of the natural logarithms, approximately 2.718. Then the probability of the event not occurring is estimated as

Prob (no event) $=1$ - Prob(event) 
In multiple logistic regression, the interpretation of the regression coefficient is the same as in multiple linear regression. It tells the amount of change in the dependent variable for a one-unit change in the independent variable.

For the purposes of this dissertation this means that

Prob(Failure on parole) $=\frac{1}{1+e^{-z}}$

For example, if the value of $\mathrm{z}$ were equal to -0.54 , the estimated probability of a failure on parole would equal 0.37 and the probability of success on parole would equal 0.63 ( 1 0.037). The odds of failure on parole would then be estimated as

$$
\text { odds }=\operatorname{prob}(\text { failure }) / \text { prob }(\text { success })=\frac{0.37}{1-0.37}=0.59
$$

This means that an offender whose values when put into the regression formula equaled -0.54 , would have a 59 percent chance of failure while on parole.

As mentioned previously, the use of logistic regression has advantages over other types of statistical analysis. The two most important ones are that in this case the analysis fits the data and the product of the mathematical process provides the correctional practitioner with the odds of an event taking place rather than just the probability. 
a. Test of significance

The second type of analysis involves a simple test of significance. The goal of this analysis is the determination of whether or not the addition of the variable suggested in this dissertation significantly increases the predictive power of the new model over the old.

In order to test whether or not the explained variance of the new model is significantly greater than that of the old model, a multiple regression model must be used. The reason for using the explained variance found in the multiple regression model rather than the explained variance of the logistic regression model is owing to stability. The $\mathbf{R}^{2}$ derived from the logistic regression formula is not a "true" $R^{2}$ (Norusis, 1990). The test of significance is an $F$ test in which:

$$
F=\frac{\left(R^{2}-R_{2}^{2}\right) /\left(K_{1}-K_{2}\right)}{\left(1-R_{1}^{2}\right) /\left(N-K_{1}-1\right)}
$$

where, $R^{2}$ is derived from the larger model, $R_{2}{ }_{2}$ is the product of the smaller model, $K_{1}$ is the number of independent variables in the larger model, $K_{2}$ is the number of independent variables in the smaller model and $N$ is the number of cases in the models.

In the next chapter the result of both the model testing and the test of significance are discussed. 


\section{CHAPTER V}

\section{RESULTS}

\section{OVERVIEW}

This chapter contains the results of the data analysis and is separated into five parts. The first section contains the descriptive information on the sample. In the second section the results of the logistic regression analysis are discussed. The third section details the results of the test. of significance between the SFS and the model suggested in this dissertation, and the final section contains the summary.

\section{DESCRIPTIVE RESULTS}

The data set is made up of $10 \%$ offenders who were sentenced to the Department of Public Safety and Corrections for a period of incarceration. After the period of incarceration, the offenders were released by the parole board to periods of at least one year of supervised parole.

\section{a. Demographic Information}

All of the offenders in the sample are male. The average age at the time of the current offense was 23.8 (std $=4.67)$. 
There were 36 (35.3\%) whites, 62 (60.8\%) blacks, and 4 individuals for whom race could not be determined. The average education level of the offenders was 10.1 years ( $s$ ) $=2.47)$. There were $25(24.5 \%)$ offenders who were married and $70(68.6 \%)$ who were not married.

\section{b. Incarceration Information}

The sample includes 61 offenders who were not on probation for another crime when sentenced, while 37 of the offenders were under some kind of correctional supervision such as probation. The sample consists of $73(71.6 \%)$ offenders who served time in an intensive incarceration program and 29 offenders who served "regular" time. The average length of sentence was 44.63 months $(s d=21.38)$. The information for prior incarceration shows that 80 (85.1\%) of the offenders had no prior periods of commitment, while 14 (14.9\%) had at least one prior incarceration.

\section{c. Age Information}

As previously noted, the average age at the time of the current offense was 23.8 years. The average age at the time of the first reported crime was 20.135 ( $s d=4.67$ ), while average age at the time of release from incarceration was 24.6 years $(s d=4.69)$. 


\section{d. Elements of the Social Bond Information}

The values for involvement were calculated using the method described in the methods section. The values for attachment, commitment, and belief have been calculated by summing the score of the items for each individual and then dividing by the number of items. A score of 1 for attachment, commitment, and belief indicates an increase in the conventionality of the individuals. As the value of belief approaches 0 , the involvement of the individuals in conventional activity decreases(see Table 5.1).

\begin{tabular}{lcccc} 
Table 5.1. & \multicolumn{2}{c}{ Values for the Elements of the Social Bond } \\
\hline & Mean & sd & Maximum & Minimum \\
\hline ATTACHMENT & 1.723 & .249 & 2.00 & 1.00 \\
COMMITMENT & 1.689 & .196 & 2.00 & 1.00 \\
INVOLVEMENT & .873 & .612 & 2.00 & 0.00 \\
BELIEF & 1.500 & .264 & 1.00 & 1.00
\end{tabular}

\section{e. Association Information}

Two measures of association were described in previous chapters. The first involves the number of family members having had contact with the criminal justice system. The second is the number of prior criminal offenses committed by the offender, as indicated by an arrest (see Table 5.2). 
Table 5.2. Values for the Elements of Association.

\begin{tabular}{|c|c|c|c|c|}
\hline & Mean & sd & Maximum & Minimm \\
\hline $\begin{array}{c}\text { FAMILY MEMBERS } \\
\text { ARRESTED }\end{array}$ & 1.75 & 1.679 & 6.00 & 0.00 \\
\hline PRIOR ARREST & 2.24 & 0.612 & 10.00 & 0.00 \\
\hline
\end{tabular}

\section{F. Salient Factor Score Information}

The last variable to be described is the SFS. The scale is a composition of several variables that include whether or not there is a prior criminal conviction, indications of a prior incarceration, age at current offense, recent commitment-free period, status at time of arrest (escapee,. parolee, probationer, or free), and prior drug use. Each of the variables was assigned a value in which the lower the sum total, the great the likelihood of dangerousness on parole. The mean SFS score for the sample was 6.2 (sd $=1.856)$.

\section{LOGISTIC REGRESSION RESULTS}

The results of the logistic regression models will be reviewed in three parts. In the first model, the SFS score is regressed on the parole outcome. In the second, the model SFS score and the variables suggested in this dissertation have been regressed on parole outcome. In the final model the effects of the type of incarceration experience are added to the second model. 
There are two products of the logistic regression analysis that are useful. The first is the measure of the success of the predictive model. This method generates a classification table in which the predicted outcomes are compared to the observed outcomes. The second useful product is the beta coefficients, which are placed in a regression formula. The suggested method of reviewing the results is to use scenarios. This means that the value of each variable will be changed, while the remainder of the variables are held constant. The results of the model provide indications of the individual's likely success or failure on parole, given the values that are provided. This method allows for a case-by-case examination of the results. By using the range of each variable, an infinite number of scenerios can be developed. It should be noted that, while the significance of the individual variables is important, it is not as important as is the validity of the total model.

As suggested in the methods section of this dissertation a univariate analyses in which each independent variable is regressed upon the parole outcome is used in order to determine the strength independent variables separately. The results of this analysis are found in Table 5.3. A table containing the results of the zero order correlation is located in Appendix A. 
Table 5.3 Univariate Analysis of the Effect of the Independent Variables on Parole Outcome.

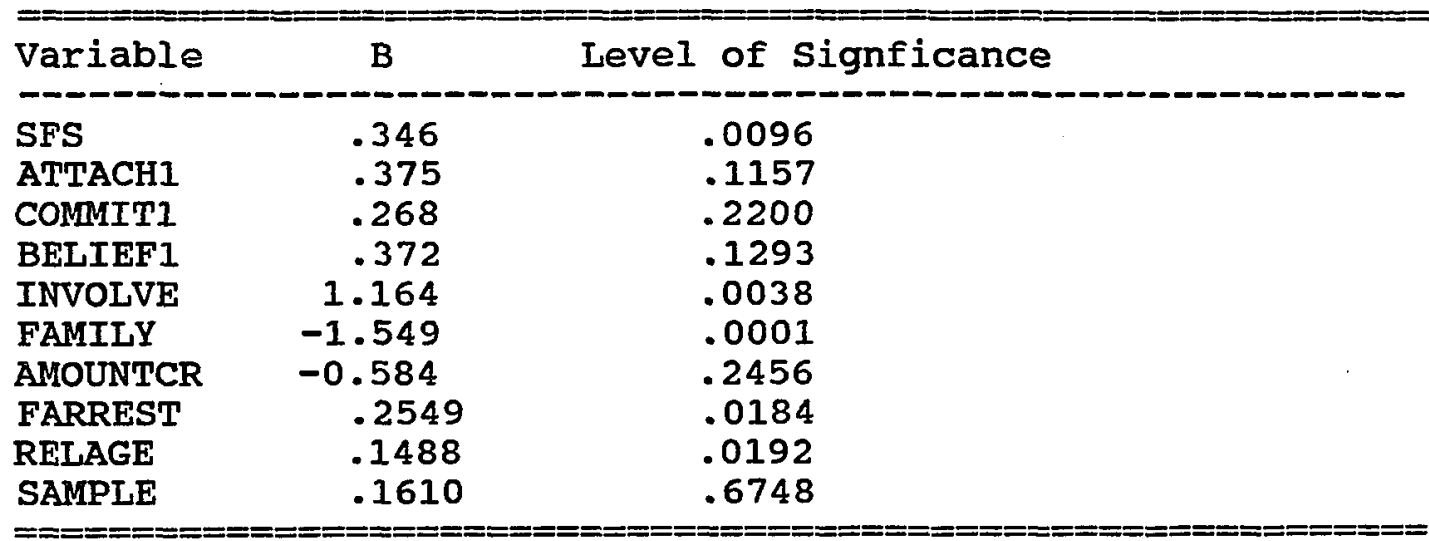

The results of the use of the 0.25 level as a screening method for the selection of the variables to be included in the multivariate analysis would suggest that the results of the SFS score and those measures of future criminality suggested in this dissertation should be included in the multivariate analysis. The only variable that far exceeds the 0.25 limit is GROUP, the variable that classifies the type of incarceration. As we shall see later GROUP though not signficant in its effect on outcome, does add a certain measure of stability to the model.

\section{SFS REGRESSION AFALYSIS}

The results of the model in which the SFS score was regressed on outcome indicate that the SFS had an overall accuracy rate of $73.52 \%$ in predicting parole outcome(This is referred to later as Model I). As indicated in Table 5.4, the 
SFS had a $90.78 \%$ accuracy rate in predicting successes but only a $23.07 \%$ accuracy rate in predicting failures.

Table 5.4. SFS Prediction Accuracy

\begin{tabular}{|c|c|c|c|}
\hline \multirow[b]{2}{*}{ observed } & \multicolumn{2}{|c|}{ Predicted } & \multirow[b]{2}{*}{ \%correct } \\
\hline & Failure & Success & \\
\hline Failure & 6 & 20 & $23.07 \%$ \\
\hline \multirow[t]{2}{*}{ Success } & 7 & 69 & $90.78 \%$ \\
\hline & & \multicolumn{2}{|c|}{ overall 73.52} \\
\hline
\end{tabular}

These findings indicate that 7 of the offenders predicted to fail actually succeeded, and that 20 of the offenders that the SFS predicted to succeed actually failed. These results indicate that from a public safety standpoint, 20 parolees were released into the community who presented a danger to it. From an offender's view-point, had this model been strictly adhered to, 7 offenders who succeeded on parole might not have been released. The variation explained by this model is moderately low $\left(R^{2}=.29\right)$.

As mentioned previously, one of the advantages of logistic regression is the ability to predict the probability of success or failure based on the observed values. The beta coefficient for the SFS is equal to .346 and the constant for the model is -1.1087. When this information is plugged into the regression formula, the resulting $\mathrm{Z}$ value is 0.2769 . 
Based upon this information, two scenarios have been developed.

In the first scenario, the SFS score of 4 has been assigned, and in the second scenario, a value of 10 has been assigned. It should be remembered that the higher the SFS score, the greater the projected chance of success on parole; conversely, the lower the SFS score, the less likely the individual is to succeed on parole. Using just the score from the SFS the value of 4 suggests that the probability of failure is equal to .43. A score of 10 results in an. individual probability of .087 chance of failure on parole. This clearly indicates that the offender scoring high on the SFS has a better projected chance of success on parole; however, there does appear to be a high rate of error, particularly in the ability to predict failures. This tendency of the SFS to err in predicting failure is to the disadvantage of public safety; however, its ability to predict success is high.

\section{SUGGESTED MODEL REGRESSED ON PAROLE OUTCORE}

In this section the variables described in Chapter III and IV plus the SFS are regressed on the parole outcome (This is referred to later as Model II). The results suggest an overall accuracy rate of $93.13 \%$ in predicting parole outcome. As indicated in Table 5.5, this model had a 95.52\% accuracy 
rate in predicting successes while the accuracy rate in predicting failure was $86.66 \%$.

Table 5.5. Suggested Model Prediction Accuracy

\begin{tabular}{|c|c|c|c|}
\hline \multirow[b]{2}{*}{ Observed } & \multicolumn{2}{|c|}{ Predicted } & \multirow[b]{2}{*}{ :correct } \\
\hline & Failure & Success & \\
\hline Failure & 31 & 4 & $88.57 \%$ \\
\hline \multirow[t]{2}{*}{ Success } & 3 & 64 & $95.52 \%$ \\
\hline & & \multicolumn{2}{|c|}{ overall 93.13} \\
\hline
\end{tabular}

These findings indicate that 3 of the offenders predicted to fail actually succeeded, and that 4 of the offenders predicted to succeed actually failed. These results indicate that, from a public safety standpoint, only 4 parolees were released into the community who presented a danger. From an offender's view-point, had this model been strictly adhered to, only 3 offenders who succeeded on parole would not have been released. The addition of variables representing the elements of the social bond, differential association, and age have added a significant amount of predictive accuracy. Although only 4.8 percentage points were added to the accuracy of predicting successes, 65.82 percentage points were added to the ability to accurately predict parole failures. The additional accuracy in predicting offenders who are likely to fail on parole has important ramifications from both a public safety and a policy point of view. These ramifications will 
be discussed in Chapter VI. The variation explained by this model is moderately high $\left(R^{2}=.78\right)$.

Although the model as a whole has a great deal of explanatory power, most of the individual variables are not significant. The beta coeffecients were not highly significant, but they are all in the expected direction (see Table 5.6).

Table 5.6. Regression Product for Suggested Model

\begin{tabular}{|c|c|c|c|}
\hline Variable & B & S.E. & sig \\
\hline $\begin{array}{l}\text { SFS } \\
\text { ATTACH1 } \\
\text { COMMIT1 } \\
\text { BELIEF1 } \\
\text { INVOLVE } \\
\text { FAMILY } \\
\text { AMOUNTCR } \\
\text { FARREST } \\
\text { REIAGE } \\
\text { COnStant }\end{array}$ & $\begin{array}{r}0.819 \\
-0.856 \\
-0.567 \\
-0.419 \\
1.814 \\
-1.095 \\
0.246 \\
0.206 \\
-0.037 \\
-4.589\end{array}$ & $\begin{array}{r}.6667 \\
.9166 \\
.9030 \\
.8350 \\
1.8140 \\
.7234 \\
.6042 \\
.3422 \\
.0205\end{array}$ & $\begin{array}{l}.2192 \\
.0923 \\
.3018 \\
.1154 \\
.0542 \\
.0088 \\
.4833 \\
.5468 \\
.0205\end{array}$ \\
\hline
\end{tabular}

For the remainder of this dissertation, the variable names used in Table 5.6 will be used. To avoid confusion, the variable names and a description of each are provided here. SFS refers to the Salient Factor Score. ATTACH1 refers to attachment, COMMIT1 refers to commitment, BELIEF1 refers to belief, and INVOLVE refers to involvement. FAMILY is the variable name for the amount of criminality reported for the offender's family, while AMOUNTCR refers to the number of arrests reported for the offender. FARREST refers to the age 
of the offender at the time of his first reported arrest, and RELAGE refers to the age of the offender when he was released on parole.

Because there are nine variables in this model, there will be nine scenarios. In each scenario the value of the variable of interest will be changed in order to review the effect on predicted parole outcome. In order to understand the variation in values, it is first necessary to explain the coding system for the variables in the model (see Table 5.7).

Table 5.7. Table of Values Used in Suggested Model.

\begin{tabular}{|c|c|c|}
\hline Variable & Values Possible & Expected Relationship \\
\hline SFS & 0 through 10 & $\begin{array}{l}\text { As the value of the SFS } \\
\text { increases for the individual } \\
\text { offender, the likelihood of } \\
\text { successful completion of } \\
\text { parole is expected to } \\
\text { increase. }\end{array}$ \\
\hline
\end{tabular}

ATTACH1 1 through 2

As the value of ATTACHI approaches 1 the attachment of the offender, to the conventional increases and the likelihood of failure is expected to decrease.

COMMIT1 1 through 2

As the value of COMMITI approaches 1, the commitment of the offender to the conventional increases and the likelihood of failure is expected to decrease. 
Table 5.7 (continued) Table of Values Used in Suggested Model.

\begin{tabular}{|c|c|c|}
\hline Variable & Values Possible & Expected Relationship \\
\hline BELIEF1 & 1 through 2 & $\begin{array}{l}\text { As the value of BELIEFl } \\
\text { approaches } 1 \text {, the belief of } \\
\text { the offender in the } \\
\text { conventional increases and } \\
\text { the likelihood of failure } \\
\text { is expected to decrease. }\end{array}$ \\
\hline INVOLVE & 0 through 2.5 & $\begin{array}{l}\text { As the value of INVOLVE } \\
\text { approaches } 0 \text {, the } \\
\text { involvement of the offender } \\
\text { in conventional activities } \\
\text { decreases and the likelihood } \\
\text { of failure is expected to } \\
\text { increase. }\end{array}$ \\
\hline
\end{tabular}

FAMILY 0 through 6

AMOUNTCR 0 through 10

FARREST

13 through 35

RELAGE

18 through 36
As the value of FAMILY approaches 0 , the number of family members involved in criminal activity decreases and the likelihood of failure is expected to decrease.

As the value of AMOUNTCR approaches 0 , the number of prior arrests for the offender decreases and the likelihood of failure is expected to decrease.

As the age of the offender at the time of the first recorded arrest decreases the likelihood of failure is expected to increase.

As the age of the offender at the time of release on parole increases the likelinood of success on parole increases.

It is unlikely that any offender would exactly fit any of the following scenarios; thus the scenarios are for 
illustrative purposes only. A value change has been effected for each variable while holding the others constant. The result of these findings is illustrated in Table 5.8.

Table 5.8. Scenario for Model II

\begin{tabular}{|c|c|c|c|c|}
\hline Variable & Value & Z & $\begin{array}{l}\text { Probability } \\
\text { of Failure }\end{array}$ & $\begin{array}{l}\text { Odds } \\
\text { of Failure }\end{array}$ \\
\hline SFS & $\begin{array}{l}1 \\
8\end{array}$ & $\begin{array}{r}-0.204 \\
3.683\end{array}$ & $\begin{array}{l}.88 \\
.02\end{array}$ & $\begin{array}{l}7.7 \\
0.025\end{array}$ \\
\hline АTTACHI & $\begin{array}{l}1 \\
2\end{array}$ & $\begin{array}{l}1.263 \\
0.407\end{array}$ & $\begin{array}{l}.22 \\
.39\end{array}$ & $\begin{array}{l}0.28 \\
0.66\end{array}$ \\
\hline COMMITI & $\begin{array}{l}1 \\
2\end{array}$ & $\begin{array}{l}0.974 \\
0.407\end{array}$ & $\begin{array}{l}.27 \\
.39\end{array}$ & $\begin{array}{l}0.37 \\
0.66\end{array}$ \\
\hline BELIEF 1 & $\begin{array}{l}1 \\
2\end{array}$ & $\begin{array}{l}0.826 \\
0.407\end{array}$ & $\begin{array}{l}.30 \\
.39\end{array}$ & $\begin{array}{l}0.43 \\
0.66\end{array}$ \\
\hline INVOLVE & $\begin{array}{l}1 \\
1.5\end{array}$ & $\begin{array}{r}-0.449 \\
0.407\end{array}$ & $\begin{array}{l}.62 \\
.39\end{array}$ & $\begin{array}{l}1.64 \\
0.66\end{array}$ \\
\hline FAMILY & $\begin{array}{l}0 \\
2\end{array}$ & $\begin{array}{l}2.590 \\
0.407\end{array}$ & $\begin{array}{l}.06 \\
.39\end{array}$ & $\begin{array}{l}0.07 \\
0.6 .6\end{array}$ \\
\hline AMOUNTCR & $\begin{array}{l}0 \\
3\end{array}$ & $\begin{array}{r}0.653 \\
-0.084\end{array}$ & $\begin{array}{l}.34 \\
.52\end{array}$ & $\begin{array}{l}0.52 \\
1.08\end{array}$ \\
\hline FARREST & $\begin{array}{l}17 \\
21\end{array}$ & $\begin{array}{r}-0.210 \\
0.613\end{array}$ & $\begin{array}{l}.55 \\
.35\end{array}$ & $\begin{array}{l}1.23 \\
0.54\end{array}$ \\
\hline RELAGE & $\begin{array}{l}24 \\
27\end{array}$ & $\begin{array}{l}0.296 \\
0.407\end{array}$ & $\begin{array}{l}.42 \\
.39\end{array}$ & $\begin{array}{l}0.74 \\
0.66\end{array}$ \\
\hline
\end{tabular}

As the values in each scenario were changed, the expected effect took place; however, some of the value changes may not be realistic. For example, it would be possible but not probable for an offender to score low on belief, commitment, and attachment, while scoring high on involvement. In order 
to attain a more realistic view of the score method, two offenders from the sample have been selected from the data set.

Table 5.9 Example of offenders from the Sample

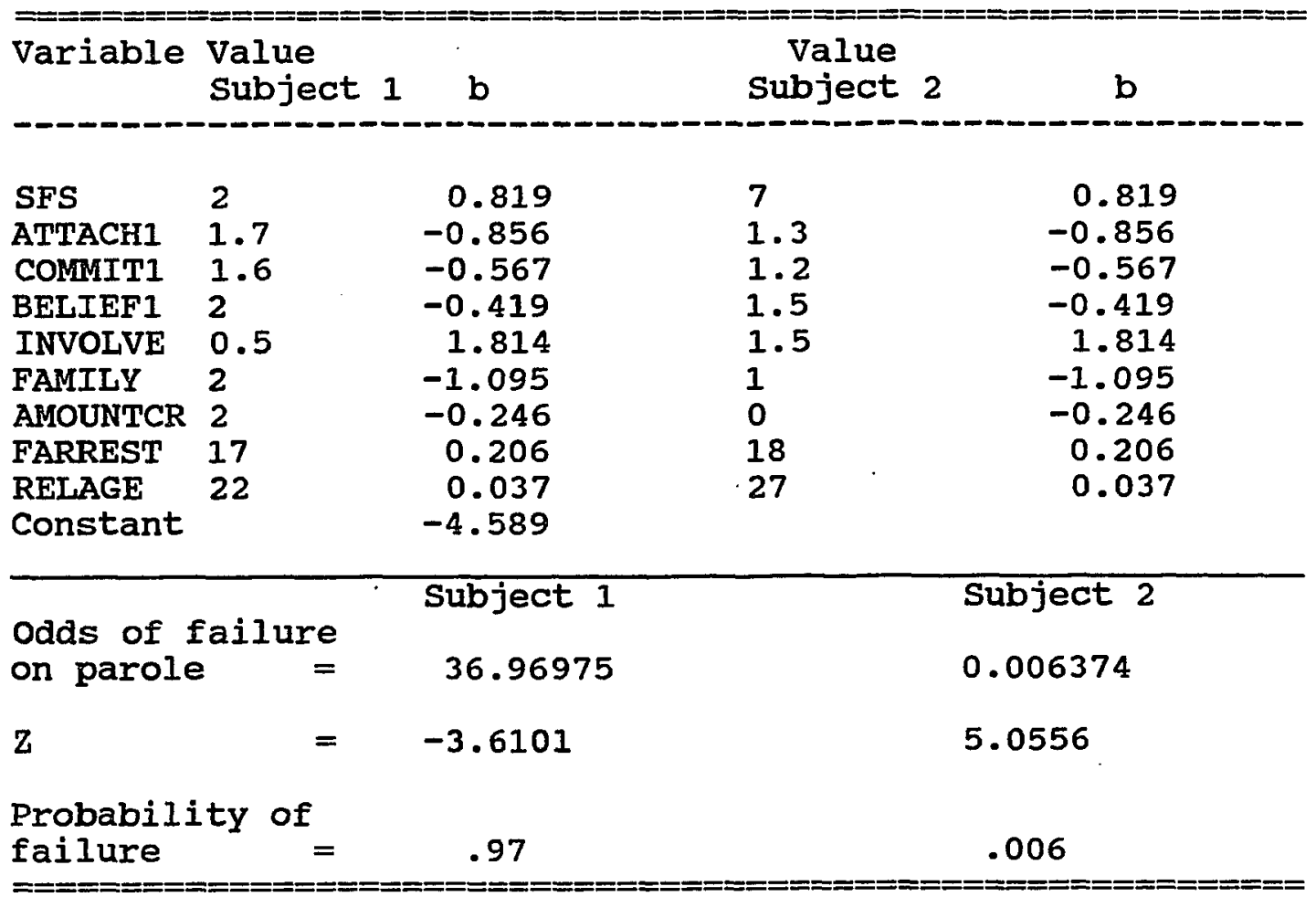

A scenario is intended to tell a story. The story told by the actual cases in Table 5.9 clearly indicates that the lower the SFS score, the more positive are the elements of the social bond; the less often the offender is associated with criminal activity, the older the offender is at the age of first arrest; and the older the offender is at the age of release, the less likely that offender is to fail while on parole. The successful prediction of these outcomes is 
accurate approximately 93 percent of the time. In this example the offender predicted to fail did in fact fail, while the offender predicted to succeed actually succeeded.

SUGGESTED MODEL PLUS INCARCERATED EXPERIENCE REGRESSED ON PAROLE OUTCOME

As noted previously, the sample used in this dissertation consists of offenders having experienced two different types of incarceration. This difference must of course be tested for its effect on the parole outcome (This will be referred. to as MODEL III). The addition of this variable also affords an opportunity to test a situation that might occur in actuality. There are different types of incarceration to which an offender might be sentenced, such as regular incarceration, a motivation program, a work camp, or a halfway house. Some the offenders in this sample were sentenced to a shock incarceration program rather to than regular incarceration.

The results of this model, in which the type of incarceration (GROUP) is added in, suggest an overall accuracy rate of $95.09 \%$ in predicting parole outcome. As indicated in Table 5.5, this model had a $97.05 \%$ accuracy rate in predicting successes, while the accuracy rate in predicting failure was $91.11 \%$ 
Table 5.10. $\begin{aligned} & \text { Suggested Model Plus Incarceration Type } \\ & \text { Prediction Accuracy }\end{aligned}$

\begin{tabular}{cccc} 
& Predicted & & \\
Failure & Success & \%correct \\
Falilure & 31 & 3 & $91.11 \%$ \\
Success & 2 & 66 & $97.05 \%$ \\
& & & Overall $95.09 \%$ \\
\hline
\end{tabular}

These findings indicate that 2 of the offenders predicted to fail actually succeeded, and that 3 of the offenders predicted to succeed actually failed. These results indicate that, from a public safety standpoint, only 3 parolees were released into the community who presented a danger to it. From an offender's view-point, had this model been strictly adhered to, only 2 offenders who succeeded on parole would not have been released. The results of this model are a vast improvement over the model that uses only the SFS as a predictor and a slight improvement over the model that did not account for the type of incarceration. The variation explained by this model is moderately high $\left(R^{2}=.78\right)$.

As in the previous model, there is a great deal of explanatory power. As opposed to the previous model, the explanatory power of the individual models, though for the most part not significant, has improved. Again, all of the beta values are in the expected direction (see Table 5.11). 
Table 5.11. Regression Product for Suggested Model plus Incarceration Type

\begin{tabular}{|c|c|c|c|}
\hline Variable & B & S.E. & Sig \\
\hline $\begin{array}{l}\text { SFS } \\
\text { ATTACH1 } \\
\text { COMMIT1 } \\
\text { BELIEF1 } \\
\text { INVOLVE } \\
\text { FAMILY } \\
\text { AMOUNTCR } \\
\text { FARREST } \\
\text { RELAGE } \\
\text { SAMPLE } \\
\text { ConStant }\end{array}$ & $\begin{array}{r}1.331 \\
-0.780 \\
-1.252 \\
-1.204 \\
3.116 \\
-2.192 \\
-0.487 \\
0.382 \\
-0.068 \\
3.379 \\
-12.548\end{array}$ & $\begin{array}{l}.9573 \\
.0238 \\
.3022 \\
.1619 \\
.2793 \\
.9812 \\
.6734 \\
.4386 \\
.2675 \\
.6611\end{array}$ & $\begin{array}{l}.1643 \\
.1025 \\
.3362 \\
.3000 \\
.1715 \\
.0254 \\
.4695 \\
.3829 \\
.2988 \\
.2042\end{array}$ \\
\hline
\end{tabular}

There are ten variables in this model; thus there will be ten scenarios. As in the previous model, in each scenario the value of the variable of interest will be changed in order to review the effect on predicted outcome. For the purposes of this model, the type of incarceration is labeled SAMPLE. The expected effect of SAMPLE is that those offenders having been sentenced to the shock incarceration program should do better on parole than those offenders sentenced to regular incarceration. ${ }^{1}$ The offenders in the shock incarceration have been coded 1, while those in regular incarceration have been coded 0 . The expected effect and coding of the other variables in the model can be found in Table 5.6.

\footnotetext{
. 1 For more information on the expected effects of the shock incarceration Mackenzie, et al. (1989) is recommended reading.
} 
As noted in the previous model, the scenarios are for illustrative purposes only. For each of the scenarios, the values of only one variable at a time have been changed, while the rest have been held constant (see Table 5.12).

Table 5.12. Scenarios

\begin{tabular}{|c|c|c|c|c|}
\hline Variable & Value & z & $\begin{array}{l}\text { Probability } \\
\text { of Failure }\end{array}$ & $\begin{array}{c}\text { Odds } \\
\text { of Failure }\end{array}$ \\
\hline SFS & $\begin{array}{l}1 \\
8\end{array}$ & $\begin{array}{r}-5.025 \\
4.291\end{array}$ & $\begin{array}{l}.99 \\
.01\end{array}$ & $\begin{array}{l}152.2 \\
0.013\end{array}$ \\
\hline ATTACH1 & $\begin{array}{l}1 \\
2\end{array}$ & $\begin{array}{l}-0.252 \\
-1.037\end{array}$ & $\begin{array}{l}.56 \\
.73\end{array}$ & $\begin{array}{l}1.28 \\
2.80\end{array}$ \\
\hline COMMIT1 & $\begin{array}{l}1 \\
2\end{array}$ & $\begin{array}{r}0.219 \\
-1.037\end{array}$ & $\begin{array}{l}.44 \\
.73\end{array}$ & $\begin{array}{l}0.80 \\
2.80\end{array}$ \\
\hline BELIEF 1 & $\begin{array}{l}1 \\
2\end{array}$ & $\begin{array}{r}0.171 \\
-1.032\end{array}$ & $\begin{array}{l}.45 \\
.73\end{array}$ & $\begin{array}{l}0.84 \\
2.80\end{array}$ \\
\hline INVOLVE & $\begin{array}{l}1 \\
1.5\end{array}$ & $\begin{array}{l}-2.590 \\
-1.032\end{array}$ & $\begin{array}{l}.93 \\
.73\end{array}$ & $\begin{array}{r}13.33 \\
2.80\end{array}$ \\
\hline FAMILY & $\begin{array}{l}0 \\
2\end{array}$ & $\begin{array}{r}3.351 \\
-1.032\end{array}$ & $\begin{array}{l}.03 \\
.73\end{array}$ & $\begin{array}{l}0.03 \\
2.80\end{array}$ \\
\hline AMOUNTCR & $\begin{array}{l}0 \\
3\end{array}$ & $\begin{array}{l}-0.545 \\
-2.006\end{array}$ & $\begin{array}{l}.63 \\
.88\end{array}$ & $\begin{array}{l}1.72 \\
7.44\end{array}$ \\
\hline FARREST & $\begin{array}{l}17 \\
21\end{array}$ & $\begin{array}{l}-2.178 \\
-0.650\end{array}$ & $\begin{array}{l}.89 \\
.65\end{array}$ & $\begin{array}{l}8.83 \\
1.91\end{array}$ \\
\hline RELAGE & $\begin{array}{l}24 \\
27\end{array}$ & $\begin{array}{l}-1.237 \\
-1.037\end{array}$ & $\begin{array}{l}.77 \\
.73\end{array}$ & $\begin{array}{l}3.44 \\
2.80\end{array}$ \\
\hline GROUP & $\begin{array}{l}1 \\
0\end{array}$ & $\begin{array}{l}-1.237 \\
-4.616\end{array}$ & $\begin{array}{l}.77 \\
.99\end{array}$ & $\begin{array}{r}3.44 \\
101.11\end{array}$ \\
\hline
\end{tabular}

As occurred in the previous model when the values in each scenario were changed, the expected effect took place; however, some of the changes may not be realistic. The 
scenarios displayed in Table 5.12 would tend, for the most part, to exemplify an offender with poor scoring on each of the variables. As in the previous model, it might be possible but not probable for an offender to score low on belief, commitment, and attachment, while scoring high on involvement. In order to attain a more realistic view of the score method, the two offenders from the sampie used in the previous model are used again here.

Table 5.13 Example of offenders from the Sample for Model III

\begin{tabular}{|c|c|c|c|c|}
\hline Variable & $\begin{array}{l}\text { Value } \\
\text { Subject }\end{array}$ & b & $\begin{array}{l}\text { Value } \\
\text { Subject } 2\end{array}$ & b \\
\hline $\begin{array}{l}\text { SFS } \\
\text { ATTACH1 } \\
\text { COMMIT1 } \\
\text { BELIEF1 } \\
\text { INVOLVE } \\
\text { FAMILY } \\
\text { AMOUNTCR } \\
\text { FARREST } \\
\text { RELAGE } \\
\text { GROUP } \\
\text { Constant }\end{array}$ & $\begin{array}{l}2 \\
1.7 \\
1.6 \\
2 \\
0.5 \\
2 \\
2 \\
17 \\
22 \\
0\end{array}$ & $\begin{array}{r}1.331 \\
-0.780 \\
-1.252 \\
-1.204 \\
3.116 \\
-2.192 \\
-0.487 \\
0.382 \\
0.068 \\
3.379 \\
-12.548\end{array}$ & $\begin{array}{l}7 \\
1.3 \\
1.2 \\
1.5 \\
1.5 \\
1 \\
0 \\
18 \\
27 \\
1\end{array}$ & $\begin{array}{r}1.331 \\
-0.780 \\
-1.252 \\
-1.204 \\
3.116 \\
-2.192 \\
-0.487 \\
0.382 \\
0.068 \\
3.379\end{array}$ \\
\hline $\begin{array}{l}\text { Odds of } \\
\text { on parol }\end{array}$ & Eailure & $\begin{array}{l}\text { Subject } 1 \\
91949.98\end{array}$ & & $\begin{array}{l}\text { Subject } 2 \\
0.000889\end{array}$ \\
\hline Z & $=$ & -11.429 & & 7.025 \\
\hline $\begin{array}{l}\text { Probabil } \\
\text { failure }\end{array}$ & & 1.00 & & .009 \\
\hline
\end{tabular}

The scenarios in Table 5.13 clearly indicate that the lower the SFS score, the more positive are the elements of the 
social bond; the less often the offender is associated with criminal activity, the older the offender is at the age of first arrest and the older the offender is at the age of release, the less likely that offender is to fail while on parole. This is the same as in the previous model; however; the effects of the independent variables on the dependent variable have a higher level of significance. The successful prediction of these outcomes is accurate approximately 95 percent of the time.

In order to review the effect which the group membership has on parole, four more scenarios will be described. The first scenario is the same as the one depicted in Table 5.13. In the other three scenarios, the value of the variable GROUP will be changed (see Table 5.14).

Table 5.14 Comparison of Results for Group Membership

\begin{tabular}{|c|c|c|c|c|}
\hline subject & Rating* & Value of Group & Prob. & $\begin{array}{l}\text { Odds of } \\
\text { Failure }\end{array}$ \\
\hline $\begin{array}{l}1 \\
2 \\
1 \\
2\end{array}$ & $\begin{array}{l}\text { poor } \\
\text { good } \\
\text { poor } \\
\text { good }\end{array}$ & $\begin{array}{l}0 \\
1 \\
1 \\
0\end{array}$ & $\begin{array}{l}100.0 \\
.009 \\
99.9 \\
.02\end{array}$ & $\begin{array}{l}91949 \\
.0008 \\
3133 \\
.027\end{array}$ \\
\hline
\end{tabular}

As indicated in Table 5.14, once the score for the offender is established, the group membership has little effect on outcome. Subject 1 was predicted to fail in both groups 1 and 2 , while subject 2 was predicted to succeed in both groups. This is not to suggest that group membership is 
not important; it is pointed out so as to not confuse the issue of whether or not addition of the variables suggested in this dissertation are important. Although a measure of the offender's type of incarceration does not add significantly to predictive power of the model, it is suggested that the variable remain in light of the fact that it appears to add stability to the model. This stability is noted in the lowering of the levels of signficance and the decrease in the values of the standard error for each variable. In the next section, the amount of variance explained by each model is compared to determine whether or not there has been a significant increase in the explanatory power of one model over the other.

\section{RESULTS OF THE TEST OF SIGNIFICANCE}

The analysis thus far indicates that the addition of the the variables suggested in this dissertation have resulted in a significant increase in predictive power. Although this is clear, one more test of significance -- an $F$ test using the $R^{2}$ of each model -- is suggested. The formula is repeated here:

$$
F=\frac{\left(R^{2}-R_{2}^{2}\right) /\left(K_{1}-K_{2}\right)}{\left(1-R_{1}^{2}\right) /\left(N-K_{1}-1\right)}
$$

where: 
Table 5.15 Explained Variance for Each Model.

\begin{tabular}{lccc}
$=====$ & Model I & Model II & Model III \\
\hline $\mathrm{R}_{2}$ & .29 & .786 & .789 \\
$\mathrm{~K}$ & 1 & 9 & 10 \\
$\mathrm{~N}$ & 102 & 102 & 102 \\
$\mathrm{~S}$ & & &
\end{tabular}

The results of the $F$ test indicate that there is a statistically significant difference between Models I and II as well as Models $I$ and III. There is not a significant. difference between Model II and III (see Table 5.16). As indicated by earlier tests of signifcance, the addition of the variable indicating the type of incarceration does not add a significant amount of information to the model suggested in this dissertation. Further indication of this lack of significance is found when GROUP is added to Model II. As the degrees of freedom in Model III are increased by the addition of the variable GROUP there is not a correspondently significant increase in the numerator. The addition of GROUP membership results in a lower $F$ value for Model III as compared to Model II which does not contain the variable GROUP.

Table 5.16 Results of Tests of Significance Between Models

\begin{tabular}{lll}
$==$ & $=====1$ \\
Models Tested & F Value & Prob \\
\hline Model I \&. II & 26.65 & p. $<.01$ \\
Model II \& III & 1.29 & N.S. \\
Model I \& III & 22.16 & p. $<.01$ \\
\hline
\end{tabular}


SURMARY

In each model, the expected effect was achieved. As mentioned previously, the beta coefficients were not always significant; however, each was in the predicted direction. Although the low levels of significance for the beta coefficients might be problematic in a linear regression model, they are of much less concern in the logistic regression model. The test of the logistic regression model lies in its ability to test the goodness of fit of the model.

The best method of summary for logistic regression is to compare the goodness of fit between the predicted and observed outcomes for the three models presented in this chapter. Logistic regression provides output for four tests of significance of the goodness of fit for the model tested. Two of these tests are used here to summarize the findings: model Chi-square and goodness of fit. Both methods test the current model against a perfect model given the variables used in the model. The greater the level of significance for the model chi-square the closer the fit. For the goodness of fit approach, as the level of significance approaches 1 , the greater the fit between the perfect fit and the model being tested.

The model in which only the SFS was used to predict outcome does not appear to have a close fit between the model tested and the predicted perfect fit (model chi-square = 6.192, df $=1, p=.073)$. The Chi-square value for the 
goodness of fit also indicates a poor fit between the model tested and the perfect fit (goodness of fit $=78.061$, df $=85$, $p=.4177)$. In the second model there does appear to be a close fit between the model tested and the perfect fit (model Chi-square $=45.12$, df $=9, p<.0001$ and the goodness of fit $=33.55, \mathrm{df}=48, \mathrm{p}=.9435)$. In the final model -- the one in which the type of incarceration was added to the model suggested in this dissertation -- there also appears to be a close fit between the model tested and the perfect fit (model Chi-square $=47.15$, af $=10, p<.0001$ and goodness of fit $=$ $34.19, \mathrm{df}=47, \mathrm{p}=.9182$ ).

In addition to the above indications of improvement in the power to predict outcome, the F tests indicate that there is a highly significant increase in the amount of variance explained by the new models as opposed to the old model.

In sum, it is clear that the two "new" models are superior to the model in current use. This superiority exists not only in the amount of variance explained but, more importantly, in the goodness of fit between the models tested and the perfect fit.

The next chapter contains a discussion on the connection between the theoretical points made in this dissertation and the results. Additionally, the ramifications that the findings might have on parole prediction and correctional policy are reviewed. 


\section{DISCUSSION AND CONCLUSION}

\section{OVERVIEW}

This chapter is composed of four major sections. In the first section, the role of prediction in criminology is reviewed along with its ethical considerations In the second, a connection is drawn between that statement of the problem, the theoretical solution suggested in this dissertation and the results of the data analysis. In the third some of the policy implications for parole prediction are discussed. The last section contains the conclusions followed by a summary.

\section{PREDICTION IN CRIMINOLOGY}

Criminologists have a long history of interest in prediction, presumably because the ability to accurately predict outcomes would be of immense practical use. The administration of the criminal justice system involves a large number of decisions, many of which might be improved if decision-makers were better informed about what the future is likely to hold. For example, police officers must decide 
whether or not to arrest a suspicious character, prosecutors must decide whether or not to bring a case to trial, and judges must decide whether or not to grant pre-trial release and what type of sentence to impose on convicted offenders. Correctional officials must decide on the security level and the activities of their charges, and parole boards must decide whether to release an inmate before the expiration of his or her sentence. Most criminal justice decision-makers base their decisions, at least in part, on their prediction of the likely future actions of the individual whose fate they are considering.

Most such predictions are made informally, on the basis of experience or "clinical" judgement. However, there has recently been increased interest in statistical or actuarial predictions. This is partly because statistical predictions may be justified on objective scientific grounds, and partly because of an accumulation of evidence that statistical predictions tend to be more accurate than clinical and other informal methods, and can provide a decision aid to criminal justice decision-makers (Monahan, 1981; Gottfredson \& Gottfredson, 1986).1

2 Gottfredson and Gottfredson (1986, p. 247) conclude that "in virtually every decision-making situation for which the issue has been studied, it has been found that statistically developed predictive devices outperform human judgments." 
The possibility of using formal methods of prediction in criminal justice decision-making raises the question of when and in what ways it is ethical to do so. This question has been much discussed in the criminological literature (Blumstein, et al, 1986; Farrington, 1987; Morris \& Miller, 1985; Tonry, 1987).

The most obvious set of ethical concerns has to do with the possible uses of prediction. For example, proponents of selective incapacitation, such as Greenwood (1982), clearly find it acceptable to treat certain individuals more harshly than they would otherwise be treated on the basis of a prediction of their likely future behavior. Not everyone agrees with this position. Morris and Miller (1985) believe that an increase in penalties because of a prediction of likely future criminality is acceptable only if the punishment is not increased beyond that which would be justified as "deserved", independently of such a prediction. Others, such as Gottfredson and Gottfredson (1986), would support the use of prediction to select individuals for less severe punishment ("selective deinstitutionalization"), but they would not support any use of prediction to select individuals for more severe punishment.

It is obvious that opinions differ on the extent to which it is ethically proper for predictive considerations to influence either the choice of criminal justice sanctions or the continuation of those sanctions. The weight one considers 
acceptable for prediction-based classification rules should be dependent on the gravity of the harm one is trying to prevent through the use of a classification system. An additional consideration is the accuracy of the classification system in assessing risk. Commonly invoked criteria for assessing whether a potential predictor is ethically acceptable include its relationship to the blameworthiness of the offender, and the empirical and logical relationship of the predictor to the behavior being predicted. The literature suggests that variables such as prior adult criminal history, behavior, attitude, employment status and family relations meet the criteria for inclusion in a predictive model. Characteristics such as race, ethnicity, and religion are especially unacceptable as predictors because they "lack a relationship to blameworthiness, they have no logical relationship to offending pattern and their use affronts basic social values" (Blumstein, et al, 1986).

Assuming that the acceptable uses of prediction in criminal justice had already been decided, we would still be left with the issue of deciding what information should be used in making these predictions. This of course is the major issue which has been discussed thus far in this dissertation. In the usual settings in criminal justice, the available information generally consists of extensive data on the attributes, experiences, and activities of the offenders. The use of such information for prediction generally involves two 
steps. First, a set of individual data is used, to estimate a model. Second, the model is used together with information on an individual, to predict the individual's future behavior. These steps have been followed, thus the remaining tasks involve the development of the relative importance of findings and their connection with the theoretical concepts which have been used to suggest the present form of quantification.

THE THEORETICAL, CONNECTION

The review of the literature indicates several problems with the current criteria used to assist in the parole decision process. The problems with the current model of parole prediction outcome are that: 1) it is not accurate in its predictive ability; 2) it explains very little of the variance in the parole outcome: 3 ) it makes use of subjective information that can be objectively quantified; and 4) it fails in its mission to protect the public while at the same time providing equality to offenders. The question asked in this dissertation is whether or not an improvement in the prediction models is available. The partial solution to this question, as has been proposed in this dissertation, is to turn to criminological theory for an answer.

This dissertation proposes that elements of the social bond, measures of differential association along with information concerning important points in the offenders life 
cycle, can provide objectively that information which is many times used subjectively in the parole decision process. The question answered in the results section of this dissertation is the amount of improvement which can be expected from the addition of the variables proposed in this dissertation.

The first problem -- the SFS is not accurate in its predictive ability -- is that, as currently used the SFS can only achieve an accuracy rate of approximately 73 percent as indicated by the results in this dissertation. The review of the literature suggests that the accuracy rate in predicting outcome for other offender populations may be as low as 20 percent (Champion, 1990; Bureau of Justice Statistics, 1989; Gottfredson \& wilkens, 1978). The range of accuracy, twenty to eighty percent, is also consistent with the literature (Champion, 1990; Gottfredson \& Tonry, 1987). The accuracy with which either of the models suggested in this dissertation predicts parole outcome is over 92 percent. This increase is not only statistically significant, it has substantive value in addressing the issue of public safety versus offender rights, which will be discussed later.

The second problem involves the effectiveness of the SFS as a lone predictive tool. The amount of variance explained in parole outcome by the SFS, while significant at the .10 level, has low explanatory power $\left(R^{2}=.29\right)$. The amount of variance explained by either of the models suggested here is .78 , which is highly significant. As reported in the results 
section, the tncrease in the amount of variance-is significant. The univariate analysis (Table 5.3) indicates that all of the variables except SAMPLE $(p=.674)$ and AMOUNTCR $(p=.275)$ are significant at the $p$-value $=.25$. Mickey and Greenland (1989) suggest that, in model building, each of the variables which met this criteria should be included in the multivariate model. The significance level of the elements of the social bond, association and the ages at first arrest and at release to parole suggest that they be included in the multivariate model. The increase in the explanatory power of the new models over the old indicate that criminological variables add a significant amount of explanatory power to a parole prediction model.

The third problem, which involves the need for quantification of the subjective criteria used by parole boards, is one of the most important. First there is little evidence that any objective criteria have been consistently used in predicting parole outcome (Greenfield, 1987). The subjectiveness of parole decisions to date has led many scholars, parole board members, study panels and correctional researchers to agree that release decisions which are based on predicted outcome are at times arbitrary, capricious, inconsistent and prejudiced (Champion, 1990; Greenfield, 1987; Carter, Glaser, and Wilkins, 1984; Carlson, 1979; Gottfredson \& Wilkens, 1978; American Bar Association, 1968). The variables which have been objectified. in this dissertation 
have been repeatedly documented as being subjectively used by parole board members for predicting parole outcome. As already noted, subjective measurement has been unreliable and the validity of personal observation may not be valid. The improvement in the predictive models in the goodness of fit suggests that the new models are an improvement in reliability and validity over the process currently used. In order to test this to its fullest extent more research in needed.

The fourth problem with the current model of parole outcome is that it fails in one of its stated missions, which is public protection. The SFS predicted that, of the 102 offenders in this sample, 89 would succeed on parole. Of the 89 who were predicted to succeed, 20 (22.4\%) actually failed. This is a strong indication that a large number of offenders are being released while still presenting a significant danger to the public. The addition the variables suggested in this dissertation improves the accuracy of the prediction considerably. Using the new model, only 4 offenders (5.8\%) reported as possible successes actually failed. From a public safety point of view this has strong policy implications. The third model, the one in which the type of incarceration was included, had only a slightly improved predictive ability over model two. In the third model, only 3 offenders $(4.3 \%)$ actually posed a false positive problem.

The solution to each of these problems has been the addition of variables which have a grounding in criminological 
theory. While these variables have not been used in parole prediction, each has been repeatedly used in predicting criminal activity. The major concern of a parole board, when deciding whether to release an offender or deny parole is the perceived risk of danger that offender presents to the public. The danger to the public is the risk of reinitiation of criminal activity by the released parolee, thus the parole board is making their decision to release an offender based upon their perception of the probability of future criminal activity.

As noted, the parole boards generally use an instrument such as the SFS along with subjective (sometimes individual) evaluation. The measures of the subjective evaluation used by parole boards have been previously noted and each of the variables suggested for inclusion in the model used in this dissertation have been used by parole boards in a subjective manner. Thus in addition to having a foundation in the criminological literature, the variables suggested here have been used in a subjective manner by parole boards (Monahan, 1981; Gottfredson \& Gottfredson, 1986). 
Social control

As individual predictors of parole outcome, each of the elements of the social bond have been included in the model, using the .25 level of significance suggested by Hasti and Tibshirani (1986, 1987), Bendel and Afifi (1977) and Mickey and Greenland (1989). Using the univariate approach the element of the social bond having the greatest level of significance is involvement $(b=1.164, p=.038)$. Attachment $(\mathrm{b}=-.375, \mathrm{p}=.115)$, and belief $(\mathrm{b}=-.372, \mathrm{p}=.129)$ are both within the suggested guidelines for inclusion into the additive model. Commitment has the weakest predictive ability at the univariate level of analysis $(b=-.268, p=.220)$; however, it should also be included in the additive model. When these variables are added to the rest of the model the predictive value of each of the variables is of course changed but their relative order of significance remains the same (see Table 5.6). More importantly, the effect of each variable is in the expected direction.

Hirschi (1969) suggests that the relative strength of each of the elements of the social bond is affected by the strength of each of the other elements. This would suggest that to eliminate any of the elements simply because of a low level of significance would not be appropriate. In light of both the moderate levels of significance and Hirschi's suggestion of an interrelationship of the elements, it is felt that, in 
this case, all of the variables measuring the social bond should be left in the model.

\section{Differential Association}

Two measures of association with unconventional (criminal) others were used in this research to predict parole outcome. The first measured the total number of criminal acts committed by the offender and the second measured the amount of criminality within the offenders immediate family. As noted in Chapter III, Matsueda (1982) and Voss (1969) previously used the number of prior arrests as a measure of association with unconvention activity. Their findings indicated that prior criminal activity was a good indicator of future criminal activity. MacDonald (1989), Matsueda (1982) and Short (1957) found that as the associate of an individual with unconventional others increased the likelihood of the unconventional activity of the individual was also likely to increase. These findings are supported in this dissertation.

The univariate analysis indicates that the amount of criminality in the immediate family has a highly significant effect on the parole outcome $(b=-1.549, p=.0001)$. These results could have at least two possible explanations. The first possibility is that the effect of the family's criminality has a direct influence on the future criminality 
of the offender, in that the past association of the offender with significant non-conventional individuals has had an effect on future criminality. The second possible explanation is that when the offender is released on parole he goes back into a situation in which family members are criminal. In this case the peer or family influences may not be supportive of conventional activity, thus present association may lead to future criminal activity. In either case, the association of the offender with significant individuals who are criminals appears to be significant in predicting outcome. When this measure of association is inserted into the multivariate model it maintains a high level of predictive significance ( $b=-$ $.1 .095, p=.008)$. It is important to note that association of this type has been found to be a significant predictor of future criminality when used in conjunction with the elements of the social bond (MacDonald, 1989; Marcos, et al, 1986), and Hirschi (1969) indicates that association should have had a greater importance in his work.

The second measure of association uses the amount of prior criminality to predict parole outcome. As a measure of association this variable is similar to differential reinforcement. The univariate analysis revealed that the amount of prior criminality barely met the p-value of .25 bench $(b=-.584, p=.2456)$. When this variable was inserted into the multivariate model it lost even more explanatory power. While the effect of prior criminality does not have 
the predictive power suggested by the literature, the fault may lie with either the small sample size or the lack of variance of this variable. Another problem may involve the type of measure. The sum total of criminality used here involves both violent and nonviolent crimes. A particular type of crime may be useful in predicting future types of crime; however, this would to a certain extent violate the assumptions of the generality of deviance.

Overall, both measures of association had the expected direction of effect. The family's criminality had a significant effect, while the prior criminal record had a lesser effect in predicting future criminality. Thus, the ability of these measures to predict future criminality is concurrent with the ability to predict parole outcome.

Age

There are two age points in the life cycle of the offender which appear to have importance in predicting future criminality, and thus parole outcome. The first is the age of first criminal activity, as represented by the age of the first arrest. The second is the age of the offender at the time of release. Blumstein (1987) and Blumstein, Cohen and Visher (1986) have reported that the earlier in the life cycle that the first criminal activity occurs the more likely the 
offender is to continue committing crimes. These findings have been repeated in this research. The age of first criminal contact is highly significant in the univariate analysis $(b=.254, p=.018)$. The significance of age at first arrest is reduced considerably when added to the multivariate model $(b=.206, p=.546)$. This, however, appears to be a coliniarity problem rather than a theoretical problem. It should be remembered that many of the members of this sample are first time offenders. The age of the first offense and the age of current offense (part of the SFS) are highly correlated. The effect of the age of current offense appears to be washing out the effect of age of first arrest.

The offender's age at the time of release is significant in both the univariate $(\mathrm{b}=-.148, \mathrm{p}=.019)$ and multivariate analysis $(b=-.037, P=.020)$. As the age of the offender at the time of release goes up, the likelihood of failure while on parole goes down. These findings are similar to the findings of Blumstein (1987), Blumstein, Cohen and Farrington (1988) and Farrington (1986), which indicate that the best predictor of future criminal activity is the age of the offender at release. As an offender ages the likelihood of future criminal activity decreases, thus the older the parole candidate the better he is as a parole risk. Of those variables in the multivariate models, age at release is second only to family criminality in its level of significance. This 
has very serious policy implications which will be discussed latter.

SFS

As a sole measure of parole outcome, the SFS leaves much of the variation in parole outcome unexplained. The results of the univariate analysis indicate that SFS is significant as an explanatory variable $(b=.346, p=.0096)$; however, when SFS is included in the multivariate analysis much of its explanatory power is lost $(\mathrm{b}=.819, \mathrm{p}=2192)$. As explained earlier, much of this is due to a coliniarity problem, rather than to the value of the SFS as a predictive variable. The effect of the SFS is in the predicted direction and its explanatory power using this data set is within the limits experienced in other research (Champion, 1990; Gottfredson, 1979; Gottfredson \& Wilkins, 1978).

\section{Type of Incarceration}

At the univariate level the effect of the incarcerative experience on the parole outcome is not significant. This supports the findings of Mackenzie, et al, which indicate that the IMPACT parolees recidivate at about the same rate as those offenders in regular incarceration. (In press). The significance level of the type of incarceration is increased 
when it is put into the multivariate analysis $(b=3.37, p=$ $.204)$. The addition of the type of incarceration also appears to increase the levels of significance of the other variables in the model. It appears that GROUP is a suppressor variable, that is, it has close to a zero correlation with the outcome but is correlated with one or more of the other predictor variables. The inclusion of GROUP in the analysis increases the partial correlation because it serves to suppress, or control for, irrelevant variance, which is, the variance that is shared with the other predictors rather with the outcome. This rids the analysis of irrelevant variation. While this variable has not been significant in its predictive ability as used in this model it should be re-evaluated in future models if there are different types of programs.

\section{Theoretical Implications}

Previous research indicates that the variables which have been added to the SFS in this research have had significant value in the prediction of prior criminality. Hirschi (1969), MacDonald (1989) and Marcos, et al. (1986) have found that each of the elements of the social bond have relevance in predicting the incident of future deviance, criminal activity and/or drug use. Each of the elements has been found to have been interrelated with each other. The strongest of the elements in each case has been attachment. The results of this research suggests that the social control theory has 
significant value in the prediction of parole outcome. In this research involvement in conventional activities appears to have the strong effect of the four elements on parole outcome $(B=1.814, p=.05)$. While this differs from Hirschi's findings the explanation could be found in the age of the individuals. Hirschi's study involved juveniles still living with there respective parents, while this study involved adult offenders. It would seem likely that the adult offenders would be more likely to be effected by marital status and employment than by attachment to parents. Attachment in this case does not have the strongest effect; however, it is still significant ( $\mathrm{B}=-0.856, \mathrm{p}=.09)$. The measures of commitment and belief, while not statistically significant did add to the model.

Differential association theory has had a long and significant history in explaining and predicting future criminal activity (Sutherland, 1947; Short, 1960; Voss, 1966; Sutherland \& Cresses, 1978; Vold \& Bernard, 1986; Marcos, et al. 1986; MacDonald, 1989). The findings in this research suggest that variables measuring association can add to the predictive powers of a parole outcome model. The measure of the amount of family involvement in criminal activities used in this research was a significant predictor of parole outcome ( $B=-2.192, p=.02)$. The other measure association which has been used sparingly in the past was not a good indicator in this case and should be replaced with a different and more 
effective measure of association. Overall the effects of association as an indicator of parole outcome was good and continued to live up to its reputation as a measure of future criminal activity.

The use of the criminal career's approach as a predictor of future criminal activity is unique as a predictor. It's uniqueness lies in the fact that it makes no attempt at explaining the cause of crime, only the duration and end of the period of criminality based on the age at the inception of the criminal and the offender's current age. The age of the offender at release has a significant effect on parole outcome $(B=-0.037, p=.02)$. Thus, the older an offender is at the time of release the less likely he is to have the conditions of his parole revoked. The impact of this is the same here as it is in predicting future criminal activity.

Overall, each of the variables mentioned above have had a relatively good history in prediction future criminal activity. This same success appears to be applicable to the prediction of parole outcome. This would suggest that the use of criminological theory as grounding for policy have some positive implications.

Policy Implications

In theory development we are attempting to do three things: explain, predict and control. If we can explain and 
predict, then we can control. The only issue left involves the ethics of our approach, which has, for the purpose of this dissertation, been discussed previously. The "control" objective in parole prediction concerns a balance between the objective of public safety through incarceration (which is one of the goals of the justice model in criminal justice) and other concerns. of most interest in a parole prediction concept is the effects that the justice model has had on overcrowding in prisons, the necessity of providing for public safety, and fulfillment of the offender's rights and needs: Blumstein (1986) indicates that incapacitation of offenders works, but at an extreme cost.

\begin{abstract}
"Under 1970 incarceration policies, incapacitation was estimated to have reduced the number of FBI index crimes by 10 to 20 percent. For robberies and burglaries, incapacitation is estimated to have reduced their number by 25-35 percent in 19.73; in 1982, after the national inmate population had almost doubled, the incapacitative effect for these offenses is estimated to have increased to about 35-45 percent. For general increases in incarceration to reduce index crimes by an additional 10 to 20 percent from 1982 level, inmate population again would have to have more than doubled" (Blumstein et al, 1986, p 6).
\end{abstract}

Blumstein goes on to note that the extent of general incarceration needed to achieve the estimated reduction in crime is not acceptable. His proposal involves selective incapacitation of inmates, which includes the continued incarceration of inmates classified as high risk. Blumstein estimates that selective incapacitation policies involving 
increases in the total inmate population of as little as 10 to 20 percent can achieve results similar to the general incarceration rates. Selective incapacitation policies can offer an attractive tradeoff between crime reduction and inmate population increases. The major ethical issue surrounding these policies involves the development of a predictive model of dangerousness (parole outcome).

From this point of view, one of the possible policy implications coming from this research is the development of a model which may be used to selectively incapacitate incarcerated offenders until they become low risk offenders or have served their sentences: Although this serves the public's need for security from criminal activity it does not meet the needs of those offenders presenting a low risk. Prediction models such as the one presented here also entail policy implications for low risk offenders. Low risk offenders present little danger to the public, thus once they are identified in an incarcerated population their release should be as speedy as possible. Two purposes could be served by their early release. The first is the avoidance of the negative effects of an extended prison term on the offender. The second is the reduction of prison overcrowding, through the release of low risk offenders.

Resources are wasted when an offender is evaluated as being ready for release is not released. Additionally, research suggests that low risk offenders held in prison too 
iong suffer many negative effects of prison. Thus from a policy standpoint an instrument that identifies low risk offenders serves several purposes. The first is to reduce prison overcrowding, the second is the release of the offender prior to the negative effects of imprisonment, and the third is to provide an objective forum for release decision making.

\section{Future Research}

While the model developed and tested in this dissertation shows great improvement over the existing prediction instrument, further research and testing is clearly indicated. It should be remembered that this is secondary data analysis and that some of the problems inherent to secondary data analysis were present. Further refinement of the measures of the elements of the social bond are suggested. While the current measures are adequate for development purposes, others might be more closely associated with those used by Hirschi. This is not to suggest that those measures used here are inadequate, it is simply suggested that primary research may be necessary in order to test specific questions.

The measures of differential association used in this research are very similar to the types of measures used in other research. MacDonald (1989), Matsueda (1982) and Short (1957) found that as the associate of an individual with unconventional increased the likelihood of the unconventional 
activity of the individual was also likely to increase. Matsueda (1982) and Voss (1969) used the number of prior arrests as a measure of association with unconventional activity. Their findings indicated that prior criminal activity was a good indicator of future criminal activity. As noted previously, these findings are supported in this dissertation. On the whole the performance of the indicators was satisfactory and in the expected direction. Some refinement and expansion may, however, be in order. Future research should attempt to determine whether or not certain types of prior criminal activity are better predictors of future criminal behavior. Additionally work should be done to determine if specific crimes committed in the past can adequately predict specific types of criminal activity in the future. This could aid parole officers and parole boards in the identification of specific needs of individual offenders. The most serious problem with age appears to be a coliniarity problem between the age measure used in the SFS, which is the age for the current offense, and the age at which the first arrest occurred. This is a problem in this data set because the members were are primarily first offenders. This indicates the next and more serious need for further research. While this model suggested by the research measures with a high rate of accuracy the parole outcome for these offenders, the question of generalizability still needs to be answered. More research needs to be done on larger samples, on general 
parole eligible populations, and on special parole eligible populations of incarcerated offenders. The use of this model on a larger population of offenders would test the generalizability of the results by adding variability of offender types. Identification and testing of special parole eligible offenders, such as violent or repeat offenders, is needed in order to test the reliability of the model on higher risk offenders.

Another area of future research should include the testing of the model on different race or ethnic groups. Many of the tests and prediction models thus far developed tend to have a slight racial bias. Blacks are generally predicted to fail more often while on parole than are whites. While this is not an issue in this dissertation, early and independent research on this sample indicates that the model does not appear to be racially biased. More research concerning the effect of race is, however, needed. For ethical reasons race should not be a part of the predictive model. Race if often nothing more than an indicator of other deeper problems each of which must be tested independently. This does not, however, mean that an offenders race in not important. Future research should be done to insure the unbiased use of predictive instruments such as the one suggested here. 
Summary

The goal of this research has been the development of a model of parole prediction which could overcome the problems of subjectivity, inaccuracy, in validity and unfairness in the currently used prediction instruments, such as the SFS. The results of this research indicate that all of the propositions mentioned in chapter III were found to be in the expected direction. Although some of the measures were not as statistically significant within the models as might be desired, each was found to cumulatively add to the predictive power of the model to such an extent that a fifty percent increase in explanatory power was realized.

The elements of the social bond and differential association have proven in the past to be important predictors of future criminal activity. As indicators of parole outcome the addition of the variables grounded in criminological theory (elements of the social bond and differential association) met the task of being able to add significant predictive value to the existing model of parole outcome prediction.

The criminal careers approach uses participation, start of criminal career, duration and cessation of participation to predicted the extent of the career. The major components of the criminal careers approach, such as age of first offense and current age, have been used as predictors of continued 
criminal activity. These same variables add significant predictive powers to the parole outcome model siggested here.

Continued research is clearly needed in the development of predictive models in criminology; however, the use of criminological theory in order to solve concrete policy problems does have promise.

There is a false perception among academicians that policymakers and practitioners largely ignore research findings (Petersilia, 1991). Petersilia, also, reports that policymakers tend to see academicians as people with their heads in the clouds. The assumption taken in this dissertation is that theoretical criminology may have more to offer policy makers than is typically recognized by either group. The correct path appears to be the one suggested by Quinney and wildeman (1991) in which the recognition of concrete problems rather than the development of a single theoretical perspective is preferred. The approach used in this dissertation has been to develop the problem and then use the appropriate criminological theories and perspectives to solve the problem. Thus the goal has been to use the additive powers of the various approaches rather than to find the single most powerful (explanatory) theoretical approach.

The findings in this dissertation suggest that criminologically grounded variables previously used to predict criminality can be successfully used to predict the continuation of an already existing criminal career. These 
same variables can also be used to predict the end of the criminal career or disengagement. Additionally these measures are more accurate than either the previously used subjective measures or the objective instrument in current use. 


\section{Bibliography}

Akers, R. L. (1984). "Delinquent Behavior, Drugs and Alcohol: What is the Relationship?" Todays's Delinquent, 3:19-47.

Allen, H. E., Eskridge, C. W., Latessa, E. J. and Vito, G. F. (1985). Probation and Parole in America. New York: The Free Press.

Allinson, R. (1982) "Crisis in the Jails", Corrections Magazine, 8:18.

American Bar Association (1969). Post-conviction Remedies. Washington, D.C.:ABA.

Archambeault, W. G. and Archambeault, B. J. (1982). Correctional supervisory Management: Principles of organization, Policy, and Law, Englewood Cliffs: PrenticeHall.

Babst, D. V., Inciardi, J. A., and Jaman, D. R. (1970). The Uses of Configural Analysis in Parole Prediction Research. New York: Narcotics Control Commission.

Bankston, W. B., C. J. Forsyth, and H. H. Floyd 1981, "Toward a General Model of Radical Conversion." Qualitative Sociology $4: 279-97$.

Barnett, A., A. Blumstein and D. P. Farrington (1989) . "A Prospective Test of a Criminal Career Model". Criminology, 27:373-388.

Beccaria, C. (1819). An Essay on Crimes and Punishment. Philadlphia: $\mathrm{Nicklin}$ as reported in Corrections in America 5th ed. H. Allen \& C. Simonsen (1989) New York:Macmillan.

Bendel, R. B. and Afifi, A. A. (1977). "Comparison of Stopping Rules in Forward Regression". Journal of the American Statistical Association, 72, 46-53.

Bentham, J. (1779). as reported in Corrections in America 5th ed. H. Allen \& C. Simonsen (1989) New York:Macmillan.

Blumer, H., (1969). Symbolic Interactionism, Englewood Cliffs, N.J.: Prentice-Hall.

Blumstein, A. and J. Cohen (1987). "Characterizing Criminal Careers." Science, 70:561-585. 
Blumstein, A., J. Cohen, J. A. Roth, and C. A. Visher (1986). Criminal Careers and "Career Criminals." Vol. 1. Washington, D. C.: National Academy Press.

Blumstein, A., J. Cohen, and D. P. Farrington (1988a). "Criminal Career Research: Its Value for Criminology." Criminology, 26:1-26.

(1989b). "Longitudinal and Criminal Career Research: Further Clarification." Criminology, 26:57-74.

Bromley, E. and Gathercole, C. E. (1969). "Boolean Prediction Analysis: A New Method of Prediction Index Construction," British Jounal of Criminology, 17:287-92.

Brotman, R., Silverman, I., and Suffet, F. (1970). "Some Social Correlates of Student Drug Use". Crime and Delinquency, 16:(1), 67-74.

Bottomlely, A. K. (1984). "Dilemmas of Parole in a Penal Crisis", The Howard Journal of Criminal Justice, 23:2440 .

Burkett, S. R. (1977). "Religion, Parental Influence, and Adolescent Alcohol and Marijuana Use." Journal of Drug Issues, $7: 263-73$.

Burkett, D. R., \& Jensen, E. L. (1975). "Conventional Ties, Peer Influence, and the Fear of Apprehension: A Study of Adolescent Marijuana Use". The Sociological Quarterly, 16. 522-533.

Burgess, E. W. (1928). "factors Determining Success or Failure on Parole." In The Workings of the Indeterminate Sentence Law and the Parole System in Illinois, Eds. B. Harmo, E. W. Burgess, and C. L. Landeson. Springfield: Illinios State Board of Parole.

Carrol, L. (1976). "Racial Bias in the Decision to Grant Parole," Law and Society Review, 11:93-107.

Carter, R., Glaser, D. and Wilkins, I. (1984). Probation, Parole, and Community Corrections. New York: John Wiley.

Carlson, R. (1979) . Comtmeporary United States Parole Board Practices. San Jose: San Jose State University Foundation.

Champion, D. J. (1990). Probation and Parole in the United States. Columbus: Merrill Publishing Co. 
Clear, T. R. \& Cole, G. F. (1990). American Corrections 2nd, Brook/Cole Publishing: Pacific Grove, CA.

Conrad, J. P. (1981). "Where There's Hope, There,s Life". In Justice as Fairness: Perspective on the Justice Model (eds.) D. Fogel and J. Hudson. Cincinnati: Anderson.

Cullen, F. T., Clark, G. A., \& Wozniak, J. K. (1985). "Explaining the Get Tough Movement: Can the Public Be Blamed?" Federal Probation, 49(2), 16-24.

Cullen, F. T. \& Gilbert, K. E. (1982). Reaffirming Rehabilitation. Cincinnati: Anderson.

D'Artri, D. A., Fitzgerald, E. F., Kasl, S. V., \& Ostfeld, A. M. (1981). "Crowding in Prison: The Relationship Between Changes in Housing Mode and Blood Pressure. Pyschosomatic Medicine, 43(2): 95-105.

Donovan, J. E. \& R. Jessor (1985). "Structure of Problem Behavior in Adolescence and Young Adulthood." Journal of consulting and clinical Psychology, 53:890-904.

Eisenber, M. (1985a). Release Outcome Series: Halfway House Research, Austin, TX: Board of Pardons and Paroles.

Eisenber, M. (1985a). Factors Associated with Recidivism, Austin, TX: Board of Pardons and Paroles.

Eisenber, M. (1985a). Selective Early Release: Research-Based Criteria, Austin, TX: Board of Pardons and Paroles.

Farnworth, M. , and Horan, P. M. (1980). "Separate Justice: An Analysis of Race Differences in Court Processes". social Science Research, 9:381-399.

Farrington, D. (1986). "Age and Crime." Pp. 189-50 in Crime and Justice: An Annual Review of Research, edited by $M$. Tonry and N. Morris. Chicago. University of Chicago Press.

Farrington, D. and R. Tarling, (1985). prediction in Criminology. Albany, Ny: State University Press of New York.

Fogel, D. (1975). We Are the Living Proof. Cincinnati: Anderson Pub.

Gibbons, D. C. (1986). "Breaking out of prisons". Crime and Delinquency, 32(4), 503-514. 
Gibson, B. (1978). "Race as a Determinate of Criminal Sentences: A Methodological Critique and A Case Study". Law and Society Review, 12:455-477.

Glaser, D. (1983). "Supervising Offenders Outside of Prison," in Crime and Pulic Policy, ed. J. Q. Wilson. San Francisco: ICS Press.

Glaser, D. (1962). "Prediction Tables As Accounting Devices for Judges and Parole Boards," Crime and Delinquency, $\underline{8}: 239-58$.

Greenfeld, I. (1987). Probation and Parole. Washington, D.C.: Department of Justice.

Grooms, R. M. (1982). "Recidivist" Crime \& Delinquency, 14:3. Goffman, Irving. 1961. Asylums.

Goodstein, L. and Hepburn, J. (1985). Determinate Sentencing and Imprisonment: A Failure of Reform. Cincinnati: Anderson Pub.

Gottfredson, D. M. \& Wilkins, L. T. (1978). Classification for Parole Decision Policy, Washington, D. C.: Law Enforcement Assistance Administration, U.S. Department of Justice.

Cottfredson, D. M., Wilkins, I. T., Hoffman, P. B. \& Singer, S. M. (1974). The Utilixation of Experience in Parole Desicsion-Making: Summary Report. Washington, D. C.: U.S. Goverment Printing office.

Gottfredson, D. M., Babst, D. V. and Ballard, K. B. (1958). "Comparison of Multiple Regression and Configural Analysis Techniques for Developing Base Expectancy Tables, " Journal of Research in Crime and Delinquency, 5:72-80.

Gottfredson, M. \& Hirsch, T. (1986). "The True Value of Lambda Would Appear to Be Zero: An Essay on Career Criminals, Criminal Careers, Selective Incapacitation, Cohort Studies, and Related Topics." Criminology 24: 21334 .

Gottfredson, M. R. (1979). "Parole Guidelines and the Reduction of Sentencing Disparity: A Prliminary Study," Journal of Research in Crime and Delinguency, 16:218-31.

Gottfredson, M. R. (1979). "Parole Board Decision Making," The Journal of Criminal Law and Criminology, 70(1). 
Gusfield, J. (1967). "Moral Passage" Social Problems, 15:175188 .

Hanushek, E. A., \& Jackson, J. E. (1977). Statistical Methods for Social Scientists. New York: Academic.

Hardt, R. \& Hardt, s. (1977) "On Determining the Quality of the Delinquency Self-Report Method," Journal of Research in Crime and Delinquency, 14:247-261.

Harris, M. K. (1984). "Rethinking Probation in the Context of the Justice Model". In Probation and Justice, (eds.).P. McAnany, D. Thomson, and D. Fogel. Cambridge: Oelgeschlager, Gunn \& Hain.

Hastie, T. and Tibshirani, R. (1986). "Generalized Additive Models". Statistical Science, 3, 297-318.

Hastie, T. and Tibshirani, R. (1987). "Generalized Additive Models: Some Applications". Journal of the American Statistical Association, 32, 371-386.

Hindelang, M. J. (1973). "Causes of Delinquency: A Partial Replication and Extention". Social Probelms, 20:(4), 471487.

Hirschi, T. (1984). "A Frief Commentary on Akers" "Delinquent Behavior, Drugs, and Alcohol: What is the Relationship?" . Today's Delinguent, 3:49-52.

Hirschi, T. \& Gottfredson, M. (1983). "Age and the Explanation of Crime." American Journal of Sociology 89: 55-84.

Hirschi, T. and Stark, R. (1969) • "Hellfire and Delinquency." Social Problems, 17:202-13.

Hoffman, P. B. (1983). "Screening for Risk: A Revised Salient Factor Score (SFS/81)," Journal of Criminal Justice, 11: 539-47.

Hosmer, D. W. and Lemeshow, S. (1989). Applied Logistic Regression. New York: John Wiley.

Humphries, D. (1984). "Reconsidering The Justice Model", Contempory Crisis, 8:167-173.

Jacks, I. and Cox, S. G. (1984). Psychological Approaches to Crime and Its Correction: Theory, Research, Practice. Chicago: Nelson-Hall. 
Jessor, R. and S. Jessor (1977). Problem Behavior and Psychosocial Development: A Lonitudinal study of Youth. New York: Acadmic Press.

Jensen, G. F. (1972). "Parents, Peers and Delinquent Action: A Test of the Differential Association Perspective". American Journal of Sociology, 78: (3), 562-575.

Kandel, D. B., Treiman, D., Faust, R., \& Single, E. (1977). "Adolescent Involvement in Legal and Illegal Drug Use: A Multiple Classification Analysis". Social Forces, 55 (2), 438-458.

Kassebaum, G., Ward, D. and wilmer, D. (1971) Prison Treatment and Parole Survival: An Empirical Assessment.

Kelly, H. E. (1976). "Comparison of Defense Strategy adn Race as Influences in Differential Sentencing". Criminology. 14: 241-249.

Kercher, K. (1987). "Explaining the Relationship Between Age and Crime: The Biological vs. Sociological Model." Presented at the annual meeting of the American Society of Criminology, Montreal.

Killinger, G. C. and Cromwell, P. F. (1973) - Penology, st. Paul: West Publishing.

Lane, M. (1986). "A Case for Early Release." Crime and Delinguency, 32(4), 399-403.

Lofland, John. 1966. Doomsday Cult. Prentice-Hall: Englewood Cliffs, NJ Pp. 31-66.

Lombroso, c. (1911). Crime, Its causes and Remedies. Iittle, Brown.

MacDonald, P. T., (1989). "Competing Theoretical Explanations of Cocaine Use: Differential Association Versus Control Theory" , Journal of Contemporary Criminal Justice, $5:(5)$, 73-88.

MacKenzie, D. L. (1989) "The Parole Performance of Offenders Released From Shock Incarceration (Boot Camp Prisons): A Survival Time Analysis" Presented at the 14th Meeting of the American Probation and Parole Association, Milwaukee, Wisconsin.

Mackenzie, D. L., Gould, L.A., Riechers, L. M., and Shaw, J. W., (In Press). "Shock Incarceration: Rehabilitation or Retribution?" Journal of offender counseling, Services \& Rehabilitation. 
Marcos, A. C., Bahr, S. J., \& Johnson, R. J. (1986). "Testing of a Bonding/Association Theory of Adolescent Drug Use", Social Forces 65:1.

Markley, G. \& Eisenberg, M. (1987). Follow-up Study of Texas Parole Case Management Project. Austin: Texas Board of Pardons and Paroles.

Martinson, R. (1976). "What Work? Questions and Answers about Prison Reform." The Public Interest, 35:22-54.

Mickey, J. and Greenland, S. (1989). "A Study of the Ipact of Confounder-Selection Criteria on Effect Estimation". American Journal of Epidemiology, 129, 125-137. As Reported in Applied Logistic Regression, D. W. Hosmer and S. Lemeshow.

Morris, N. (1974). The Future of Imprisonment. Chicago: University of Chicago Press.

O'Leary, V. and Clear, T. R. (1984). Directions for Community Corrections int he 1990's. Washington, DC: National Institute of Corrections.

Petersilia, J. (1991). "Policy Relevance and the Future of Criminology: The American Society of Criminology, 1990 Presidential Address" Criminology, 29:1.

Petersilia, J., Turner, S., Kahan, J., \& Peterson, J. (1985) Granting Felons Probation: Public Risks and Alternatives Santa Monica, Rand Corportation.

Petersilia, J. (1985). "Probation and Felony offenders". Federal Probation, 49(2), 4-9.

Reiss, A. J. (1951). "Delinquency as the Failure of Personal and Social Controls," American Sociological Review, 16:196-207.

Rothman, D. J. (1983). "Sentencing Reforms in Historical Perspective". Crime and Delinquency, 29:631-647.

Rotter, J. B. (1954). Social Learning and clinical Psychology. Englewood cliffs, NJ.: Prentice-Hall.

Rowe, D. C., D. W. Osgood, and W. A. Nicewander (1990). "A Latent Trait Approach to Unifying Criminal Careers." Criminology, 28:237-270.

Quetelet, A. (1831). Research on the Propensity to crime of Different Ages. Brussels: Hayez. 
Quinney, R. \& Wildeman, J. (1991). The Problem of Crime, 3rd. Mayfield Publishing: Mountain View, CA.

Sacks, H. R. \& Logan, C. H. (1984). "Does Parole Make a (Lasting) Difference?" in Criminal Justice: Law and Politics. ed. George Cole, 4th ed. Pacific Grove, CA: Brooks/Cole.

Scott, J. E. (1974). "The Use of Discretion in Determining the Severity of Punishment for Incarcerated offenders," Journal of Criminal Law and Criminology, 65:214-224.

Scott, J. E. (1972). "An Examination of the Factors Utilized by Parole Boards in Determining the Severity of Punishment," Ph.D. dissertation, Indiana University.

Shichor, D. (1985). "Male-Female differences in Elderly Arrests: An Exploratory Analysis". Justice Quarterly. 2, 399-414.

Short, Jr. J. F. (1960). "Differential Association as a Hypothesis: Problems of Empirical Testing". Social Problems, $\underline{8}$ : $14-25$.

Short, Jr., J. F. (1957). "Differential Association as a Hypothesis: Problems of Empirical Testing". Social Problems, $\underline{8}: 14-25$.

Shover, N. (1985). Aging Criminals. Beverly Hills:Sage.

Steffensmeier, D. J., Allan, E. A., Harer, M. D. \& Streifel, C. (1989). "Age and the Distribution of Crime". American Journal of Sociology 94(4), 803-831.

Sutherland, E. H., \& Cressey, D. R. (1978) . Criminology, 10th ed. Philadelphia, PA. J. P. Lippincott.

Sutherland, E. H. (1947). Pinciples of Criminology, 4th ed. Philadelphia: Lippincott.

Sykes, G. M. and Matza, D. (1957). "Techniques of Neutralizaiton: A Theory of Delinquency," American Sociological Review, 23, 664-670.

Tec, N. (1972). "The Peer Group and Marijuana Use". Crime and Delinquency, 18(3), 298-309.

Tittle, C. R., and Welch, M. R. (1983). "Religiosity and Deviance: Toward a contingency Theory of Constraining Effects." Social Forces, 61:653-82. 
Toberg, If. A. (1984). Pretrial Release Assessment of Danger and Flight: Methods Makes a Difference. McLean, VA: Lazar Management Group.

Vold, G. B. \& Bernard, T. J., (1986). Theoretical Criminology, 3rd. New York: Oxford Universtiy Press.

Von Hirsch, A. (1984). "The Ethics of Selective Incapacitation: observations on the Contemporary Debate." Crime and Delinquency, 30: 175-194.

Voss, H. (1964). "Differential Association and Containment Theory: A Theoretical Convergence". Social Forces, $14:(2), 128-147$.

Wallace, Samuel E. 1968. "The Road To Skid Row." Social Problems 16:96-102

Wiatrowski, M. D., Griswold, D. B., \& Roberts, M. K. (1981). "Social Control Theory and Delinquency", American Sociological Review, 46:525-541.

Wilkins, L. E. and MacNaughton-Smith, P. "New Prediction and Classification Methods in Criminology," The Journal of Research in Crime and Delinquency, 1:19-31.

Wilkins, I. T., Kress, J. T., Gottfredson, D. M., Calpin, J. C., and Gelman, A. M. (1976) Sentencing Guidelines and structuring Judical Discretion, New York: Criminal Justice Research Center.

Wilson, J. Q. \& Herrnstein, R. (1985). Crime and Human Nature. New York: Simon and Schuster.

Wolfgang, M. , Figlio, R, \& Sellin, T. (1972). Delinquency in a Birth Cohort. Chicago: University of Chicago Press. 
APPENDIX A

146

Reproduced with permission of the copyright owner. Further reproduction prohibited without permission. 
Table 1. Salient Factor Score (SFS/81)

A. PRIOR CONVICTIONS/ADJUDICATIONS (ADULT OR JUVENILE)

None . . . . . $=3$

One . . . . . $=2$

Two or three . . = 1

Four or more. $=0$

B. PRIOR COMMITMENTS OF MORE THAN 30 DAYS (ADULT OR JUVENILE)

None ...... $=2$

One or two ... $=1$

Three or more. $:=0$

C. AGE AT CURRENT OFFENSE/PRIOR COMMITMENTS

Score

Age at commencment of the current offense:

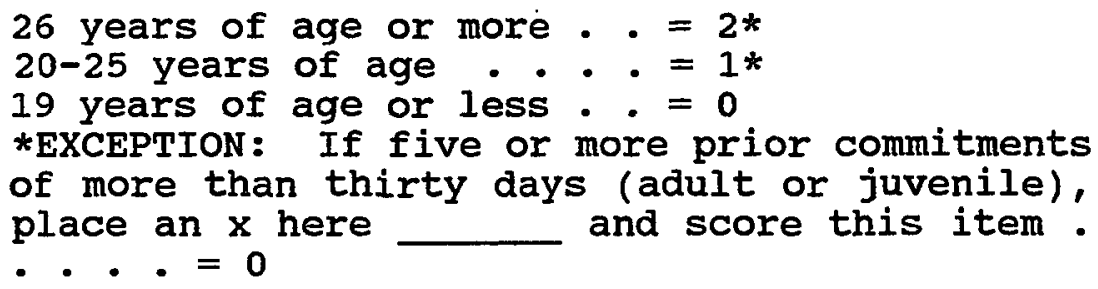

D. RECENT COMMITMENT-FREE PERIOD (THREE YEARS)

Score

No prior commitment of more than thirty days (adult or juvenile), or released to the community from last such commitment at least three years prior to the commencement of the current offense . . . . . . . ......$=1$

Otherwise

$=0$

Score

E. PROBATION/PAROLE/CONFINEMENT/ESCAPE STATUS VIOLATOR THIS TIME

Neither on probation, parole, confinement, or escape status at the time of the current offense; nor committed as a probation, parole, confinement or escape status violator this time. . . . . . . . ..... $=1$

otherwise

0

F. HEROIN/OPIATE DEPENDENCE

Score

No history of herion or opiate dependence . $\cdot=1$

Otherwise .................. . = 0

TOTAL SCORE

Score 
Table 2. Expecteả Kelationships

Salient Factor score

Variable

No. of Prior Convictions

No. of Prior Commitments

Age at Current offense

Recent Free Period

Status at current offense

Heroin/Opiate Dpendence

Expected Relationship

As the number of prior convictions increases the likelihood of success on parole is expected to decrease.

As the number of Prior commitments of 30 days or more to a correctional facility increase the likelihood of success on parole is expected to decrease.

The older the offender was when the current offense was committed the less likely the offender is to fail while on parole.

The longer the time between the release from custody for the previous offense before the current offense was committed the greater the chance of success on parole.

If the offender is not on probation, parole, confinement, or escape status at the time of the current offense the greater the likelihood of success on parole.

If the offender is not drug involved the greater the likelihood of success on parole. 
Table 2. (Continued)

Criminological

Variables

Expected Relationship

Attachment

As indication of

attachment increase the

likelihood of success on

parole is expected to

increase.

Commitment

As commitment increase the likelihood of success on parole is expected to increase.

Involvement

As involvement increase the likelihood of success on parole is expected to increase.

Belief

As belief in the system increases the success of an individual on parole is expected to increase.

Association

The greater the number of friends and family with criminal activity the less likely the offender is to succeed on parole.

Age of First Arrest

As the age of first arrest decreases the likelihood of success on parole decreases.

Age at Release

As the age of release from incarceration increases the likelihood of success on parole is expected to increase. 


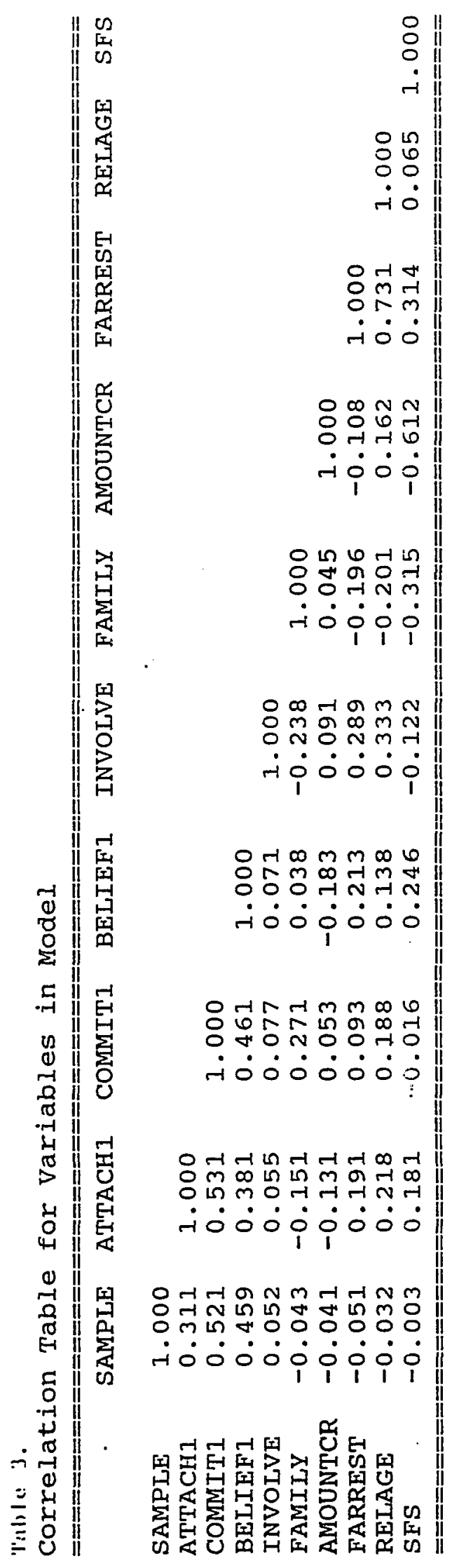


APPENDIX B

151

Reproduced with permission of the copyright owner. Further reproduction prohibited without permission. 
Factor Table 1 .

ATTACHMENT

If the item was did not receive at least 7 out of 10 votes from the judges it was dropped and the label is used in the Loading column. The remaining scores in the loading column are the result of the factor analysis. Those items being retained in order to measure attachment are marked with an '*'. The remaining items, those without an '*' either did not load very high or were loading on extraneous scales.

\begin{tabular}{|c|c|c|}
\hline Variable & Loading & Question \\
\hline JI6. & Dropped & I am smarter than most people I know. \\
\hline JII. & .4056 & $\begin{array}{l}\text { When you're in trouble, it's best to keep } \\
\text { quiet about it. }\end{array}$ \\
\hline JI3. & Dropped & I get into a lot of fights. \\
\hline JI15. & Dropped & $\begin{array}{l}\text { A person is better off if he doesn't } \\
\text { trust people. }\end{array}$ \\
\hline JI16. & Dropped & $\begin{array}{l}\text { Sometimes I wish I could get away and } \\
\text { forget about everything. }\end{array}$ \\
\hline JI17. & $.5023 *$ & $\begin{array}{l}\text { Sometimes I feel like I don't really have } \\
\text { a home. }\end{array}$ \\
\hline JI18. & Dropped & $\begin{array}{l}\text { People always seem to favor certain } \\
\text { persons ahead of others. }\end{array}$ \\
\hline JI22 . & Dropped & $\begin{array}{l}\text { A person like me fights first and asks } \\
\text { questions later. }\end{array}$ \\
\hline JI25. & Dropped & $\begin{array}{l}\text { I get nervous when I ask someone to do me } \\
\text { a favor. }\end{array}$ \\
\hline JI26. & Dropped & $\begin{array}{l}\text { If I could, I'd just as soon quit school } \\
\text { or my job right now. }\end{array}$ \\
\hline JI28. & Dropped & $\begin{array}{l}\text { I notice my heart beats fast when people } \\
\text { keep asking me questions. }\end{array}$ \\
\hline JI33. & $.5692 *$ & $\begin{array}{l}\text { A lot of fathers don't seem to care if } \\
\text { they hurt your feelings. }\end{array}$ \\
\hline
\end{tabular}


Factor Table 1. (Continued)

\begin{tabular}{|c|c|c|}
\hline JI46. & $.5523 *$ & $\begin{array}{l}\text { My father was too busy to worry much } \\
\text { about me, or to spend much time with me. }\end{array}$ \\
\hline JI55. & Dropped & I don't care if people like me or not. \\
\hline JI61. & Dropped & $\begin{array}{l}\text { You can hardly ever believe what parents } \\
\text { tell you. }\end{array}$ \\
\hline JI83. & Dropped & $\begin{array}{l}\text { Teachers always have favorites who can } \\
\text { get away with everything. }\end{array}$ \\
\hline JI85. & .4250 & $\begin{array}{l}\text { I would usually prefer to be alone than } \\
\text { with others. }\end{array}$ \\
\hline JI97. & .4103 & $\begin{array}{l}\text { Talking over your troubles with another } \\
\text { person is usually a waste of time. }\end{array}$ \\
\hline JI103. & .4495 & $\begin{array}{l}\text { Parents are always nagging and picking on } \\
\text { young people. }\end{array}$ \\
\hline JI107. & $.5785 *$ & $\begin{array}{l}\text { At home I am too often blamed for things } \\
\text { I don't do. }\end{array}$ \\
\hline JI125. & $.6237 *$ & $\begin{array}{l}\text { When you're in trouble, nobody much cares } \\
\text { to help you. }\end{array}$ \\
\hline JI137. & $.6141 *$ & $\begin{array}{l}\text { I feel alone even when there are other } \\
\text { people around me. }\end{array}$ \\
\hline JI5. & Dropped & $\begin{array}{l}\text { I always like to hang around with the } \\
\text { same bunch of friends. }\end{array}$ \\
\hline JI21. & Dropped & $\begin{array}{l}\text { I worry about what other people think of } \\
\text { me. }\end{array}$ \\
\hline JI24. & Dropped & $\begin{array}{l}\text { It' hard to have fun unless you're with } \\
\text { your friends. }\end{array}$ \\
\hline JI31. & Dropped & It is easy for me to talk with strangers. \\
\hline JI39. & Dropped & Most people are really very nice. \\
\hline JI51. & $.4722 *$ & $\begin{array}{l}\text { If someone is your family gets into } \\
\text { trouble, it's better for you to stick } \\
\text { together than to tell the police. }\end{array}$ \\
\hline JI66. & .4616 & $\begin{array}{l}\text { It's hard for me to show people how I } \\
\text { feel about them. }\end{array}$ \\
\hline
\end{tabular}




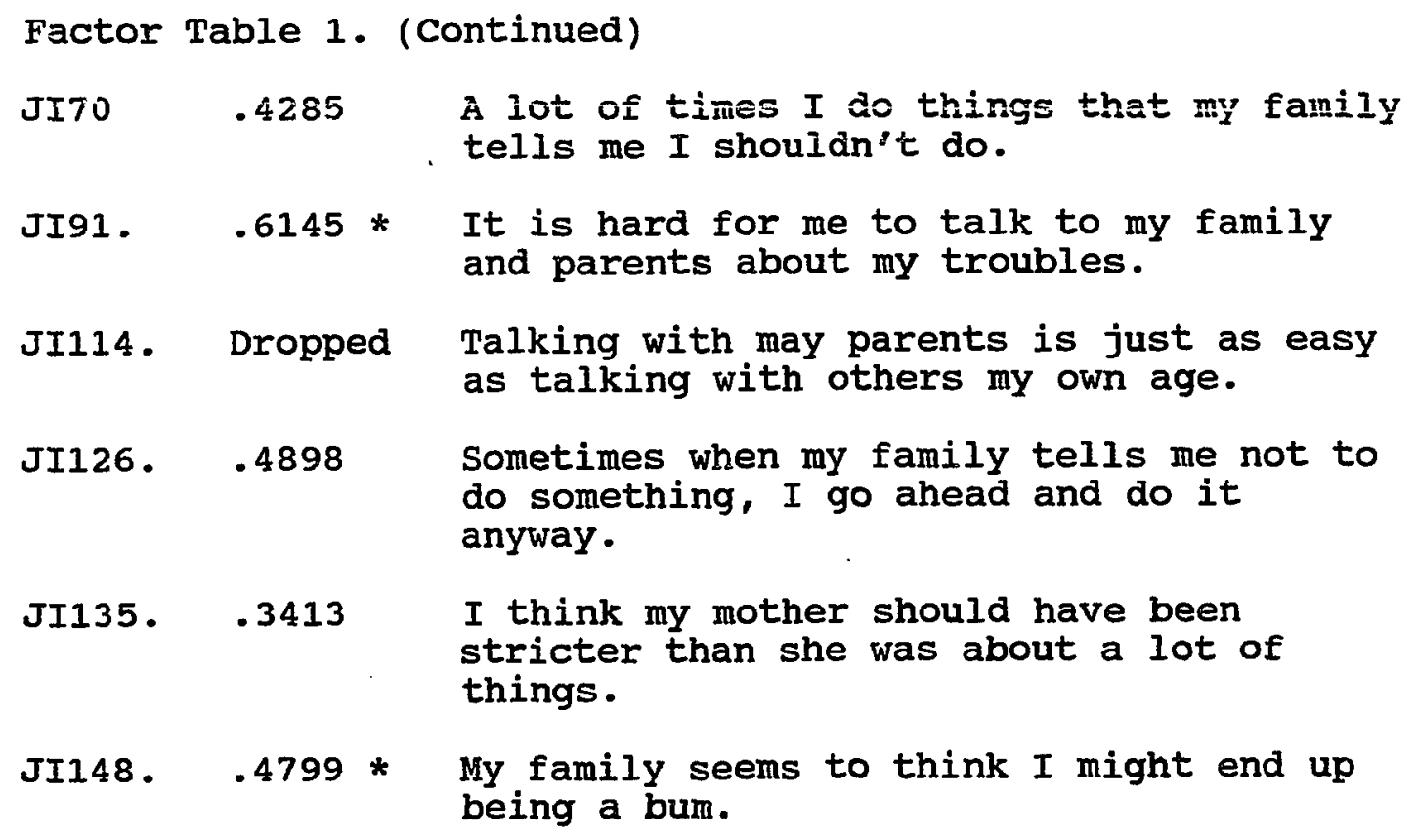


Factor Table 2 .

COMMITMENT

If the item was did not receive at least 7 out of 10 votes from the judges it was dropped and the label is used in the Loading column. The remaining scores in the loading column are the result of the factor analysis. Those items being retained in order to measure commitment are marked with an '*'. The remaining items, those without an '*', either did not load very high or were loading on extraneous scales.

\section{Variable coding Question}

JI26 .5171 * If I could, I'd just as soon quit school or my job right now.

JI12 Dropped Most people will cheat a little in order to make some money.

JI27 .4710* Sometimes it feels good to put one over on somebody.

JI43 .4069 I get a kick out of getting some people angry.

JI63 .2467 I don't think I will ever be a success or amount to much.

JI65 $.5177 *$ Most of the time I can't seem to find anything to do.

JI69 .4698* Nothing much ever happens.

JI71 .5261* It's fun to give the police a bad time.

JI90 Dropped Policemen and judges tell you one thing and do another.

JI101 .4259 I will do a lot of crazy things if somebody dares me.

JI118 .5447 * I don't mind lying if I'm in trouble.

JI152 .4752 Sometimes it seems like I'd rather get into trouble instead of trying to stay away from it.

II4 Dropped I worry too much about doing the right thing. 
Factor Table 2. (Continued)

JI21 Dropped I worry about what other people think of me.

JI45 Dropped It would be interesting to work in a carnival.

JI49 Dropped It makes me feel bad to be bawled out or criticized.

JI77 .5352 * If I only had more money, things at home would be all right.

JI84 .4610* Every day is full of things that keep me interested.

JI104 Dropped Some day I would like to drive a race car.

JI105 .4011 I sit and daydream more than I should.

JI136 Dropped I like to read and stuay.

JI141 Dropped Whatever I do, I tend to worry about how well I'm doing.

JI148 Dropped My family seems to think I might end up being a bum.

JI150 .3553 I feel better when I know exactly what will happen form one day to the next.

JI155 Dropped When I get into trouble, it's usually my own fault. 
Factor Table 3 .

BELIEF

If the item was did not receive at least 7 out of 10 votes from the judges it was dropped and the label is used in the Loading column. The remaining scores in the loading column are the result of the factor analysis. Those items being retained in order to measure belief are marked with an '*'. The remaining items, those without an '*', either did not load very high or were loading on extraneous scales.

Variable coding Question

JI12 Dropped Most people will cheat a little in order to make some money.

JI14 .6610* If the police don't like you, they will try to get you for anything.

JI20 .5122 * Most police are pretty dumb.

JI32 .6726 * Police stick their noses into a lot of things that are none of their business.

JI44 .5601 * Nowadays they make it a big crime to get into a little mischief.

JI51 .5843* If someone in your family gets into trouble, it's better for you to stick together than to tell the police.

JI54 .6581* Most people in authority are bossy and overbearing.

JI58 Dropped I think that boys fourteen years old are old enough to smoke.

JI59 Dropped Most parents seem to be too strict.

JI61 Dropped You can hardly ever believe what parents tell you.

JI64 .7262 * Police usually treat you dirty.

JI70 Dropped A lot of times I do things that my family tells me I shouln't do.

JI71 Dropped It's fun to give the police a bad time.

JI83 Dropped Teachers always have favorites who can get away with everything. 


\begin{tabular}{|c|c|c|}
\hline JI90 & $.64079 *$ & $\begin{array}{l}\text { Policemen and judges tell you one thing } \\
\text { and do another. }\end{array}$ \\
\hline JI103 & Dropped & $\begin{array}{l}\text { Parents are always nagging and picking on } \\
\text { young people. }\end{array}$ \\
\hline JI116 & Dropped & $\begin{array}{l}\text { If you want to get ahead, you can't worry } \\
\text { too much about the other guy. }\end{array}$ \\
\hline JI118 & $.5390 *$ & I don't mind lying if $I^{\prime} m$ in trouble. \\
\hline JI130 & .4186 & $\begin{array}{l}\text { The people who run things are usually } \\
\text { against me. }\end{array}$ \\
\hline JI132 & .4249 & $\begin{array}{l}\text { Most people who act so perfect are just } \\
\text { putting on a big front. }\end{array}$ \\
\hline JI147 & Dropped & $\begin{array}{l}\text { Stealing isn't so bad if it's from a rich } \\
\text { person. }\end{array}$ \\
\hline JI149 & Dropped & Things don't seem real to me. \\
\hline JI4 & Dropped & $\begin{array}{l}\text { I worry too much about doing the right } \\
\text { thing. }\end{array}$ \\
\hline JI7 & Dropped & $\begin{array}{l}\text { It makes me mad that some crooks get off } \\
\text { free. }\end{array}$ \\
\hline JI9 & .4818 & Most police will try to help you. \\
\hline JI53 & Dropped & $\begin{array}{l}\text { It often seems like something bad happens } \\
\text { when } I " m \text { trying to do what it right. }\end{array}$ \\
\hline JI62 & Dropped & I have a real mean streak in me. \\
\hline JI94 & Dropped & $\begin{array}{l}\text { Too many people like to act big and } \\
\text { tough. }\end{array}$ \\
\hline JI100 & $.4517 *$ & $\begin{array}{l}\text { I have a lot of bad things on my mind } \\
\text { that people don't know about. }\end{array}$ \\
\hline I124 & Dropped & My mind is full of bad thoughts. \\
\hline JI129 & Dropped & $\begin{array}{l}\text { When something bad happens, I almost } \\
\text { always blame myself instead of the other } \\
\text { person. }\end{array}$ \\
\hline
\end{tabular}


Factor Table 3. (Continued)

JI135 Dropped I think my mother should have been stricter than she was about a lot of things.

JI141 Dropped Whatever I do, I tend to worry about how well I, m doing.

JI155 Dropped When I get into trouble, it's usually my own fault. 
Factor Table 4.

The items that lead to this factor analysis are result of the judging process. In order develop a set of items that measured each of these concepts, independent of extraneous concepts, those items that have a low loading in Factor 1 or load high in more than one factor are marked by '*' and dropped for the next factoring.

\begin{tabular}{|c|c|c|c|c|c|}
\hline & & & Attachme & & \\
\hline & Factor & 1 & Factor 2 & Factor 3 & Factor 4 \\
\hline JI11 & .40561 & * & .46583 & -.14133 & .00736 \\
\hline JI17 & .50233 & & -.14010 & -.25574 & -.04007 \\
\hline JI33 & .56927 & & -.38829 & -.07556 & -.10241 \\
\hline$J I 46$ & .55233 & & -.25336 & -.42589 & -.03897 \\
\hline JI85 & .42582 & $*$ & -.30401 & .15606 & .50283 \\
\hline JI97 & .41038 & * & .03380 & .54404 & -08775 \\
\hline JI103 & .44952 & * & -.01021 & .24471 & -.50161 \\
\hline JI107 & .57855 & & -.07453 & -.08003 & -.33336 \\
\hline JI125 & .62374 & & -.29281 & .24127 & .18009 \\
\hline JI137 & .61417 & & .04253 & .08479 & .12053 \\
\hline JI51 & .47227 & & .04402 & .35502 & .15238 \\
\hline JI66 & .46167 & * & .11040 & .41794 & .00333 \\
\hline JI70 & .42850 & $*$ & .47574 & -.23180 & .41670 \\
\hline JI91 & .61455 & & .14931 & -.10564 & -.13849 \\
\hline JI126 & .48936 & * & .62509 & -.08158 & .08829 \\
\hline JI135 & .34613 & * & -.37134 & -.30063 & .30305 \\
\hline
\end{tabular}


Commitment

\begin{tabular}{|c|c|c|c|c|c|}
\hline & Factor & 1 & Factor 2 & Factor 3 & Factor 4 \\
\hline JI26 & .51718 & & .17402 & .01224 & .08583 \\
\hline JI27 & .47102 & & .08041 & -.23284 & .20383 \\
\hline JI43 & .40691 & $*$ & .28290 & -.15914 & .43827 \\
\hline JI63 & .24678 & * & .18944 & .56328 & -.49366 \\
\hline JI65 & .51774 & & -.39543 & -.07617 & .18846 \\
\hline JI69 & .46984 & & -.22496 & .19917 & .33228 \\
\hline JI71 & .52613 & & .30841 & .35752 & .11663 \\
\hline JI101 & .42596 & $\star$ & .48246 & -.26961 & -.25930 \\
\hline JI118 & .54476 & & -.12865 & .22015 & .28789 \\
\hline JI152 & .47526 & & .52833 & -.18251 & -.18105 \\
\hline JI77 & .53521 & & -.17060 & .33035 & -.20146 \\
\hline JI84 & .46102 & & .41869 & .19822 & .25860 \\
\hline JI105 & .40114 & $\star$ & -.23078 & -.51104 & -.33136 \\
\hline JI150 & .35539 & * & -.37345 & .08147 & -.24150 \\
\hline
\end{tabular}


Factor Table 4. (Continued)

$\begin{array}{lccc} & & \text { Belief } & \\ & \text { Factor } 1 & \text { Factor } 2 & \text { Factor } 3 \\ \text { JI14 } & .66105 & .03430 & .31937 \\ \text { JI20 } & .51226 & -.45351 & .17757 \\ \text { JI32 } & .67364 & -.31334 & -.23529 \\ \text { JI44 } & .56010 & .44014 & .11812 \\ \text { JI51 } & .58436 & -.01987 & .07580 \\ \text { JI54 } & .65813 & .23045 & .09850 \\ \text { JI64 } & .72629 & -.36611 & .07238 \\ \text { JI90 } & .64079 & .14195 & -.02873 \\ \text { JI118 } & .53698 & .03434 & .42959 \\ \text { JI130 } & .41869 * & .06655 & -.68811 \\ \text { JI132 } & .42493 * & .46596 & -.10845 \\ \text { JI9 } & -.48189 & .38820 & .29522 \\ \text { JI100 } & .45170 & .33610 & -.23740\end{array}$


Factor Table 5 .

\section{Attachment}

$\begin{array}{ll}\text { Item } & \text { Loadi } \\ \text { JI17 } & .6133 \\ \text { JI33 } & .6587 \\ \text { JI46 } & .6590 \\ \text { JI107 } & .5980 \\ \text { JI125 } & .6376 \\ \text { JI137 } & .5876 \\ \text { JI151 } & .3447 \\ \text { JI91 } & .5926\end{array}$

Eigenvalue $=2.824 \quad$ Percent of Variance $=35.3$

Commitment

$\begin{array}{lll}\text { Item } & \text { Loading } & \text { Loading } \\ \text { JI26 } & .5349 & .3235 \\ \text { JI27 } & .4747 & .2570 \\ \text { JI65 } & .5801 & -.5557 \\ \text { JI69 } & .5562 & -.3981 \\ \text { JI71 } & .5315 & .4305 \\ \text { JI118 } & .6231 & .1650 \\ \text { JI77 } & .5772 & .2052 \\ \text { JI84 } & -.4794 & .4202\end{array}$

Factor 1 Eigenvalue $=2.391$ Percent of Variance $=29.9$

Factor 2 Eigenvalue $=1.069$ Percent of Variance $=13.4$

* Dropped in next factoring

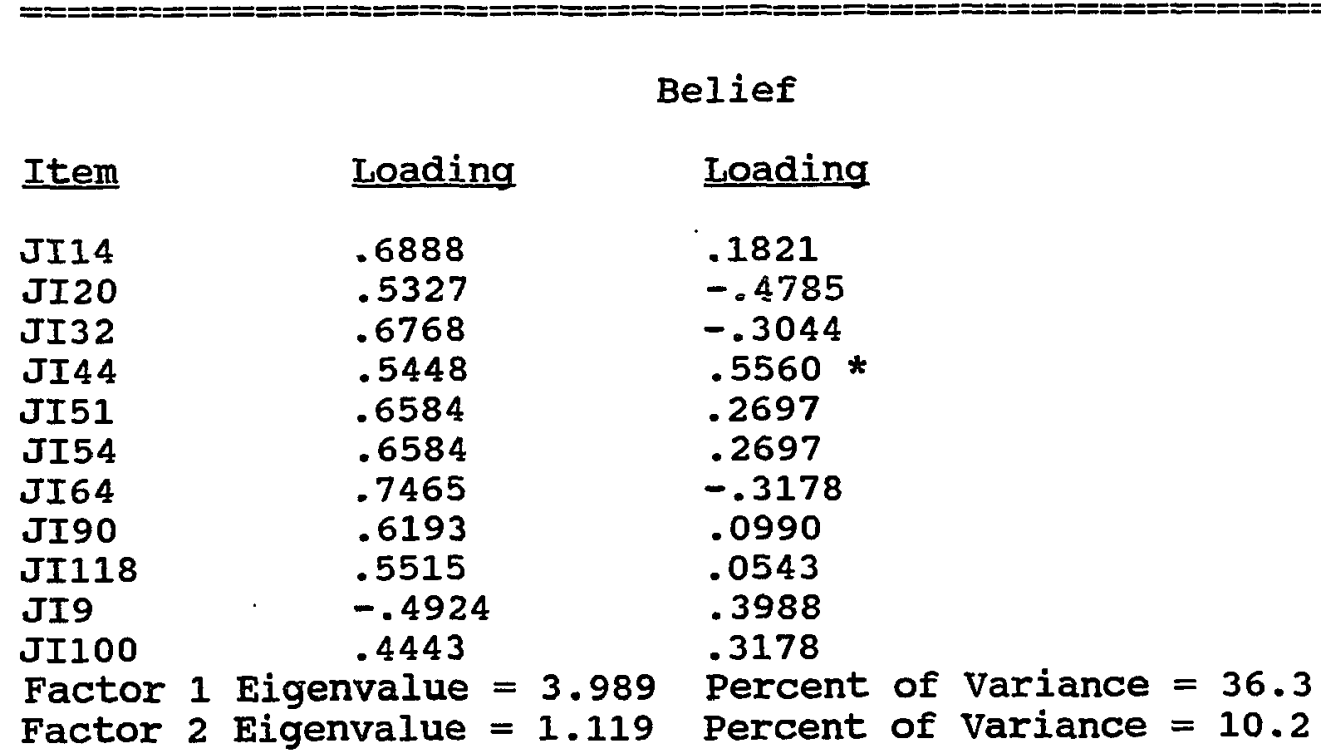


Factor Table 6 .

Attachment

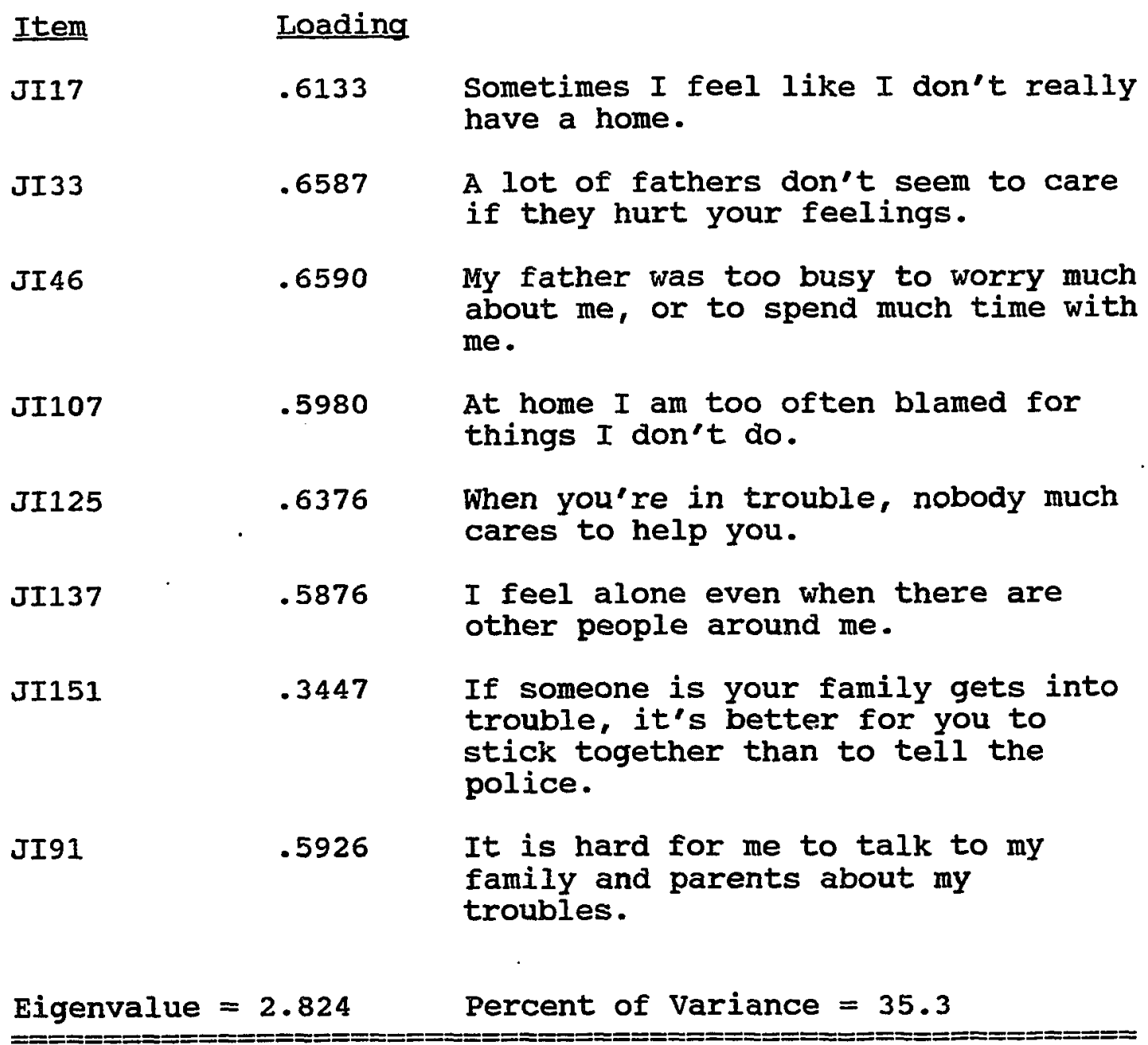


Factor Table 6. (continued)

\section{Commitment}

Item

JI26

JI27

.5102

JI69

JI71

JI118

JI77

JI84

\section{Loading}

.5651 If I could, I'd just as soon quit school or my job right now.

Sometimes it feels good to put one over on somebody.

.5562 Nothing much ever happens.

.5737 It's fun to give the police a bad time.

.6577 I don't mind lying if $I$ ' $m$ in trouble.

.6134 If I only had more money, things at home would be all right.

-.4443 Every day is full of things that keep me interested.

Factor 1 Eigenvalue $=2.168$ Percent of Variance $=31.0$ 
Factor Table 6. (continued)

Belief

Item

JI14

JI20

JI32

JI51

.5990

JI54

JI64

JI90

JI118

JI9

JI100

\section{Loading}

.6733

If the police don't like you, they will try to get you for anything.

.5566

Most police are pretty dumb.

.6903

Police stick their noses into a lot of things that are none of their business.

If someone in your family gets into trouble, it's better for you to stick together than to tell the police.

Most people in authority are bossy and overbearing.

.7676 Police usually treat you dirty.

.6224 Policemen and judges tell you one thing and do another.

.5565 I don't mind lying if $I^{\prime} m$ in trouble.

-.5176 Most police will try to help you.

.4291 I have a lot of bad things on my mind that people don't know about.

Factor 1 Eigenvalue $=3.738$ 
Larry A. Gould was born July 12, 1950, in Oakland, California. Since that time he has lived in ohio, Wyoming, and Louisiana. He is a 1969 graduate of Robert E. Lee High School in Baton Rouge. After graduation from high school he attended the University of Southwestern Louisiana at Lafayette, majoring in Agricultural Engineering.

In 1972 he transferred to Louisiana State University in Baton Rouge, where he majored in Criminal Justice. He remained at LSU until 1976, while also working for the LSU Police Department. In 1976 he began working for the Louisiana State Police and in 1980 he graduated from LSU with a. Bachelors Degree in Criminal Justice.

In 1984 Larry returned to LSU to begin work on a Masters degree in Criminal Justice, which was awarded in 1986. The thesis for the M.C.J. Degree concerned measures of DWI enforcement. In 1986 he began work on a Doctorate in Sociology. During his pursuit of the Doctorate he worked as a graduate assistant in sociology, then as a researcher in Experimental statistics, and finally as a faculty member in Criminal Justice. While working on his dissertation, Larry published several articles in refereed journals in such diverse areas as DWI characteristics, evaluation of shock incarceration and evaluation of computer assisted monitoring of offenders. During his graduate career Larry lived in Port Allen, Louisiana, with his wife Kristin. 


\section{DOCTORAL EXAMINATION AND DISSERTATION REPORT}

Candidate: Larry Allen Gould

Major Field: Sociology

Title of Dissertation: A Comparison of Models of Parole Outcome

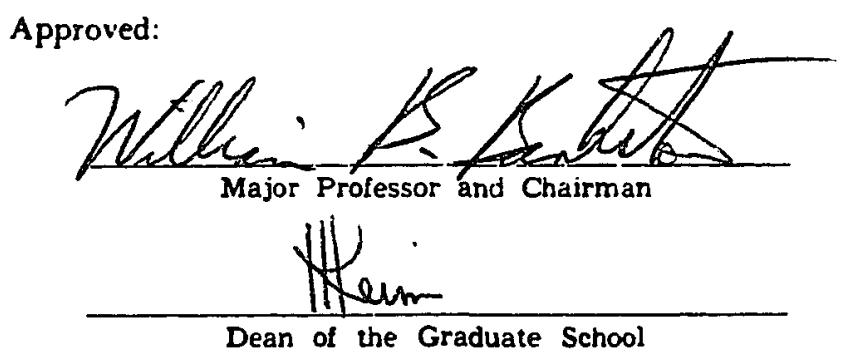

EXAMINING COMMITTEE:
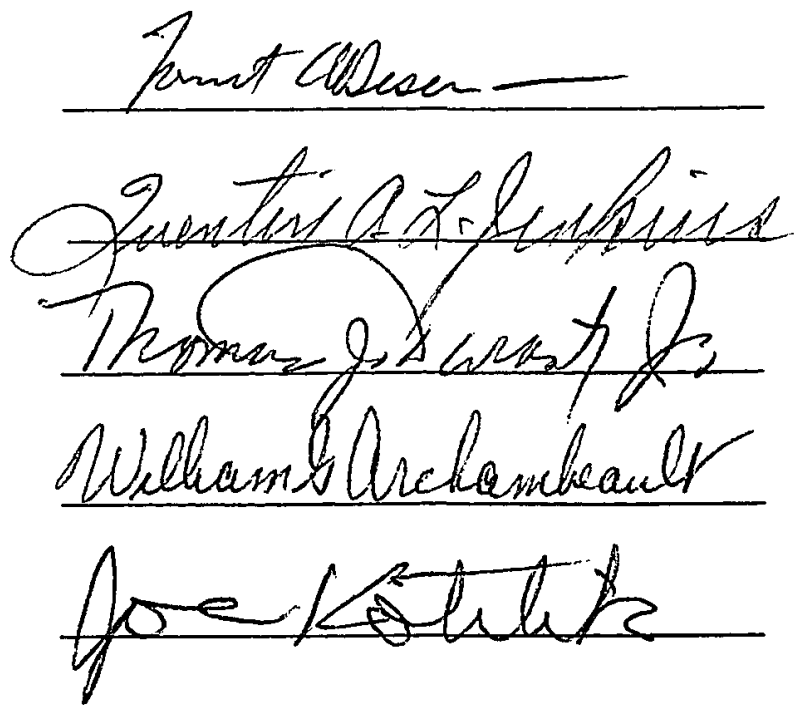

Date of Examination: 